\title{
Macroeconomic Impacts of Gender Inequality and Informality in India
}




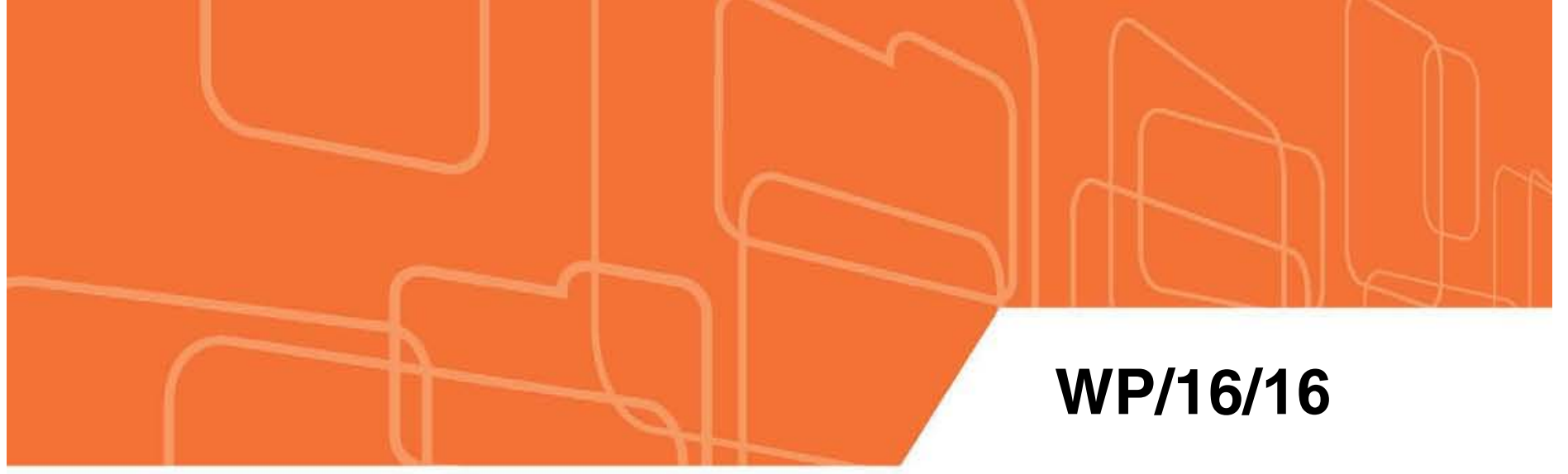

\section{IMF Working Paper}

Macroeconomic Impacts of Gender Inequality and Informality in India

by Purva Khera

I N T ER N A T I O N A L M O NETAR Y F U N D 


\title{
IMF Working Paper
}

Asia and Pacific Department

\section{Macroeconomic Impacts of Gender Inequality and Informality in India}

\author{
Prepared by Purva Khera ${ }^{1}$
}

\author{
Authorized for distribution by Paul Cashin
}

February 2016

IMF Working Papers describe research in progress by the author(s) and are published to elicit comments and to encourage debate. The views expressed in IMF Working Papers are those of the author(s) and do not necessarily represent the views of the IMF, its Executive Board, or IMF management.

\begin{abstract}
This paper examines the macroeconomic interaction between informality and gender inequality in the labor market. A dynamic stochastic general equilibrium model is built to study the impact of gender-targeted policies on female labor force participation, female formal employment, gender wage gap, as well as on aggregate economic outcomes. The model is estimated using Bayesian techniques and Indian data. Although these policies are found to increase female labor force participation and output, lack of sufficient formal job creation due to labor market rigidities leads to an increase in unemployment and informality, and further widens gender gaps in formal employment and wages. Simultaneously implementing such policies with formal job creating policies helps remove these adverse impacts while also leading to significantly larger gains in output.

JEL Classification Numbers: E24, E26, J16, J71, O15

Keywords: gender inequality, informality, DSGE model, Indian economy, Bayesian estimation

Author's E-Mail Address: pkhera@imf.org

\footnotetext{
${ }^{1}$ This is an extension of Chapter II of my PhD dissertation at the University of Cambridge. I am grateful to Petra Geraats, Tiago Cavalcanti, and Pontus Rendahl at the University of Cambridge for their suggestions and feedback, and particularly Sean Holly for his guidance and support. I also thank Juzhong Zhuang, Jesus Felipe, Maria Socorro Bautista and other participants at the Economics Gender Workshop and Seminar Series at the Asian Development Bank (August 2014), and seminar participants at the Indian Ministry of Finance for helpful comments (December 2015).
} 


\section{Introduction}

Gender inequality is one of the biggest challenges facing Indian policy makers trying to achieve faster, sustainable, and more inclusive growth. In particular, division along gender lines in the labor market is one of the key concerns. For instance, India's female labor force participation rate is the third lowest in the South Asian region at 27 percent in 2011-12; and less than one-third of male labor participation of 84 percent. In addition, they receive lower wages, are overrepresented in informal and unpaid domestic work, with gender gaps existing along several other dimensions including education, access to productive inputs, and bargaining power at home (Figure 1).

Figure 1: Gender inequality remains high in India

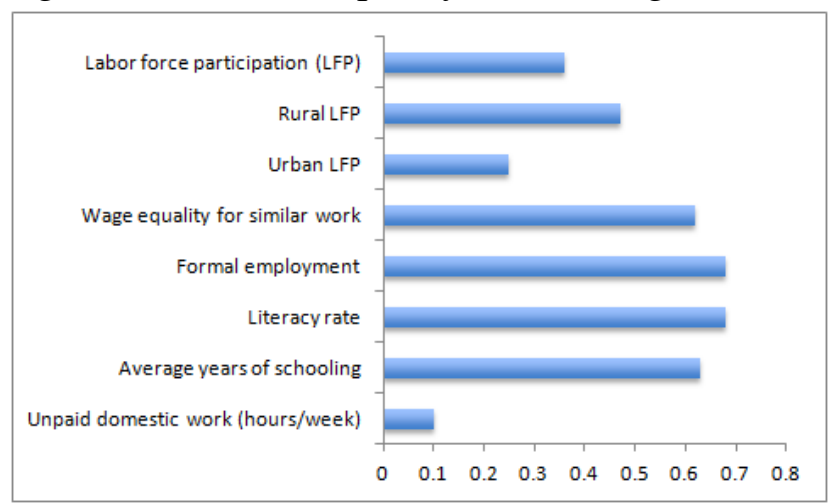

Note: The figure shows the female-to-male ratios for all variables, except for unpaid domestic work which is the male-to-female ratio.

Notwithstanding rising education levels amongst women in India, female labor participation has been declining and fell from 34 percent in 1999-00 to 27 percent in 2011-12, in both rural and urban areas (Figure 2). Lack of decent quality jobs in the formal economy discourage female participation. More than 80 percent of the workforce is employed informally in India, and among the ones that are employed in the formal sector, females constitute only 19-20 percent (Consensus 2011). Rigidities in the labor market due to strict regulations have been identified as the main drivers of this large informality ${ }^{1}$.

A considerably vast empirical literature finds a negative impact of gender inequality in employment and education on economic growth ${ }^{2}$. Indeed, researchers have attempted to model gender inequality within macroeconomic frameworks, to study the effect of a number of gender-specific public policies on both gender and the overall economy ${ }^{3}$. However, much of this literature has focused on how the relationship between gender and growth is mediated

\footnotetext{
${ }^{1}$ See, for instance, Besley and Burgess (2004), Sharma (2009), and ILO (2008, 2014).

${ }^{2}$ See Klasen (1999), Dollar and Gatti (1999), Klasen and Lamanna (2009), and Barro and Lee (2013) among others.

${ }^{3}$ Galor and Weil (1996), Fontana (2004), Cavalcanti and Taveres (2008), Esteve-Volart (2009), Agenor (2012), Agenor and Canuto (2013), Cuberes and Teigner (2014), and Agenor (2015).
} 
Figure 2: Falling female labor participation even in periods of economic growth

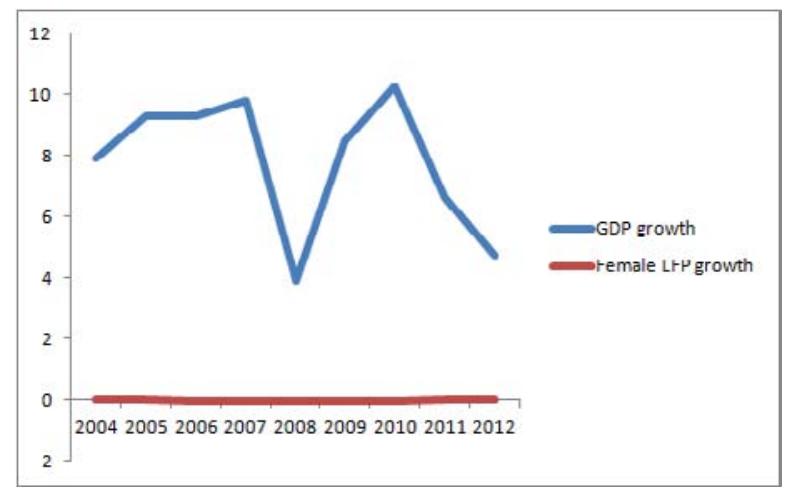

Source: World Bank Gender Data Portal

through changes in female labor force participation rate and productivity. Labor force participation rates only provide a partial analysis of women's work, especially in India, where women are more likely to be engaged in vulnerable, low paid jobs in the informal sector. Hence, these frameworks are not rich enough to capture the impact of policies on the quality of female employment, wages, and unemployment, all of which impact economic growth.

Motivated by these observations, we ask the following questions: What is the interaction between informality and gender in the labor market? How do labor and gender-targeted policies affect female labor force participation, females' access to formal employment, gender wage gaps, as well as aggregate economic activity? In this regard, we build an open economy dynamic stochastic general equilibrium (DSGE) model with both informality and gender inequality in the labor market. The model is estimated using Bayesian techniques and applied to quarterly data from India.

The key contribution of this paper is to link the issue of gender inequality to informality within a unified theoretical framework. In addition, in contrast to the existing literature, which has largely focused on long run outcomes alone, we are instead able to capture the short run effects of policy as well.

For our analysis, we consider an economy where two goods are produced, a market-good and a home-good. Firms in the formal and informal sector combine labor with capital to produce different varieties of market goods. There are labor market rigidities (modeled as hiring costs) in both sectors, where informality results from significantly higher rigidities in the formal sector, and wages are determined through Nash bargaining between workers and firms ${ }^{4}$. Home goods are instead produced by individuals working at home in home production ${ }^{5}$. Households consist of males and females, where the labor supply decision of each individual is an outcome of an optimal allocation among paid market-good production, unpaid home-good production, job search, and leisure; while also being dependent on their relative intra-household bargaining

\footnotetext{
${ }^{4}$ This is related to the level of labor unionization.

${ }^{5}$ According to the OECD Gender Data Portal, routine housework (cooking, cleaning, home maintenance etc.), and care for household members makes up the greatest proportion of India's unpaid care work.
} 
power 6 .

We use the findings from the empirical literature to model gender inequality by imposing several frictions on workers' labor supply and demand ${ }^{7}$. Constraints on female labor demand are modeled as: (i) lower education (skill) level of female relative to male workers (World Bank (2013a)); (ii) lower bargaining power in the wage bargaining process (ILO (2011)); and (iii) firm-based gender bias against females in formal employment (ILO (2012), Campbell and Ahmed (2012), OECD (2008)). Whereas, constraints on female labor supply are modeled in the utility function as: (i) lower preference for working outside home in paid market-good production relative to staying at home, which corresponds to concerns regarding female safety and mobility in developing countries (World Bank (2011)); and (ii) higher preference for working in home-production relative to leisure, which is related to social norms and the lack of public provisions, including childcare support (Duflo (2012)).

Using this framework, we study and quantify the impact of a number of gender-based policies on aggregate economic activity (GDP, formality in the labor market, and unemployment), and on labor market indicators of gender inequality (female labor force participation, female formal employment, and gender wage gaps). Increase in female education and stronger enforcement of laws against gender discrimination which lower constraints on female labor demand, as well as increase in public provisions and improvements in female safety and mobility which lower constraints on female labor supply are considered as gender-specific policies. Finally, we also investigate the effects of increasing labor market flexibility in the formal sector, i.e. lowering labor regulations.

Policy analysis yields three key insights. First, gender-targeted policies boost female labor force participation, leading to gains in GDP in the long run. However, owing to the presence of labor market rigidities, these policies do not generate sufficient job creation in the formal sector, resulting in a large proportion of the increased female participants either being employed in low paying informal jobs or staying unemployed. This further widens gender gaps in wages and informal employment, thus worsening gender inequality, while also increasing aggregate informality and unemployment in the economy. For instance, an increase in public provisions that increases female participation by 1.5 percent would increase GDP by 1.25 percent, but it would also increase unemployment and informality by 1 and 0.1 percent, respectively. However, we do find one exception with the policy that increases female education, which by increasing female workers' efficiency in employment, leads to an increase in female formal employment. This in turn increases the overall productivity in the formal sector, leading to creation of more formal jobs for both males and females. However, due to slow reallocation of workers to the formal sector, female formality falls and gender wage gaps are higher in the short run.

Second, lowering formal regulations that increase labor market flexibility, allows more women and men to be employed in the formal sector, which lowers aggregate informality and unem-

\footnotetext{
${ }^{6}$ Intra-household bargaining power is related to relative female-to-male earnings which captures the feedback effect of female employment and wages on their bargaining position at home.

${ }^{7}$ Elborgh-Woytek et al. (2013) present an overall review of this work in the literature. In addition, using detailed household surveys, Das et al. (2015) and Klasen and Pieters (2015) identify a combination of supply and demand factors that explain the declining female labor force participation trends in India.
} 
ployment in the economy boosting GDP in the long run. However, male workers gain more, as unchanged constraints on female labor supply and demand along with a positive household income effect, both lower female labor force participation (as opposed to increasing in the short run and falling marginally in the long run for males) and lead to a smaller increase in female formality in comparison to males. For instance, lower labor regulations that decrease informality by 1.5 percent would increase GDP by 2 percent and lower unemployment by 1.5 percent, but it would also lower female participation by 0.5 percent.

Finally, we show that combining gender-targeted policies that lower constraints on female labor participation with reforms that boost formal job creation not only improves gender equality in the labor market but also leads to significantly larger gains in GDP, employment and formality; along with minimizing any short run losses.

The remainder of this paper is organized as follows. Section 2 presents a description of the previous literature. In Section 3 we outline the theoretical framework, and Section 4 discusses the data, calibration and method of estimation. In Section 5, we discuss results of the estimation and robustness checks. Section 6 presents an analysis of several policy experiments. Section 7 concludes the paper.

\section{Literature Survey}

Now we turn to comparing our work with the existing theoretical policy literature on gender inequality. A considerably vast literature has investigated the effects of gender-specific policies with competitive labour markets. This literature can be broadly classified into talent allocation models (Cuberes and Teigner (2014)), occupational choice models (Esteve-Volart (2009), Hsieh et al. (2013)), overlapping generations (OLG) model (Galor and Weil (1996), Cavalcanti and Taveres (2008), Agenor and Canuto (2013), Agenor (2015)), and computable general equilibrium (CGE) models (Fontana and Wood (2000), Fontana (2004), Hendy and Zaki (2010)). Female labour supply in these models is often modeled using the framework of the time allocation model ${ }^{8}$, where women's labour supply decision is based not only on the trade-off between leisure and labour, but also on home production modeled as investment in childcare. These studies analyze the impact of one or more of the following policies: increase in female education, increase in childcare provisions, better access to infrastructure, as well as fall in exogenously given gender wage discrimination. In sum, their results suggest that each of the above policies increase female labour participation that has a positive impact on their productivity, hence leading to higher growth. One or more of the following channels drive these results: (i) higher female labour participation increases female employment (under the assumption of flexible labour markets) and females' labour income; (ii) this increase in females' income improves the average human capital (skill) in the economy, as females are assumed to invest more in children's education relative to males; and (iii) higher participation in turn has a direct effect on per capita GDP, as females move from unpaid home-good production (not accounted for in GDP) into market-good production.

\footnotetext{
${ }^{8}$ Refer to Becker (1965).
} 
However, this existing literature has not paid attention to how the presence and effects of labour market rigidities (i.e. regulations) vary by gender. In addition, much of the above analysis is based on small, illustrative models (with notable exceptions such as Agenor (2012, 2015)). Thus, they may not be adequate for policy analysis as important channels are 'not modeled' or 'shut down' - by imposing for instance exogenously given wages, exogenously given wage gaps in gender, in addition to assuming labour market flexibility. Hence, while this literature has significantly improved our understanding of the various links between gender equality and growth, the relevance of any policy-related study strongly depends on whether the specific model used to draw recommendations captures all the key transmission channels of policy or not. Moreover, the computable general equilibrium (CGE) modelling technique ${ }^{9}$ is commonly used to capture the general equilibrium effects of gender-specific policies. Compared with the more recent general equilibrium modelling strategies, CGE models are mainly non-stochastic and static. Thus, while they are useful for quantifying the long run effects of reforms, they do not take into account the dynamic impact and the interplay between macroeconomic policies and gender inequality.

We are only aware of one recent study by Albanesi and Patterson (2014) who model gender differences in labour force participation rates within a New Keynesian framework. However, they abstract from analysing gender-specific policies and instead focus on the impact of changes in female labour force participation on business cycles. Although the goal of their study is different to ours, they do highlight the relevance of using a DSGE framework for gender-related policy study.

Our model builds on their framework by adding a number of relevant frictions on the labour supply and demand of female workers, and by integrating this with the literature on labour market rigidities to model informality ${ }^{10}$.

\section{The Model}

This section presents the Baseline model. We provide a brief description before specifying the details of the model in the following subsections.

The small open economy consists of households, wholesale producers, retailers, capital producers, and a government. Two goods are produced in the economy: market-good and a home-good. Market-good consist of formal tradable goods $(F)$, informal non-tradable goods $(I)$, and imported goods $\left(f^{*}\right)$. The first two are produced domestically by formal and informal retailers in each sector $s \varepsilon(F, I)$, respectively, while the latter is produced in the foreign economy and sold domestically by import retailers in the formal sector. On the other hand, home goods $\left(H^{0}\right)$ are produced by individuals of the household who work at home, and is for household consumption only.

\footnotetext{
${ }^{9}$ CGE modeling (also referred to as Applied General Equilibrium (AGE) models), use actual data to estimate the impact of policy changes using input-output tables.

${ }^{10}$ This literature on informality includes Conesa et al. (2002), Zenou (2008), Castillo and Montoro (2008), and Satchi and Temple (2010).
} 
Households consist of male $(m)$ and female $(f)$ members who derive utility from consuming market goods, home goods, and leisure. Each member either supplies labor (i.e. participate in the labor market) to wholesale firms or instead stays at home. The ones that participate in the labor market are either employed in the formal sector, employed in the informal sector, or stay unemployed. The employed engage in paid market-good production, whereas the unemployed work in unpaid home-good production in the residual time when unoccupied by job search. On the other hand, the ones that stay at home, are either working in home-good production, or consuming leisure.

Formal and informal wholesale firms combine labor with capital to produce formal and informal wholesale goods, respectively. Unemployment exists as wholesalers in each sector pay a hiring cost when hiring new labor a la Blanchard and Gali (2006). Wages in each sector are determined through Nash bargaining between workers and firms.

Formal and informal retailers purchase wholesale goods from wholesalers, differentiate these into different varieties of market-goods, and set the retail price for each individual variety in an environment of monopolistic competition and price adjustment costs a la Rotemberg (1982). A group of competitive capital producers combine formal market- and imported goods to produce final investment goods, which is then combined with the used capital goods rented from wholesalers to produce new capital. Government conducts monetary and fiscal policy: it sets the nominal interest rate using a Taylor-type rule, and receives tax wage income from households which is used to finance public spending and unemployment benefit payments.

Details regarding each agent's behaviour are described below.

\subsection{The Labor Market}

There are a continuum of households $(0,1)$, out of which $p^{m}$ proportion are males, and $p^{f}=$ $1-p^{m}$ proportion are females ${ }^{11}$. Households either supply their labor to wholesale firms, which determines the labor market participation rate, or stay at home forming the pool of non-participants.

Hence, there are two types of workers $h \varepsilon(m, f)$ in the labor market where $m$ denotes male workers and $f$ denotes female workers. They can either be employed in one of the two sectors $s \varepsilon(F, I)$, where $F$ is the formal sector and $I$ is the informal sector, or stay unemployed. The mass of male workers who are employed in the formal sector, employed in the informal sector, and unemployed, are denoted by $L_{F, t}^{m}, L_{I, t}^{m}$, and $U_{t}^{m}$. Similarly, the mass of female workers are denoted by $L_{F, t}^{f}, L_{I, t}^{f}$, and $U_{t}^{f}$. Non-participants consist of $N P_{t}^{m}$ males and $N P_{t}^{f}$ females.

The pool of male and female workers who participate in the labor market is then given by: $P_{t}^{m}=p^{m}-N P_{t}^{m}$ and $P_{t}^{f}=p^{f}-N P_{t}^{f}$, whereas the male and female unemployment is determined by: $U_{t}^{m}=P_{t}^{m}-L_{F, t}^{m}-L_{I, t}^{m}$ and $U_{t}^{f}=P_{t}^{f}-L_{F, t}^{f}-L_{I, t}^{f}$, respectively. Hence, we can express unemployment as:

${ }^{11}$ As per the 2001 consensus, females in India constitutes half of the country's population and therefore we assume $p^{m}=p^{f}=\frac{1}{2}$. 


$$
\begin{gathered}
U_{t}^{m}=p^{m}-N P_{t}^{m}-L_{F, t}^{m}-L_{I, t}^{m} \\
U_{t}^{f}=p^{f}-N P_{t}^{f}-L_{F, t}^{f}-L_{I, t}^{f}
\end{gathered}
$$

The labor market dynamics closely follow the framework in Campolmi and Gnochhi (2014). The stock of employed labor varies because of the endogenous variation in hiring, and an exogenous probability of getting fired, $\sigma_{s}$, every period ${ }^{12}$. At the end of period $t-1$, after all decisions have been taken and executed, $F_{s, t-1}^{m}=\sigma_{s}^{m} L_{s, t-1}^{m}$ and $F_{s, t-1}^{f}=\sigma_{s}^{f} L_{s, t-1}^{f}$ male and female workers are fired by wholesalers in sector $s$. In period $t$, new male and female workers are hired, $H_{s, t}^{m}$ and $H_{s, t}^{f}$, from the pool of job searchers, $S_{t}^{m}$ and $S_{t}^{f 13}$. The evolution of male and female labor in each sector $s$ is given by:

$$
\begin{aligned}
& L_{s, t}^{m}=L_{s, t-1}^{m}-F_{s, t-1}^{m}+H_{s, t}^{m}=\left(1-\sigma_{s}\right) L_{s, t-1}^{m}+p\left(H_{s, t}^{m}\right) S_{t}^{m} \\
& L_{s, t}^{f}=L_{s, t-1}^{f}-F_{s, t-1}^{f}+H_{s, t}^{f}=\left(1-\sigma_{s}\right) L_{s, t-1}^{f}+p\left(H_{s, t}^{f}\right) S_{t}^{f}
\end{aligned}
$$

where male and female workers' probability of getting hired, $p\left(H_{s, t}^{m}\right)$ and $p\left(H_{s, t}^{f}\right)$, is determined endogenously by wholesalers' optimization ${ }^{14}$.

The unemployed, the non-participants, and fired individuals, $U_{t-1}^{m}+N P_{t-1}^{m}+F_{F, t-1}^{m}+F_{I, t-1}^{m}$ and $U_{t-1}^{f}+N P_{t-1}^{f}+F_{F, t-1}^{f}+F_{I, t-1}^{f}$, form the pool of males and females that are not employed at the end of period $t-1$. Among these, some are job searchers in the following period $t$, and the remaining ones are non-participants:

$$
\begin{gathered}
S_{t}^{m}+N P_{t}^{m}=U_{t-1}^{m}+N P_{t-1}^{m}+\sigma_{F}^{m} L_{F, t-1}^{m}+\sigma_{I}^{m} L_{I, t-1}^{m} \\
S_{t}^{f}+N P_{t}^{f}=U_{t-1}^{f}+N P_{t-1}^{f}+\sigma_{F}^{f} L_{F, t-1}^{f}+\sigma_{I}^{f} L_{I, t-1}^{f}
\end{gathered}
$$

Inserting Eq. 3.1 in Eq. 3.5, and Eq. 3.2 in Eq. 3.6, gives us the following expressions for male and female job searchers in period $t$ :

$$
\begin{gathered}
S_{t}^{m}=P_{t}^{m}-\left(1-\sigma_{F}\right) L_{F, t-1}^{m}-\left(1-\sigma_{I}\right) L_{I, t-1}^{m} \\
S_{t}^{f}=P_{t}^{f}-\left(1-\sigma_{F}\right) L_{F, t-1}^{f}-\left(1-\sigma_{I}\right) L_{I, t-1}^{f}
\end{gathered}
$$

\footnotetext{
${ }^{12}$ Probability of getting fired is allowed to vary across the two sectors, which corresponds to the relative difficulty in firing workers in the formal sector (i.e. employment protection policies).

${ }^{13}$ Assume instantaneous hiring, i.e. period $t$ searchers can be matched and start producing in period $t$ itself. This is a standard assumption in a sticky-price model, and seems reasonable if a period is interpreted as a quarter.

${ }^{14}$ The formal and informal labor markets are integrated as they hire workers from the same pool of male and female job searchers.
} 
Evolution of male and female formal employment (Eq. 3.3 and Eq. 3.4 with $s=F$ ) can then be written as:

$$
\begin{gathered}
L_{F, t}^{m}=\left(1-\sigma_{F}\right)\left(1-p\left(H_{F, t}^{m}\right)\right) L_{F, t-1}^{m}+p\left(H_{F, t}^{m}\right) P_{t}^{m}-p\left(H_{F, t}^{m}\right)\left(1-\sigma_{I}\right) L_{I, t-1}^{m} \\
L_{F, t}^{f}=\left(1-\sigma_{F}\right)\left(1-p\left(H_{F, t}^{f}\right)\right) L_{F, t-1}^{f}+p\left(H_{F, t}^{f}\right) P_{t}^{f}-p\left(H_{F, t}^{f}\right)\left(1-\sigma_{I}\right) L_{I, t-1}^{f}
\end{gathered}
$$

Eq. 3.10 implies that in period $t$, total female workers employed in the formal sector increases with higher female labor participation, $P_{t}^{f}$, and with a rise in their probability of getting hired in this sector, $p\left(H_{F, t}^{f}\right)^{15}$. An analogous interpretation of Eq. 3.9 follows for male workers employed in the formal sector.

Similarly, for the informal sector $(s=I)$, we get:

$$
\begin{aligned}
& L_{I, t}^{m}=\left(1-\sigma_{I}\right)\left(1-p\left(H_{I, t}^{m}\right)\right) L_{I, t-1}^{m}+p\left(H_{I, t}^{m}\right) P_{t}^{m}-p\left(H_{I, t}^{m}\right)\left(1-\sigma_{F}\right) L_{F, t-1}^{m} \\
& L_{I, t}^{f}=\left(1-\sigma_{I}\right)\left(1-p\left(H_{I, t}^{f}\right)\right) L_{I, t-1}^{f}+p\left(H_{I, t}^{f}\right) P_{t}^{f}-p\left(H_{I, t}^{f}\right)\left(1-\sigma_{F}\right) L_{F, t-1}^{f}
\end{aligned}
$$

Probability of getting hired in sector $s$ is then given by the ratio of new hires to the pool of job searchers:

$$
p\left(H_{s, t}^{m}\right)=\frac{H_{s, t}^{m}}{S_{t}^{m}} \quad p\left(H_{s, t}^{f}\right)=\frac{H_{s, t}^{f}}{S_{t}^{f}}
$$

Ratio of total job searchers to the pool of individuals not employed at the end of period $t-1$ determines the probability of searching for a job:

$$
\begin{aligned}
& p\left(S_{t}^{m}\right)=\frac{S_{t}^{m}}{U_{t-1}^{m}+N P_{t-1}^{m}+F_{F, t-1}^{m}+F_{I, t-1}^{m}} \\
& p\left(S_{t}^{f}\right)=\frac{S_{t}^{f}}{U_{t-1}^{f}+N P_{t-1}^{f}+F_{F, t-1}^{f}+F_{I, t-1}^{f}}
\end{aligned}
$$

\subsection{Wholesale Producer}

We have a continuum of wholesalers $(0,1)$ in each sector $s$ producing different intermediate goods, $Y_{F, t}^{W}$ and $Y_{I, t}^{W}$, with access to different technologies, $\theta_{F, t}$ and $\theta_{I, t}{ }^{16}$. By the beginning of period $t$, they are assumed to acquire capital, $K_{F, t-1}$ and $K_{I, t-1}$, from capital producers,

\footnotetext{
${ }^{15}$ For this to hold, female labor participation in period $t$ should be greater than the sum of female workers that are still employed from the previous period $t-1$, i.e. $P_{t}^{f}>\left(1-\sigma_{F}\right) L_{F, t-1}^{f}+\left(1-\sigma_{I}\right) L_{I, t-1}^{f}$. This always holds true for all periods in our model.

${ }^{16} \theta_{F, t}$ and $\theta_{I, t}$ are stochastic disturbances to aggregate productivity in the formal and informal sector, respectively and follow a first order autoregressive process (AR(1)) in logs.
} 
which is combined with labor hired from households, $L_{F, t}$ and $L_{I, t}$, to produce these goods over period $t$, using a Cobb-Douglas function ${ }^{17}$ :

$$
\begin{gathered}
Y_{F, t}^{W}=\theta_{F, t}\left(K_{F, t-1}\right)^{\psi_{F}}\left(L_{F, t}\right)^{1-\psi_{F}} \\
Y_{I, t}^{W}=\theta_{I, t}\left(K_{I, t-1}\right)^{\psi_{I}}\left(L_{I, t}\right)^{1-\psi_{I}}
\end{gathered}
$$

where $\psi_{s}$ is the capital intensity related to capital income share in sector $s$. They sell their goods to retailers in their respective sectors at a price of $P_{F, t}^{W}$ and $P_{I, t}^{W}$.

Total labor in each sector is a constant elasticity of substitution (CES) aggregate of male and female workers, where $\rho_{s} \varepsilon(-\infty, 1]$ determines the substitution elasticity ${ }^{18}$ :

$$
\begin{gathered}
L_{F, t}=\left[\omega_{F, t}\left(\operatorname{skill}_{F}^{m} L_{F, t}^{m}\right)^{p_{F}}+\left(1-\omega_{F, t}\right)\left(\operatorname{skill} l_{F}^{f} L_{F, t}^{f}\right)^{p_{F}}\right]^{1 / p_{F}} \\
L_{I, t}=\left[\omega_{I, t}\left(\operatorname{skill}_{I}^{m} L_{I, t}^{m}\right)^{p_{I}}+\left(1-\omega_{I, t}\right)\left(\operatorname{skill} l_{I}^{f} L_{I, t}^{f}\right)^{p_{I}}\right]^{1 / p_{I}}
\end{gathered}
$$

$\omega_{s, t} \varepsilon(0,1)$ is the firms' relative preference for male workers over female workers in sector $s^{19}$. Differences in skill level of male and female workers, $s k i l l_{s}^{m}$ and $s k i l l_{s}^{f}$, corresponds to the gender gaps in education ${ }^{20}$.

\section{Labor Market Regulations}

Wholesalers in each sector $s$ face real hiring costs, $H C_{s, t}^{h}$, when hiring new labor and the real wage, $W_{s, t}^{h}$, paid to this worker is decided by the generalized Nash bargaining solution. Per period real profit is equal to the revenue net costs spent on employing labor (wages and hiring costs) and renting capital, where $P_{t}$ is the aggregate price level and $R_{t}^{K}$ is the real rental rate of capital:

$$
\begin{aligned}
& \Pi_{F, t}^{W}=\frac{P_{F, t}^{W}}{P_{t}} Y_{F, t}^{W}-W_{F, t}^{m} L_{F, t}^{m}-W_{F, t}^{f} L_{F, t}^{f}-R_{t}^{K} K_{F, t-1}-H C_{F, t}^{m} H_{F, t}^{m}-H C_{F, t}^{f} H_{F, t}^{f} \\
& \Pi_{I, t}^{W}=\frac{P_{I, t}^{W}}{P_{t}} P_{I, t}^{W} Y_{I, t}^{W}-W_{I, t}^{m} L_{I, t}^{m}-W_{I, t}^{f} L_{I, t}^{f}-R_{t}^{K} K_{I, t-1}-H C_{I, t}^{f} H_{I, t}^{f}-H C_{I, t}^{f} H_{I, t}^{f}
\end{aligned}
$$

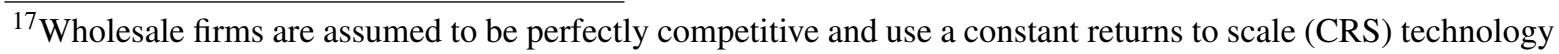
function. This allows us to treat these firms as a whole, and hence we write aggregate production function without firm specific constraints.

${ }^{18}$ The substitution elasticity between male and female labor in production is $1 /(1-\rho) \cdot \rho=1$ represents perfect substitution, $\rho \rightarrow-\infty$ represents a Leontiff production function, and $\rho \rightarrow 0$ represents the Cobb-douglas case.

${ }^{19}$ One can interpret this as the male gender bias in employment which determines the extent of gender discrimination in employment. $\omega_{s, t}=0.5$ implies no gender discrimination, whereas firms discriminate against females when $\omega_{s, t}>0.5$.

${ }^{20}$ These skills also vary across sectors, which relates to the differences in worker training and efficiency of workers across the formal and informal sector. 
Following Blanchard and Gali (2006), hiring costs depend positively on the total number of new hires, and negatively on the pool of unemployed at the beginning of period $t^{21}$ :

$$
\begin{gathered}
H C_{F, t}^{h}=\left(\beta_{H C_{F}, t}\right)\left(p\left(H_{F, t}^{h}\right)\right) \alpha_{H C_{F}} \\
H C_{I, t}^{h}=\left(\beta_{H C_{I, t}}\right)\left(p\left(H_{I, t}^{h}\right)\right) \alpha_{H C_{I}}
\end{gathered}
$$

$\beta_{\mathrm{HC}_{\mathrm{F}, \mathrm{t}}}, \beta_{\mathrm{HC}_{\mathrm{I}}, \mathrm{t}}>0$ are exogenous $\mathrm{AR}(1)$ hiring cost shocks, and $\alpha_{H C_{s}}>0$ is the elasticity of hiring cost with respect to hiring probability ${ }^{22}$.

\section{Capital and Labor Demand}

Wholesalers in sector $s$ choose $L_{s, t}^{m}, L_{s, t}^{f}, H_{s, t}^{m}, H_{s, t}^{f}$, and $K_{s, t-1}$, by maximising their expected discounted value of future profits:

$$
\max _{L_{s, t}, K_{s, t-1}, H_{s, t}} E_{t} \sum_{k=0}^{\infty} \rho_{t, t+k} \Pi_{s, t+k}^{W}
$$

subject to the law of motion of male and female employment (Eq. 3.3 and Eq. 3.4). $\rho_{t, t+k}$ is the stochastic discount rate obtained from the households' optimization problem discussed below.

Capital and labor demand functions in sector $s$ are obtained from the first order conditions as follows (see Technical Appendix for derivations):

$$
\begin{gathered}
R_{t}^{K}=\psi_{s} \frac{P_{s, t}^{W}}{P_{t}} \frac{Y_{s, t}^{W}}{K_{s, t-1}} \\
\left(1-\psi_{s}\right) \omega_{s} \frac{P_{s, t}^{W}}{P_{t}} \frac{Y_{s, t}^{W}}{L_{s, t}^{m}}\left(s k i l l_{s}^{m} \frac{L_{s, t}^{m}}{L_{s, t}}\right)^{\rho_{s}}=W_{s, t}^{m}+H C_{s, t}^{m}-E_{t}\left(\rho_{t, t+1} H C_{s, t+1}^{m}\left(1-\sigma_{s}\right)\right) \\
\left(1-\psi_{s}\right)\left(1-\omega_{s}\right) \frac{P_{s, t}^{W}}{P_{t}} \frac{Y_{s, t}^{W}}{L_{s, t}^{f}}\left(s k i l l_{s}^{f} \frac{L_{s, t}^{f}}{L_{s, t}}\right) \rho_{s}=W_{s, t}^{f}+H C_{s, t}^{f}-E_{t}\left(\rho_{t, t+1} H C_{s, t+1}^{f}\left(1-\sigma_{s}\right)\right)
\end{gathered}
$$

The equation for capital demand (Eq. 3.25) is standard in the literature, however, the labor demand for males and females (Eq. 3.26 and Eq. 3.27) is now determined by equating marginal product to the marginal cost of employing labor, which includes the real wage plus the cost generated by hiring.

\footnotetext{
${ }^{21}$ Blanchard and Gali (2006) show that the presence of hiring costs creates a friction in the labor market similar to the cost of posting a vacancy and the time needed to fill it in the standard Diamond-Mortenssen-Pissaridis (DMP) model.

${ }^{22}$ This points towards a convex structure of hiring costs, i.e. marginal hiring costs increase with the number of new hires.
} 


\section{Wage Bargaining}

Wage setting follows a Nash bargaining process between workers and wholesalers where wage bargaining power of worker $h$ in the formal and informal sector is denoted by $\lambda_{F}^{h} \varepsilon(0,1)$ and $\lambda_{I}^{h} \varepsilon(0,1)$, respectively. The bargaining power of formal workers is assumed to to be higher than informal workers. To capture gender gaps in access to labor unions, union leadership, and union priorities, we also allow for differences in bargaining power of male and female workers.

$V_{F, t}^{h}, V_{I, t}^{h}$, and $V_{U, t}^{h}$ is the marginal value to a worker $h$ of being employed formally, employed informally, and of being unemployed, whereas $V_{N P, t}^{h}$ is the value of not participating in the labor market. A formally employed worker in period $t$ receives current wage income of $\left(1-\tau_{F}\right) W_{F, t}$, where $\tau_{F}$ is the marginal tax rate. In the next period $t+1$, the worker keeps the same job with probability $\left(1-\sigma_{F}^{h}\right)$, or gets fired with probability $\sigma_{F}^{h}$. If fired, there is a probability $\left(1-p\left(S_{F, t+1}^{h}\right)\right)$ that the worker decides to stay at home, or searches for jobs with probability $p\left(S_{F, t+1}^{h}\right)$. If the worker searches for jobs, there is a probability $p\left(H_{F, t+1}^{h}\right)$ of getting re-hired in the same sector, hired in the informal sector $p\left(H_{I, t+1}^{h}\right)$, and a probability

$1-\sum_{s=F, I}\left(p\left(H_{s, t+1}^{h}\right)\right) d s$ of staying unemployed. Hence, we obtain the following expression for $V_{F, t}^{h}$ :

$$
\begin{aligned}
& V_{F, t}^{h}=\left(1-\tau_{F}\right) W_{F, t}^{h}-M R S_{H P_{t}, C_{t}}^{h}-M R S_{l e_{t}, C_{t}}^{h}+E_{t}\left[\rho_{t, t+1}\left(1-\sigma_{F}^{h}\right) V_{F, t+1}^{h}\right] \\
& +\sigma_{F}^{h} E_{t}\left\{\rho_{t, t+1} p\left(S_{t+1}^{h}\right)\left[\left(p\left(H_{F, t+1}^{h}\right) V_{F, t+1}^{h}+p\left(H_{I, t+1}^{h}\right) V_{I, t+1}^{h}\right]\right\}\right. \\
& +\sigma_{F}^{h} E_{t}\left[\rho_{t, t+1}\left(1-p\left(H_{F, t+1}^{h}\right)-p\left(H_{I, t+1}^{h}\right)\right) V_{U, t+1}^{h}\right] \\
& +\sigma_{F}^{h} E_{t}\left[\rho_{t, t+1}\left(1-p\left(S_{t+1}^{h}\right)\right) V_{N P, t+1}^{h}\right]
\end{aligned}
$$

$M R S_{H P_{t}, C_{t}}^{h}$ and $M R S_{l e_{t}, C_{t}}^{h}$, both derived from the households optimization problem below, represent the marginal rate of substitution between home-good and market-good consumption, and between leisure and market-good consumption

Similarly, we get the value of being employed in the informal sector, the only difference being that the worker does not pay wage income tax, $\tau_{I}=0$ :

$$
\begin{aligned}
& V_{I, t}^{h}=\left(1-\tau_{I}\right) W_{I, t}^{h}-M R S_{H P_{t}, C_{t}}^{h}-M R S_{l e_{t}, C_{t}}^{h}+E_{t}\left[\rho_{t, t+1}\left(1-\sigma_{I}^{h}\right) V_{I, t+1}^{h}\right] \\
& +\sigma_{I}^{h} E_{t}\left\{\rho_{t, t+1} p\left(S_{t+1}^{h}\right)\left[\left(p\left(H_{F, t+1}^{h}\right) V_{F, t+1}^{h}+p\left(H_{I, t+1}^{h}\right) V_{I, t+1}^{h}\right]\right\}\right. \\
& +\sigma_{I}^{h} E_{t}\left[\rho_{t, t+1}\left(1-p\left(H_{F, t+1}^{h}\right)-p\left(H_{I, t+1}^{h}\right)\right) V_{U, t+1}^{h}\right] \\
& +\sigma_{I}^{h} E_{t}\left[\rho_{t, t+1}\left(1-p\left(S_{t+1}^{h}\right)\right) V_{N P, t+1}^{h}\right]
\end{aligned}
$$

An unemployed worker receives social benefits today, $W_{U, t}$, and spends $\tau_{U} \varepsilon(0,1)$ proportion of her time in home-good production, while the remaining time $\left(1-\tau_{U}\right)$ is spent in searching 
for jobs ${ }^{23}$. In the next period, there is a probability $p\left(S_{t+1}^{h}\right)$ that the worker stays at home or participates in the labor market with probability $\left(1-p\left(S_{t+1}^{h}\right)\right)$, which gives us the expression for $V_{U, t}^{h}$ as follows:

$$
\begin{aligned}
V_{U, t}^{h} & =W_{U, t}-\left(1-\tau_{U}\right) M R S_{H P_{t}, C_{t}}^{h}-M R S_{l e_{t}, C_{t}}^{h} \\
& +E_{t} \rho_{t, t+1}\left\{\rho_{t, t+1} p\left(S_{t+1}^{h}\right)\left[\left(p\left(H_{F, t+1}^{h}\right) V_{F, t+1}^{h}+p\left(H_{I, t+1}^{h}\right) V_{I, t+1}^{h}\right]\right\}\right. \\
& +E_{t}\left[\rho_{t, t+1}\left(1-p\left(H_{F, t+1}^{h}\right)-p\left(H_{I, t+1}^{h}\right)\right) V_{U, t+1}^{h}\right] \\
& +E_{t}\left[\rho_{t, t+1}\left(1-p\left(S_{t+1}^{h}\right)\right) V_{N P, t+1}^{h}\right]
\end{aligned}
$$

A non-participant household member, either works in home-good production with probability $\left(1-p\left(l e_{t+1}^{h}\right)\right)$, or consumes leisure with probability $p\left(l e_{t+1}^{h}\right)^{24}$. This gives us the marginal value to worker $h$ of not participating (i.e. staying at home) as:

$$
V_{N P, t+1}^{h}=\left(1-p\left(l e_{t+1}^{h}\right)\right) V_{H P, t+1}^{h}+p\left(l e_{t+1}^{h}\right) V_{l e, t+1}^{h}
$$

Value of working in home-good production, $V_{H P, t+1}^{h}$ and value of consuming leisure, $V_{l e, t+1}^{h}$, are analogous to the value of being unemployed, except that these workers are now not entitled to receive unemployment benefits ${ }^{25}$ :

$$
\begin{aligned}
V_{H P, t}^{h} & =-M R S_{l e_{t}, C_{t}}^{h} \\
& +E_{t} \rho_{t, t+1}\left\{\rho_{t, t+1} p\left(S_{t+1}^{h}\right)\left[\left(p\left(H_{F, t+1}^{h}\right) V_{F, t+1}^{h}+p\left(H_{I, t+1}^{h}\right) V_{I, t+1}^{h}\right]\right\}\right. \\
& +E_{t}\left[\rho_{t, t+1}\left(1-p\left(H_{F, t+1}^{h}\right)-p\left(H_{I, t+1}^{h}\right)\right) V_{U, t+1}^{h}\right] \\
& +E_{t}\left[\rho_{t, t+1}\left(1-p\left(S_{t+1}^{h}\right)\right) V_{N P, t+1}^{h}\right] \\
V_{l e, t}^{h} & =-M R S_{H P_{t}, C_{t}}^{h} \\
& +E_{t} \rho_{t, t+1}\left\{\rho_{t, t+1} p\left(S_{t+1}^{h}\right)\left[\left(p\left(H_{F, t+1}^{h}\right) V_{F, t+1}^{h}+p\left(H_{I, t+1}^{h}\right) V_{I, t+1}^{h}\right]\right\}\right. \\
& +E_{t}\left[\rho_{t, t+1}\left(1-p\left(H_{F, t+1}^{h}\right)-p\left(H_{I, t+1}^{h}\right)\right) V_{U, t+1}^{h}\right] \\
& +E_{t}\left[\rho_{t, t+1}\left(1-p\left(S_{t+1}^{h}\right)\right) V_{N P, t+1}^{h}\right]
\end{aligned}
$$

\footnotetext{
${ }^{23} \mathrm{We}$ assume a unit interval for the time period.

${ }^{24}$ These probabilities are endogenously determined by households optimization

${ }^{25}$ In the context of India, the unemployment benefits could be thought of as the benefits under the scheme of the Mahatama Gandhi National Rural Employment Guarantee Act (MNREGA). The stated objective of the Act is "to enhance livelihood security in rural areas by providing at least 100 days of guaranteed wage employment in a financial year to every household whose adult members volunteer to do unskilled manual labor".
} 
An unemployed worker $h$ has a utility gain of $\left(V_{F, t}^{h}-V_{U, t}^{h}\right)$ if hired in the formal sector and a gain of $\left(V_{I, t}^{h}-V_{U, t}^{h}\right)$ if hired in the informal sector.

Following the derivations in Blanchard and Gali (2006), sector $s$ wholesalers' value of hiring an additional worker $h$ in period $t, J_{s, t}^{h}$, is simply given by the hiring cost in the same period, i.e $J_{s, t}^{h}=H C_{s, t}^{h}{ }^{26}$. Generalized Nash bargaining over the wage rate determines the division of rent between worker $h$ and wholesaler in sector $s$ :

$$
\max _{W_{s, t}^{h}}\left(V_{s, t}^{h}-V_{U, t}^{h}\right)^{\lambda_{s, t}^{h}} J_{s, t}^{h\left(1-\lambda_{s, t}^{h}\right)}
$$

and the equation determining wages, $W_{s, t}^{h}$, is:

$$
V_{s, t}^{h}-V_{U, t}^{h}=\frac{\lambda_{s, t}^{h}}{1-\lambda_{s, t}^{h}}\left(1-\tau_{s}\right) J_{s, t}^{h}
$$

We derive the expressions for wage rate of male and female workers in the Techinacal Appendix and define average male and female wages, $W_{t}^{m}$ and $W_{t}^{f}$, by the ratio of total after tax wage income divided by the total number of individuals employed:

$$
W_{t}^{m}=\frac{W_{F, t}^{m} L_{F, t}^{m}\left(1-\tau_{F}\right)+W_{I, t}^{m} L_{I, t}^{m}}{L_{F, t}^{m}+L_{I, t}^{m}} \quad W_{t}^{f}=\frac{W_{F, t}^{f} L_{F, t}^{f}\left(1-\tau_{F}\right)+W_{I, t}^{f} L_{I, t}^{f}}{L_{F, t}^{f}+L_{I, t}^{f}}
$$

where ratio of average male wages to average female wages, $\frac{W_{t}^{m}}{W_{t}^{f}}$, is defined as the 'gender wage gap'.

\subsection{Retailers}

A continuum $j_{F}$ and $j_{I}$ of monopolistically competitive formal and informal retailers buy wholesale goods to produce different final market-good varieties, $Y_{F, t}\left(j_{F}\right)$ and $Y_{I, t}\left(j_{I}\right)$, and sell these at different prices, $P_{F, t}\left(j_{F}\right)$ and $P_{I, t}\left(j_{I}\right)$, respectively ${ }^{27}$.

Total composite output in each sector $s, Y_{s, t}$, produced by retailers is a Dixit-Stiglitz (1977) CES aggregate of different varieties of goods produced by individual retailers, $Y_{s, t}\left(j_{s}\right)$.

$$
Y_{s, t}=\left(\int_{0}^{1} Y_{s, t}\left(j_{S}\right)^{\frac{\varepsilon_{s}-1}{\varepsilon_{s}}} d j_{S}\right)^{\frac{\varepsilon_{s}}{\varepsilon_{s}-1}}
$$

\footnotetext{
${ }^{26}$ This is because in our framework there is no search time for hiring new worker (i.e. instant hiring assumption), and so a firm can always replace a worker who is fired at this cost.

${ }^{27} \mathrm{We}$ assume zero cost of differentiation.
} 
$\varepsilon_{s}$ stands for the elasticity of substitution between different varieties of goods. The corresponding price of the composite consumption good, $P_{s, t}$ is:

$$
P_{s, t}=\left(\int_{0}^{1} P_{s, t}\left(j_{s}\right)^{1-\varepsilon_{s}} d j_{s}\right)^{\frac{1}{1-\varepsilon_{s}}}
$$

The demand function facing each retailer can be written as:

$$
Y_{s, t}\left(j_{s}\right)=\left(\frac{P_{s, t}\left(j_{s}\right)}{P_{s, t}}\right)^{-\varepsilon_{s}} Y_{s, t}
$$

Formal final good, $Y_{F, t}$, is exportable where it is consumed both domestically $Q_{F, t}^{d}$, by households, capital producers and government, and is also exported $Q_{t}^{x}$ to the rest of the world. On the other hand, the informal sector good $Y_{I, t}$ is nontradable and is only consumed domestically by households, $Q_{I, t}^{d}$.

\section{Price Setting}

Retailer $j_{s}$ sets its price, $P_{s, t}\left(j_{s}\right)$ that maximizes its expected discounted stream of future profits:

$$
\underset{P_{s, t}\left(j_{s}\right)}{\operatorname{Max}} E_{t} \sum_{k=0}^{\infty} \rho_{t, t+k} \Pi_{t, t+k}^{R}\left(j_{s}\right)
$$

where the one-period profit in the formal sector, $\Pi_{F, t}^{R}\left(j_{F}\right)$, is given by the sum of total revenues from its domestic demand, $\left(\frac{P_{F, t}\left(j_{F}\right)}{P_{F, t}}\right)^{-\varepsilon_{F}} Q_{F, t}^{d}$ and export demand $\left(\frac{P_{F, t}\left(j_{F}\right)}{P_{F, t}}\right)^{-\varepsilon_{F}} Q_{t}^{x}$, net of the costs of price adjustment. Per-period profits are then obtained as:

$$
\begin{aligned}
\Pi_{F, t}^{R}\left(j_{F}\right) & =\left(\frac{P_{F, t}\left(j_{F}\right)}{P_{t}}-M C_{F, t}^{W}\right)\left(\frac{P_{F, t}\left(j_{F}\right)}{P_{F, t}}\right)^{-\varepsilon_{F}}\left(Q_{F, t}^{d}+Q_{t}^{x}\right) \\
& -\frac{\phi_{F}^{a d j}}{2}\left(\frac{P_{F, t}\left(j_{F}\right) / P_{F, t-1}\left(j_{F}\right)}{\pi}-1\right)^{2}\left(Q_{F, t}^{d}+Q_{t}^{x}\right)
\end{aligned}
$$

Here $M C_{F, t}^{W}$ is the real marginal cost, which is equal to the perfectly competitive wholesalers' real price $\frac{P_{F, t}^{W}}{P_{t}}$. Aggregate price and formal price inflation are given by $\pi_{t}=\frac{P_{t}}{P_{t-1}}$ and $\pi_{F, t}=$ $\frac{P_{F, t}}{P_{F, t-1}}$, where $\pi$ is the steady state economy wide inflation ${ }^{28}$. Following Rotemberg (1982), we have quadratic costs of price adjustment $\frac{\phi_{F}^{a d j}}{2}\left(\frac{P_{F, t}\left(j_{F}\right) / P_{F, t-1}\left(j_{F}\right)}{\pi}-1\right)^{2}$, and $\phi_{F}^{a d j} \geq 0$ is a parameter determining the degree of nominal rigidity in the formal sector.

\footnotetext{
${ }^{28}$ Variables without a time subscript $t$ denotes their respective steady state values.
} 
Per-period profits of informal retailers are similar, except that the informal sector only sells its goods domestically:

$$
\begin{aligned}
\Pi_{I, t}^{R}\left(j_{I}\right) & =\left(\frac{P_{I, t}\left(j_{I}\right)}{P_{t}}-M C_{I, t}^{W}\right)\left(\frac{P_{I, t}\left(j_{I}\right)}{P_{I, t}}\right)^{-\varepsilon_{I}} Q_{I, t}^{d} \\
& -\frac{\phi_{I}^{a d j}}{2}\left(\frac{P_{I, t}\left(j_{I}\right) / P_{I, t-1}\left(j_{I}\right)}{\pi}-1\right)^{2} Q_{I, t}^{d}
\end{aligned}
$$

$\phi_{I}^{a d j} \geq 0$ determines the degree of nominal rigidity in informal prices and $\pi_{I, t}=\frac{P_{I, t}}{P_{I, t-1}}$ is the inflation in informal prices.

The first order condition of the retailer optimization problem determines the price in each sector s (refer to Technical Appendix):

$$
\begin{aligned}
\frac{P_{s, t}\left(j_{s}\right)}{P_{t}} & =\frac{\varepsilon_{s}}{\varepsilon_{s}-1} M C_{j, t}^{W}+\frac{\phi_{s}^{a d j}}{\varepsilon_{s}-1}\left(\frac{\pi_{s, t}}{\pi}-1\right) \frac{\pi_{s, t}}{\pi} \\
& -E_{t}\left\{\rho_{t, t+1}\left[\left(\frac{\phi_{s}^{a d j}}{\varepsilon_{s}-1}\right)\left(\frac{\pi_{s, t+1}}{\pi}-1\right)\left(\frac{\pi_{s, t+1}}{\pi}\right) \frac{Y_{s, t+1}\left(j_{s}\right)}{Y_{s, t}\left(j_{s}\right)}\right]\right\}
\end{aligned}
$$

$\frac{\varepsilon_{s}}{\varepsilon_{s}-1}$ is the desired (gross) mark-up, resulting from the imperfections in the retail market. We assume that import prices follow a similar pricing rule as that of the formal goods, with $\phi_{f *}^{a d j} \geq 0$ determining the degree of nominal rigidity in import prices.

\subsection{Household}

\section{Utility Function}

The households aggregate utility function is a weighted sum of male utility, $\Lambda_{t}^{m}$, and female utility, $\Lambda_{t}^{f}$, where the weights are determined by the intra-household bargaining power of males and females:

$$
\Lambda_{t}=E_{t} \sum_{t=0}^{\infty} \beta^{t}\left[\left(B P_{t}\right)\left(p^{m}\right) \Lambda_{t}^{m}+\left(1-B P_{t}\right)\left(p^{f}\right) \Lambda_{t}^{f}\right]
$$

$\beta$ is the nominal discount rate and $B P_{t} \varepsilon(0,1)$ is the endogenously determined intra-household bargaining power of males relative to females ${ }^{29}$. Following Klaveren (2009), $B P_{t}$ is an increasing function of male to female wage income ratio given by:

$$
B P_{t}=\frac{\exp \left[\frac{\left(1-\tau_{F}\right) W_{F}^{m} L_{F}^{m}+W_{I}^{m} L_{I}^{m}}{\left(1-\tau_{F}\right) W_{F}^{f} L_{F}^{f}+W_{I}^{f} L_{I}^{f}}\right]}{1+\exp \left[\frac{\left(1-\tau_{F}\right) W_{F}^{m} L_{F}^{m}+W_{I}^{m} L_{I}^{m}}{\left(1-\tau_{F}\right) W_{F}^{f} L_{F}^{f}+W_{I}^{f} L_{I}^{f}}\right]}
$$

\footnotetext{
${ }^{29}$ The higher the value of $B P_{t}$, the more the male utility function is weighted in the overall household utility.
} 
Bargaining power of male increases with an increase in his own steady state wage income, whereas it decreases with a rise in the steady state wage income of females..

Each member derives utility from consuming market-produced goods $C_{t}$, home-produced goods $H_{t}^{0}$, and leisure $l e_{t}^{h}$ :

$$
\begin{aligned}
& \Lambda^{m}\left(C_{t}, H_{t}^{0}, l e_{t}^{m}\right)=\left(1-h_{c}\right) \ln \left(C_{t}-h_{c} C_{t-1}\right)+\phi_{t}^{m}\left(\frac{\left(H_{t}^{0}\right)^{1+v_{H, t}^{m}}}{1+v_{H, t}^{m}}+\varphi_{l e, t}^{m} \frac{\left(l e_{t}^{m}\right)^{1+v_{l e, t}^{m}}}{1+v_{l e, t}^{m}}\right) \\
& \Lambda^{f}\left(C_{t}, H_{t}^{0}, l e_{t}^{f}\right)=\left(1-h_{c}\right) \ln \left(C_{t}-h_{c} C_{t-1}\right)+\phi_{t}^{f}\left(\frac{\left(H_{t}^{0}\right)^{1+v_{H, t}^{f}}}{1+v_{H, t}^{f}}+\varphi_{l e, t}^{f} \frac{\left(l e_{t}^{f}\right)^{1+v_{l e, t}^{f}}}{1+v_{l e, t}^{f}}\right)
\end{aligned}
$$

Market and home consumption are public goods, and there is risk sharing within the household, so that all its members - males and females, consume the same amount of these goods. The disutility of working, on the other hand, accrues to each member individually. Therefore, males do not get any utility from female leisure and vice-versa. $C_{t}$ denotes aggregate consumption at time $t$, while $C_{t-1}$ is the average level of consumption in $t-1$, where $h_{c} \in[0,1)$ is the external habit formation parameter. $-v_{H . t}^{h}$ is the inverse inter-temporal elasticity of substitution between market-good consumption and home-good consumption, and $-v_{l e, t}^{h}$ is the inverse inter-temporal elasticity of substitution between market consumption and leisure.

$\phi_{t}^{h}$ is an exogenously given weight each member places on their utility from consuming home goods and leisure (i.e, utility from staying at home) relative to consuming market goods (i.e. participating in paid market work). This coefficient captures the constraints on engaging in work outside home such as safety and mobility issues. $\varphi_{l e}^{h}$ determines the relative weight on utility from engaging in home-good production relative to utility from consuming leisure. This also varies across males and females, which corresponds to the deeply ingrained gender biased social norms and lack of childcare facilities in developing countries.

\section{Home-good Production}

Home goods are produced by males and females working in home production (home workers), $H P_{t}^{m}$ and $H P_{t}^{f}$, combined with the unemployed in the labor market who engage in home-good production in their residual time unoccupied by job search. After normalizing to one the total time available to each worker, the unemployed spend $\tau_{U} \varepsilon(0,1)$ proportion of their time working in home-good production, where $\left(1-\tau_{U}\right)$ is then the search cost. We assume a homegood production function with decreasing returns to scale, where $-\rho_{H}$ is a coefficient of the inverse inter-temporal elasticity between male and female home workers ${ }^{30}$ :

$$
H_{t}^{0}=\theta_{H, t}\left\{\left[\left(1-B P_{t}\right)\left(H P_{t}^{m}+\tau_{U} U_{t}^{m}\right)^{p_{H}}+B P_{t}\left(H P_{t}^{f}+\tau_{U} U_{t}^{f}\right)^{p_{H}}\right]^{1 / p_{H}}\right\}^{1-\alpha_{H}}
$$

$\theta_{H, t}$ is the exogenous $\mathrm{AR}(1)$ shock to home productivity ${ }^{31}$. Intra-household bargaining power, $B P_{t}$, determines the weight on female relative to male workers in home-good production,

\footnotetext{
${ }^{30}$ Christiano et al. (2014) use a similar home production function in their framework.

${ }^{31}$ This corresponds to public provisions and infrastructure such as sanitation, access to water and electricity.
} 
where higher the bargaining power of males at home, i.e. higher $B P_{t}$, lower is the weight on male workers in home production.

\section{Partial Derivatives}

The corresponding partial derivatives with respect to male and female leisure and home-work are:

$$
\begin{gathered}
\frac{\partial \Lambda_{t}}{\partial H P_{t}^{m}}=\left(B P_{t}\right)\left(p^{m}\right) \frac{\partial \Lambda_{t}^{m}}{\partial H_{t}^{0}} \frac{\partial H_{t}^{0}}{\partial H P_{t}^{m}}+\left(1-B P_{t}\right)\left(p^{f}\right) \frac{\partial \Lambda_{t}^{f}}{\partial H_{t}^{0}} \frac{\partial H_{t}^{0}}{\partial H P_{t}^{m}} \\
\frac{\partial \Lambda_{t}}{\partial H P_{t}^{f}}=\left(B P_{t}\right)\left(p^{m}\right) \frac{\partial \Lambda_{t}^{m}}{\partial H_{t}^{0}} \frac{\partial H_{t}^{0}}{\partial H P_{t}^{f}}+\left(1-B P_{t}\right)\left(p^{f}\right) \frac{\partial \Lambda_{t}^{f}}{\partial H_{t}^{0}} \frac{\partial H_{t}^{0}}{\partial H P_{t}^{f}} \\
\frac{\partial \Lambda_{t}}{\partial l e_{t}^{m}}=\left(B P_{t}\right)\left(p^{m}\right)\left(\frac{\partial \Lambda_{t}^{m}}{\partial l e_{t}^{m}}+\frac{\partial \Lambda_{t}^{m}}{\partial H_{t}^{0}} \frac{\partial H_{t}^{0}}{\partial l e_{t}^{m}}\right)+\left(1-B P_{t}\right)\left(p^{f}\right) \frac{\partial \Lambda_{t}^{f}}{\partial H_{t}^{0}} \frac{\partial H_{t}^{0}}{\partial l e_{t}^{m}} \\
\frac{\partial \Lambda_{t}}{\partial l e_{t}^{f}}=\left(B P_{t}\right)\left(p^{m}\right) \frac{\partial \Lambda_{t}^{m}}{\partial H_{t}^{0}} \frac{\partial H_{t}^{0}}{\partial l e_{t}^{f}}+\left(1-B P_{t}\right)\left(p^{f}\right)\left(\frac{\partial \Lambda_{t}^{f}}{\partial l e_{t}^{f}}+\frac{\partial \Lambda_{t}^{f}}{\partial H_{t}^{0}} \frac{\partial H_{t}^{0}}{\partial l e_{t}^{f}}\right)
\end{gathered}
$$

Eq. 3.47 suggests that females' leisure choice influences the household utility directly through the utility function of the female, $\frac{\partial U_{t}^{f}}{\partial l_{t}^{f}}$, as individual leisure is a private good, as well as indirectly through home-good production, because we have replaced unemployment in the homegood production as $U_{t}^{f}=p^{f}-L_{F, t}^{f}-L_{I, t}^{f}-l e_{t}^{f}-H P_{t}^{f}$. Additionally, because home-good and market-good consumption are considered as public goods, female leisure choice influences aggregate household utility through the utility of both males and females. In addition, higher the intra-household bargaining power of females, $\left(1-B P_{t}\right)$, more is the weight placed on the impact on female utility relative to male utility while choosing female leisure. The intuition for the other partial derivatives above is the same.

\section{Aggregate Market-good Consumption}

Aggregate market-good consumption, $C_{t}$ consists of domestically produced market goods, $C_{D, t}$, and imported market goods, $C_{f *, t}$ (in terms of domestic currency), and is given by the following Dixit-Stiglitz (1977) aggregator:

$$
C_{t}=\left[\alpha^{\frac{1}{\eta}} C_{D, t}^{\frac{\eta-1}{\eta}}+(1-\alpha)^{\frac{1}{\eta}} C_{f *, t} \frac{\eta-1}{\eta}\right]^{\frac{\eta}{\eta-1}}
$$

where $\alpha \in(0,1)$ can be interpreted as a measure of domestic bias in consumption, and $\eta>1$ is the elasticity of substitution between domestic and foreign goods.

Aggregate price level $P_{t}$ can be expressed as a composite of domestic price $P_{D, t}$ and import price $P_{f *, t}$, and is given by the following CES form:

$$
P_{t}=\left[\alpha P_{D, t}^{1-\eta}+(1-\alpha) P_{f *, t}^{1-\eta}\right]^{\frac{1}{1-\eta}}
$$


Domestic market-good consumption is a composite of formal market-good consumption, $C_{F, t}$, and informal market-good consumption, $C_{I, t}$ expressed as:

$$
C_{D, t}=\left[w^{\frac{1}{\mu}} C_{F, t}^{\frac{\mu-1}{\mu}}+(1-w)^{\frac{1}{\mu}} C_{I, t}^{\frac{\mu-1}{\mu}}\right] \frac{\mu}{\mu-1}
$$

where $w \varepsilon(0,1)$ is the weight on formal sector market-good, and $\mu>1$ is the elasticity of substitution between the goods produced in the two sectors. Then, aggregate domestic marketgood price, $P_{D, t}$, is determined by:

$$
P_{D, t}=\left[w P_{F, t}^{1-\mu}+(1-w) P_{I, t}^{1-\mu}\right] \frac{1}{1-\mu}
$$

By minimizing household expenditure on the total composite demand, we can derive the following optimal consumption demand functions for aggregate domestic and imported market goods:

$$
C_{D, t}=\alpha\left(\frac{P_{D, t}}{P_{t}}\right)^{-\eta} C_{t} \quad C_{f *, t}=(1-\alpha)\left(\frac{P_{f *, t}}{P_{t}}\right)^{-\eta} C_{t}
$$

Similarly, we derive the optimal consumption demand functions for domestically produced formal and informal market-goods:

$$
C_{F, t}=w\left(\frac{P_{F, t}}{P_{D, t}}\right)^{-\mu} C_{D, t} \quad C_{I, t}=(1-w)\left(\frac{P_{I, t}}{P_{D, t}}\right)^{-\mu} C_{D, t}
$$

\section{Budget Constraint}

The representative household enters period $t$ with one period (real) foreign and domestic bonds, $B_{t-1}^{*}$ (in foreign currency) and $D_{t-1}$, both of which yield a nominal interest rate of $i_{t-1}^{f}$ and $i_{t-1}$ over the period $t$, respectively. In addition, during period $t$, individuals who are employed, earn after tax wage income of $\left(\sum_{h=m, f}\left[\left(1-\tau_{F}\right) W_{F, t}^{h} L_{F, t}^{h}\right] d h\right)$ in formal jobs and $\left(\sum_{h=m, f}\left[\left(1-\tau_{I}\right) W_{I, t}^{h} L_{I, t}^{h}\right] d h\right)$ in informal jobs, and the unemployed receive social benefits, $\left(W_{U, t}\right)\left(U_{t}^{m}+U_{t}^{f}\right)$. They receive real dividends arising from the ownership of the retail firms, $\Pi_{F, t}^{R}$ and $\Pi_{I, t}^{R}$. The income is spent on the consumption of market goods, $C_{t}$, and the purchase of one period bonds for the subsequent period, $B_{t}^{*}$ and $D_{t}$. Denoting $e_{t}$ as the nominal exchange rate where an increase in its value implies depreciation of domestic currency, we have the following period budget constraint of the household in real terms, with $R E R_{t}=\frac{e_{t} P_{t}^{*}}{P_{t}}$ as the real exchange rate::

$$
\begin{aligned}
& C_{t}+R E R_{t} B_{t}^{*}+D_{t} \\
& =\left(\frac{e_{t}}{e_{t-1}}\right)\left(\frac{1+i_{t-1}^{f}}{\pi_{t}}\right)\left(R E R_{t-1}\right) B_{t-1}^{*}+\left(\frac{1+i_{t-1}}{\pi_{t}}\right) D_{t-1} \\
& +\left(1-\tau_{F}\right) W_{F, t}^{m} L_{F, t}^{m}+\left(1-\tau_{F}\right) W_{F, t}^{f} L_{F, t}^{f}+W_{I, t}^{m} L_{I, t}^{m}+W_{I, t}^{f} L_{I, t}^{f} \\
& +W_{U, t}\left(U_{t}^{m}+U_{t}^{f}\right)+\Pi_{F, t}^{R}+\Pi_{I, t}^{R}
\end{aligned}
$$


The resulting first order conditions with respect to $C_{t}, B_{t}$, and $D_{t}$ yield the standard Euler equation for consumption (see Technical Appendix):

$$
\begin{gathered}
1=\beta E_{t}\left\{\left(\frac{C_{t}-h_{C} C_{t-1}}{C_{t+1}-h_{C} C_{t}}\right)\left(\frac{1+i_{t}}{\pi_{t+1}}\right)\right\} \\
1=\beta E_{t}\left\{\left(\frac{C_{t}-h_{C} C_{t-1}}{C_{t+1}-h_{C} C_{t}}\right)\left(\frac{1+i_{t}^{f}}{\pi_{t+1}}\right)\left(\frac{e_{t+1}}{e_{t}}\right)\right\}
\end{gathered}
$$

Combining Eq. 3.55 and Eq. 3.56 (up to a log-linear approximation) gives us the uncovered interest rate parity (UIP) condition $\left(\frac{1+i_{t}}{\pi_{t+1}}\right)=\left(\frac{1+i_{t}^{f}}{\pi_{t+1}}\right)\left(\frac{e_{t+1}}{e_{t}}\right)$.

The remaining first order conditions for $H P_{t}^{m}, H P_{t}^{f}, l e_{t}^{m}$, and $l e_{t}^{f}$ yield the labor supply equation $^{32}$ :

$$
\begin{aligned}
\operatorname{MRS}_{H P_{t}, C_{t}}^{h} & =\left(1-\tau_{F}\right) W_{F, t}^{h} p\left(H_{F, t}^{h}\right)+W_{I, t}^{h} p\left(H_{I, t}^{h}\right) \\
& +W_{U, t}\left[1-p\left(H_{F, t}^{h}\right)-p\left(H_{I, t}^{h}\right)\right] \\
\operatorname{MRS}_{l e_{t}, C_{t}}^{h} & =\left(1-\tau_{F}\right) W_{F, t}^{m} p\left(H_{F, t}^{m}\right)+W_{I, t}^{m} p\left(H_{I, t}^{m}\right) \\
& +W_{U, t}\left[1-p\left(H_{F, t}^{m}\right)-p\left(H_{I, t}^{m}\right)\right]
\end{aligned}
$$

Finally, probability that a non-participant household member $h$ consumes leisure, $p\left(l e_{t}^{h}\right)$, is given by the ratio of the ones consuming leisure divided by the individuals who stay at home:

$$
p\left(l e_{t}^{h}\right)=\frac{l e_{t}^{h}}{H P_{t}^{h}+l e_{t}^{h}} \equiv \frac{l e_{t}^{h}}{N P_{t}^{h}}
$$

where $\left(1-p\left(l e_{t}^{h}\right)\right)$ is then the probability that a non-participant household member $h$ engages in home-production.

\subsection{Capital Producer}

Capital producers combine the existing undepreciated capital stock, $\left(1-\delta_{K}\right) K_{t-1}$, leased from wholesalers, with investment goods, $I_{t}$, to produce new capital $K_{t}$, using a linear technology. The capital-producing sector is perfectly competitive. Capital evolves according to the following equation:

$$
K_{t}=\left(1-\delta_{K}\right) K_{t-1}+\frac{P_{t}^{I n v}}{P_{t}} I_{t}-\frac{\kappa}{2}\left(\frac{P_{t}^{I n v}}{P_{t}} \frac{I_{t}}{K_{t-1}}-\delta_{K}\right)^{2} K_{t-1}
$$

${ }^{32}$ The expressions for $M R S_{H P_{t}, C_{t}}^{h}=\left(\frac{\partial \Lambda_{t}}{\partial H P_{t}^{h}}\right) /\left(\frac{\partial \Lambda_{t}}{\partial C_{t}}\right)$ and $M R S_{l e_{t}, C_{t}}^{h}=\left(\frac{\partial \Lambda_{t}}{\partial l e_{t}^{f}}\right) /\left(\frac{\partial \Lambda_{t}}{\partial C_{t}}\right)$ are derived in the Technical Appendix. 
where $\frac{\kappa}{2}\left(\frac{P_{t}^{I n v}}{P_{t}} \frac{I_{t}}{K_{t-1}}-\delta_{K}\right)^{2} K_{t-1}$ is the capital adjustment cost. Here $\kappa \geq 0$ is the capital adjustment coefficient, and $\delta_{K}$ is the depreciation rate of physical capital.

Capital production is confined to the formal sector, and investment is thus a composite of domestic formal goods and foreign imports:

$$
I_{t}=\left[\alpha^{\frac{1}{\eta}} I_{F, t}^{\frac{\eta-1}{\eta}}+(1-\alpha)^{\frac{1}{\eta}} I_{f *, t} \frac{\eta-1}{\eta}\right]^{\frac{\eta}{\eta-1}}
$$

and the price of investment is:

$$
P_{t}^{I n v}=\left[\alpha P_{F, t}^{1-\eta}+(1-\alpha) P_{f *, t}^{1-\eta}\right]^{\frac{1}{1-\eta}}
$$

We assume that it is in the same proportion as in the consumption basket (Eq. 3.52 and Eq. 3.53 ), except that now weight on formal good is $w=1$. Hence, optimal demand for domestic and imported investment goods is:

$$
I_{F, t}=\alpha\left(\frac{P_{F, t}}{P_{t}^{I n v}}\right)^{-\eta} I_{t} \quad I_{f^{*}, t}=(1-\alpha)\left(\frac{P_{f *, t}}{P_{t}^{I n v}}\right)^{-\eta} I_{t}
$$

The capital producer invests such that its profit is maximized, where $Q_{t}$ is the real price of capital:

$$
\max _{I_{t}} Q_{t}\left(\frac{P_{t}^{I n v}}{P_{t}} I_{t}-\frac{\kappa}{2}\left(\frac{P_{t}^{I n v}}{P_{t}} \frac{I_{t}}{K_{t-1}}-\delta_{K}\right)^{2} K_{t-1}\right)-\frac{P_{t}^{I n v}}{P_{t}} I_{t}
$$

The corresponding first order condition w.r.t. to the choice of $I_{t}$ determines the capital supply equation (see Technical Appendix):

$$
Q_{t}\left[1-\kappa\left(\frac{P_{t}^{I n v}}{P_{t}} \frac{I_{t}}{K_{t-1}}-\delta_{K}\right)\right]=1
$$

This is the Tobin's (1969) Q equation relating the price of capital to marginal adjustment costs. In the absence of capital adjustment costs $(\kappa=0)$, the price of capital is constant and equal to one.

Demand for capital by wholesalers in sector $s$ must satisfy the following condition:

$$
E_{t}\left(R_{t+1} Q_{t}\right)=E_{t}\left\{\psi_{F}\left(\frac{P_{s, t+1}^{W}}{P_{t+1}}\right)\left(\frac{Y_{s, t+1}^{W}}{K_{s, t}}\right)+\left(1-\delta_{K}\right) Q_{t+1}\right\}
$$




\subsection{Rest of the World}

Foreign economy consumes domestic formal exports, $Q_{t}^{x}$, supplies foreign goods to domestic country as imports, $Q_{t}^{m}$, and sells foreign bonds, $B_{t}^{*}$ to domestic households. We assume that the domestic economy is small, which implies that it cannot affect foreign output, $Y_{t}^{*}$, foreign inflation, $\pi_{t}^{*}=\frac{P_{t}^{*}}{P_{t-1}^{*}}$, and the foreign interest rate, $i_{t}^{*}$, all of which are assumed to be exogenously determined in the rest of the world ${ }^{33}$.

The demand for domestic exports by the foreign economy is assumed to have a similar structure to that of domestic consumption in Eq. 3.52:

$$
Q_{t}^{x}=\alpha_{x}^{*}\left(\frac{P_{X, t}^{*}}{P_{t}^{*}}\right)^{-\eta_{x}^{*}} Y_{t}^{*}
$$

where $\alpha_{x}^{*} \varepsilon(0,1)$ is a parameter determining the share of domestic goods in foreign consumption bundle, and $\eta_{x}^{*}>1$ is the substitution elasticity between exports and foreign domestic goods. We assume that law of one price (LOOP) holds for domestic goods, allowing us to express the price of exports in foreign currency as $P_{X, t}^{*}=\frac{P_{F, t}}{e_{t}} 34$.

Following Schmitt-Grohe and Uribe (2003), interest rate on foreign bond, $i_{t}^{f}$, depends not only on the exogenous foreign interest rate, $i_{t}^{*}$, but also on the foreign currency borrowing premium, $\chi$, whereby holders of foreign debt are assumed to face an interest rate that is increasing in the country's net foreign debt:

$$
\left(1+i_{t}^{f}\right)=\left(1+i_{t}^{*}\right)-\chi\left(\frac{B_{t}^{*}-B^{*}}{\frac{P_{F}}{(R E R) P} Q^{x}}\right)
$$

This is a standard assumption in the small open economy literature ${ }^{35}$.

\subsection{Government Policy}

Government consists of monetary and fiscal authorities. The monetary authority sets the nominal interest rate, $i_{t}$, based on a Taylor-type (1993) feedback rule. It responds to deviations in inflation and gross domestic product:

$$
\frac{i_{t}}{i}=\left(\frac{i_{t-1}}{i}\right) \alpha_{i}\left(\frac{\pi_{t}}{\pi}\right) \alpha_{\pi}\left(\frac{Y_{t}}{Y}\right){ }^{\alpha_{Y}} \varepsilon_{i, t}
$$

where $\alpha_{i}$ captures interest rate smoothing, and the Taylor rule coefficients, $\alpha_{\pi}$ and $\alpha_{Y}$, are the relative weights on inflation and output stabilization respectively. $i, \pi$, and $Y$ are the steady

\footnotetext{
${ }^{33}$ We normalise the value of foreign output by assuming $Y_{t}^{*}=1$.

${ }^{34}$ Substituting the LOOP condition, and $R E R_{t}=\frac{e_{t} P_{t}^{*}}{P_{t}}$ in Eq. 3.63, we get the following $Q_{t}^{x}=\alpha_{x}^{*}\left(\frac{P_{F, t}}{P_{t}} \frac{1}{R E R_{t}}\right)-\eta_{x}^{*} Y_{t}^{*}$. Therefore, a real depreciation of the currency increases exports.

${ }^{35}$ The need for such a friction is mainly technical, i.e. the country borrowing premium ensures that the model has a unique steady state and ensures stationarity.
} 
state values for nominal interest rate, inflation, and gross domestic product. $\varepsilon_{i, t}$ is a monetary policy shock to capture unanticipated changes in the nominal interest rate.

In addition, the fiscal authority finances its consumption, $G_{t}$, and unemployment benefit payments by taxing wage income in the formal sector ${ }^{36}$. The government budget constraint every period is:

$$
\frac{P_{t}^{I n v}}{P_{t}} G_{t}+W_{U, t}\left(U_{t}^{m}+U_{t}^{f}\right)=\tau_{F}\left(W_{F, t}^{m} L_{F, t}^{m}+W_{F, t}^{f} L_{F, t}^{f}\right)
$$

We assume that exogenously given government consumption basket, $G_{t}$, analogous to the investment basket in Eq. 3.60, consists of domestic formal market goods, $G_{F, t}$, along with foreign imports, $G_{f *, t}$ (in domestic currency):

$$
G_{t}=\left[\alpha^{\frac{1}{\eta}} G_{F, t}^{\frac{\eta-1}{\eta}}+(1-\alpha)^{\frac{1}{\eta}} G_{f *, t} \frac{\eta-1}{\eta}\right]^{\frac{\eta}{\eta-1}}
$$

Optimal demand for domestic formal, $G_{F, t}$, and imported government consumption, $G_{f^{*}, t}$, is given by:

$$
G_{F, t}=\alpha\left(\frac{P_{F, t}}{P_{t}^{I n v}}\right)^{-\eta} G_{t} \quad G_{f *, t}=(1-\alpha)\left(\frac{P_{f^{*}, t}}{P_{t}^{I n v}}\right)^{-\eta} G_{t}
$$

\subsection{Market Clearing and Aggregation}

Sum of employment in the formal, $L_{F, t}$, and in the sector, $L_{I, t}$, is equal to aggregate employment $L_{t}$ in the economy: $L_{F, t}+L_{I, t}=L_{t}$. Aggregate labor force participation in the economy (i.e. aggregate labor supply in the economy), $P_{t}$ is a sum of the male and female labor participation: $P_{t}=P_{t}^{m}+P_{t}^{f 37}$. Aggregate unemployment can then be written as aggregate labor supply, $P_{t}$ minus aggregate employment, $L_{t}: U_{t}=P_{t}-L_{t}$, where the unemployment rate is obtained by dividing through by the total number of labor market participants, $P_{t}$.

Equilibrium in the labor market for males and females is given by equating aggregate supply of male and female labor, $P_{t}^{m}$ and $P_{t}^{f}$, to the sum of their respective demands by formal and informal wholesalers, plus the ones unemployed:

$$
P_{t}^{m}=L_{F, t}^{m}+L_{I, t}^{m}+U_{t}^{m} \quad P_{t}^{f}=L_{F, t}^{f}+L_{I, t}^{f}+U_{t}^{f}
$$

Male and female unemployment is given by the ones searching for a job minus the ones that get hired:

$$
U_{t}^{m}=S_{t}^{m}-H_{F, t}^{m}-H_{I, t}^{m}
$$

\footnotetext{
${ }^{36}$ For simplicity, we assume that the government does not invest in domestic or international bond markets, and do not take into account capital and consumption taxes.

${ }^{37}$ Note that the female labor force participation rate is determined by the ratio of the number of female participants $P^{f}$, divided by the aggregate female population, $p^{f}$ in the economy. Similarly, the male labor force participation rate is determined by the ratio of the number of aggregate male participants $P^{m}$, divided by the aggregate male population, $p^{m}$.
} 


$$
U_{t}^{f}=S_{t}^{f}-H_{F, t}^{f}-H_{I, t}^{f}
$$

Equilibrium in the asset market implies that the total number of bonds issued is equal to the cost of desired capital in the economy:

$$
D_{t-1}=Q_{t-1}\left(K_{F, t-1}+K_{I, t-1}\right)
$$

The resource constraint for the formal sector is:

$$
\frac{P_{F, t}^{W}}{P_{t}} Y_{F, t}^{W}=\frac{P_{F, t}}{P_{t}} Y_{F, t}\left(1+\frac{\phi_{F}^{a d j}}{2}\left(\frac{\pi_{F, t}}{\pi}-1\right)^{2}\right)+H C_{F, t}^{m} H_{F, t}^{m}+H C_{F, t}^{f} H_{F, t}^{f}
$$

where total demand for formal good, $Y_{F, t}$, is the sum of its domestic demand by households, capital producers and government, $Q_{F, t}^{d}=C_{F, t}+I_{F, t}+G_{F, t}$, and foreign export demand $Q_{t}^{x}$, i.e. $Y_{F, t}=C_{F, t}+I_{F, t}+G_{F, t}+Q_{t}^{x}$.

Similarly, the resource constraint for the informal sector is:

$$
\frac{P_{I, t}^{W}}{P_{t}} Y_{I, t}^{W}=\frac{P_{I, t}}{P_{t}} Y_{I, t}\left(1+\frac{\phi_{I}^{a d j}}{2}\left(\frac{\pi_{I, t}}{\pi}-1\right)^{2}\right)+H C_{I, t}^{m} H_{I, t}^{m}+H C_{I, t}^{f} H_{i, t}^{f}
$$

where informal-market good is only consumed by domestic households, $Y_{I, t}=Q_{I, t}^{d}=C_{I, t}$.

Total foreign imports is given by the sum of imports by households, capital producers, and the government, $Q^{m}=C_{f *, t}+I_{f *, t}+G_{f *, t}$. Finally, GDP in the economy is given by:

$$
Y_{t}=C_{t}+\frac{P_{t}^{I n v}}{P_{t}}\left(I_{t}+G_{t}\right)+\frac{P_{F, t}}{P_{t}} Q_{t}^{x}-\frac{P_{f *, t}}{P_{t}}\left(C_{f^{*}, t}+I_{f^{*}, t}+G_{f^{*}, t}\right)
$$

\subsection{Shock Processes}

We include fourteen exogenously given shocks in the economy: thirteen domestic, and two determined in the rest of the world. Domestic shocks include the following gender-specific shocks which form the basis of our policy experiments relating to gender-targeted policies: shock to male gender bias in formal employment $\left(\omega_{F, t}\right)$, productivity of home production $\left(\theta_{H, t}\right)$, skill efficiency of female workers $\left(\operatorname{skill}_{F, t}^{f}\right.$, skill $\left.l_{I, t}^{f}\right)$, females' relative utility preference for staying at home versus participation in the labor market $\left(\phi_{t}^{f}\right)$, as well as a shock to females' relative utility preference for home-work versus leisure $\left(\varphi_{l e, t}^{f}\right)$. Shocks to domestic technology $\left(\theta_{F, t}\right.$ and $\left.\theta_{I, t}\right)$, government spending $\left(G_{t}\right)$, monetary policy $\left(\varepsilon_{i, t}\right)$, foreign inflation $\left(\pi_{t}^{*}\right)$, and foreign interest rate $\left(i_{t}^{*}\right)$ are also modeled. Finally, labour market shocks include shocks to wholesalers' labour hiring cost $\left(\beta_{H C_{F}, t}\right)$, and shock to wage bargaining power of male workers in the formal sector, $\left(\lambda_{F, t}^{m}\right)$. With the exception of the monetary policy shock, $\varepsilon_{i, t}$, which is assumed to be a white noise process, all shock processes in the economy are assumed to follow a first order autoregressive process $(\mathrm{AR}(1))$ in logs as follows: 


$$
\log \left(\frac{z_{t}}{z}\right)=\rho_{z} \log \left(\frac{z_{t-1}}{z}\right)+\varepsilon_{z, t}
$$

where $z_{t} \varepsilon\left\{\theta_{F, t}, \theta_{I, t}, \theta_{H, t}, \pi_{t}^{*}, i_{t}^{*}, G_{t}, \beta_{H C_{F}, t}, \lambda_{F, t}^{m}, \omega_{F, t}, \operatorname{skill}_{F, t}^{f}\right.$, skill $\left._{I, t}^{f}, \phi_{t}^{f}, \varphi_{l e, t}^{f}\right\}, \rho_{z} \varepsilon(0,1)$ is the persistence of shocks, and $\varepsilon_{z, t}$ is assumed to be i.i.d with mean zero and standard deviation given by $s d\left(\varepsilon_{z}\right)$. This completes the specification of the Baseline model.

\section{Estimation Methodology}

This section describes our data, calibration approach, and presents details regarding the main estimation procedure for India. In order to evaluate the performance of the model, we use a combination of calibrated and estimated parameters. We choose to calibrate some parameters, as these are more important in matching the first moments of the Indian data, and estimate the remaining using Bayesian approach in Dynare.

\subsection{Data}

To estimate the model, we use information on nine key macroeconomic variables for India: GDP, private consumption expenditure, investment, government consumption expenditure, exports, imports (all expressed in constant prices), the real exchange rate, the wholesale price inflation (WPI), and the nominal interest rate. The 3-month Treasury bill rate is used as a proxy for the nominal interest rate, and the real effective exchange rate (REER) is used as a proxy for the real exchange rate. The sample runs from 1996Q1 to 2012Q1, which gives us 65 observations for each of the time series. Prior to estimation, GDP, exports, imports, consumption, investment, and government spending are transformed into real per capita measures. This is done to align the scale of our data, with the steady state of our Baseline model. We remove a time trend in the data using the Hodrick-Prescott (HP) filter to obtain the stationary series, and measure these in terms of the percent deviation from the steady state (i.e. the HP trends corresponding to each) ${ }^{38}$. In addition, we remove seasonal effects in the series using the X12 arima filter (except the real exchange rate, and the nominal interest rate). All data is taken from the CEIC database.

\subsection{Calibration}

Table 1 and Table 2 summarizes the calibrated values of parameter in our model for India, where we calibrate a set of parameters, and the steady state values for some endogenous variables, which characterise the model economy.

\footnotetext{
${ }^{38}$ This makes the data suited to the log-linearised DSGE model.
} 
As in much of the literature, the depreciation rate of capital, $\delta_{K}$, is set at 10 percent per annum, implying a quarterly value of 0.025 . Steady state inflation, $\pi$, is 4.5 percent which corresponds to the average seasonally adjusted quarterly WPI over this period on an annualized basis. The discount rate $\beta$ is set at 0.994 which corresponds to an annual nominal interest rate, $i$ of 7 percent, matching the mean of the sample. Foreign inflation, $\pi^{*}$, is 2.5 percent annually, which corresponds to an annual foreign interest rate, $i^{*}$, of 5 percent $^{39}$. The depreciation rate of the nominal exchange rate, dep is calculated at 2 percent on an annual basis.

Table 1: Parameter Calibration, Baseline model for India

\begin{tabular}{|c|c|c|}
\hline Parameter & Value & Description \\
\hline$\beta$ & 0.994 & discount rate \\
\hline$\delta_{K}$ & 0.025 & capital depreciation rate \\
\hline$\alpha$ & 0.8 & share of home-good in consumption \\
\hline$\eta$ & 1.2 & substitutability between domestic and foreign goods \\
\hline$\pi$ & 4.5 & gross inflation in the steady state (\% annually) \\
\hline$\pi^{*}$ & 2.5 & gross foreign inflation in the steady state ( $\%$ annually) \\
\hline$\left(\frac{P^{I n v}}{P} \frac{G}{Y}\right)$ & 0.11 & government spending-to-GDP ratio in the steady state \\
\hline$W_{U} / Y$ & 0.014 & social spending-to-GDP ratio in the steady state \\
\hline$\left(\frac{P_{F}}{P} \frac{Q^{x}}{Y}\right)$ & 0.19 & export-to-GDP ratio in the steady state \\
\hline$\left(\frac{P_{f *}}{P} \frac{Q^{m}}{Y}\right)$ & 0.21 & import-to-GDP ratio in the steady state \\
\hline$\mu$ & 1.5 & substitutability between formal and informal goods \\
\hline$w$ & 0.39 & share of formal goods in consumption \\
\hline$\eta_{x}^{*}$ & 4.5 & price elasticity of exports \\
\hline$\psi_{F}$ & 0.34 & capital share in formal production function \\
\hline$\psi_{I}$ & 0.34 & capital share in informal production function \\
\hline$\frac{\varepsilon_{F}}{\varepsilon_{F}-1}$ & 1.2 & price mark-up in formal sector \\
\hline$\frac{\varepsilon_{I}}{\varepsilon_{I}-1}$ & 1.09 & price mark-up in informal sector \\
\hline$\frac{\theta_{F}}{\theta_{I}}$ & 1.5 & relative formal-to-informal productivity \\
\hline$\frac{H C_{F}^{m}}{W_{F}^{m}}, \frac{H C_{F}^{f}}{W_{F}^{f}}$ & 3 & share of formal hiring costs in formal wages \\
\hline$\frac{H C_{I}^{m}}{W_{I}^{m}}, \frac{H C_{I}^{f}}{W_{I}^{f}}$ & 0.5 & share of informal hiring costs in informal wages \\
\hline$\sigma_{F}$ & 0.1 & formal worker firing rate in steady state \\
\hline$\sigma_{I}$ & 0.75 & informal worker firing rate in steady state \\
\hline
\end{tabular}

The share of government expenditure in GDP is calibrated at 11 percent, as in the data. In 2005, the Government of India spent 1.4 percent of its GDP on social protection, which forms the basis of our calibration for unemployment benefits to GDP ratio ${ }^{40}$.

\footnotetext{
${ }^{39}$ This is close to the value of 6 percent used in much of the macro-RBC literature for calibrating $i^{*}$.

${ }^{40}$ The wage income tax, $\tau_{F}$, is then obtained from the government budget constraint.
} 
The substitution elasticity between imported and domestically produced goods, $\eta$, is set at 1.2 , close to the value estimated by Medina and Soto (2005) for Chile, and Castillo et al. (2006) who obtain values close to 1 . This combined with the share of domestically produced goods in the market consumption basket, $\alpha$, at 0.8 , corresponds to a steady state import to GDP ratio of 21 percent, as in the data. Elasticity of substitution of exports, $\eta_{x}^{*}$, is set at 4.5 , a value consistent with the calibrated steady state export to GDP ratio of 19 percent ${ }^{41}$.

\section{Matching Informality Statistics}

Next, we turn to parameters relating to the formal and informal sector. Because of the scarce empirical evidence on informality, our calibration strategy aims to match, as accurately as possible, the empirical evidence, and available data on key statistics relating to the two sectors in India.

Using industry level panel data for the period 1980-2007, Pal and Rathore (2013) estimate the size of the firms' mark-up in India to have a long run average of 1.19 during 2000-07. Thus, the elasticity of substitution among different retail varieties, $\varepsilon_{F}$ and $\varepsilon_{I}$, are calibrated at 6 and 12 , so that the retail firms' desired mark-up is pinned down at $\frac{\varepsilon_{F}}{\varepsilon_{F}-1}=1.2$ and $\frac{\varepsilon_{I}}{\varepsilon_{I}-1}=1.09$, correspondingly. A lower mark-up in informal prices corresponds to much higher competition in this sector.

Based on the estimates of share of compensation of employees in Chandrasekhar and Ghosh (2015), we calibrate the cost share of capital in the wholesalers' production function, $\psi_{F}$ and $\psi_{I}$, at 0.34 , for both sectors. As in Ulyssea (2009), the productivity of informal wholesalers, $\theta_{I}$ is normalised to 1 , whereas the productivity of the formal firms, $\theta_{F}$, is 1.5 capturing a productivity differential of 50 percent between the two sectors ${ }^{42}$. Productivity and labor intensity of home production is assumed to be the same as the informal sector, i.e, $\theta_{H}=\theta_{I}$, and $\left(1-\psi_{H}\right)$ is $0.67^{43}$.

According to the The Global Competitiveness Report published by the World Economic Forum (2014), the redundancy costs of workers in India is estimated to be equivalent to 55.9 weeks of annual salary since 2006, which is equivalent to 4.53 times the quarterly wage rate. Since in our model the hiring costs also reflect the difficulty in firing workers, we calibrate the hiring cost to wage ratio in the formal sector for both male and female workers at 3 , which corresponds to 38 weeks of annual salary. Since only the formal sector is regulated, for the corresponding informal sector ratio, we assume it to be much lower at $0.5 .{ }^{44}$.

${ }^{41}$ The steady state share of domestic exports in the foreign consumers' consumption bundle, $\alpha_{x}^{*}$, is calculated endogenously.

${ }^{42}$ This is consistent with the estimates in Sahoo and Raa (2009), who find that the formal sector activities are strictly more productive than the informal ones in India.

${ }^{43}$ We choose this specification as home production can also be interpreted as the output produced by home based or self-employed workers, which falls within the definition of the informal sector.

${ }^{44}$ From the hiring cost functions, steady state value of the exogenous hiring cost variable, $\beta_{H C_{F}}$ and $\beta_{H C_{I}}$, and the coefficient of elasticity of hiring costs to hiring probability, $\alpha_{H C_{F}}$ and $\alpha_{H C_{I}}$, are both endogenously obtained to be higher in the formal relative to the informal sector. 
The unorganized sector employs nearly 84 percent of the Indian workforce according to the Employment and Unemployment Survey (EUS) of the National Sample Survey Organization (NSSO, 2009-10). Setting the exogenous probability of getting fired, $\sigma_{F}$ and $\sigma_{I}$, at 0.1 and 0.75 , gives us the informal employment share, $\frac{L_{I}}{L_{F}+L_{I}}$ at 68 percent, and an unemployment rate, $\frac{U}{P}$, of 17 percent $^{45}$.

For the substitution elasticity between formal and informal goods, $\mu$, we have chosen a value of 1.5 which matches values commonly used in the literature for the substitution elasticity between traded and non-traded goods. Then the formal goods bias in consumption basket, $w$, is set at 0.39 , such that the share of informal sector output in GDP is obtained at 44 percent, close to the value of 49 percent estimated by the NCEUS (2009).

\section{Matching Gender Inequality Statistics}

Table 2 summarizes the calibration of gender-related parameters, which are chosen so as to match the Indian statistics on female participation, $P^{f}$, male participation, $P^{m}$, male formality in the labor market, $\frac{L_{F}^{m}}{L_{F}^{m}+L_{I}^{m}}$, female formality in the labor market, $\frac{L_{F}^{f}}{L_{F}^{f}+L_{I}^{f}}$, and the gender wage gaps, $\frac{W^{m}}{W^{f}}$.

Plausible estimates for the substitution elasticity between female and male workers in production function of market goods, $\frac{1}{1-\rho_{s}}$, based on Acemoglu et al. (2004), range between 3.2 and 4.2. We assign this a value of 2.5 in the formal sector, $\frac{1}{1-\rho_{F}}$, with a higher substitution elasticity of 5 in the informal sector, $\frac{1}{1-\rho_{I}} 46$. Standard estimates (e.g. Blundell and Macurdy (1999)) suggest that female's Frisch elasticity of labor supply, $-1 / v_{l e}^{f}$, is approximately three times that of males, $-1 / v_{l e}^{m}$. Assuming an 'average' elasticity of 2 in the economy which is a value frequently used in calibrated versions of small open economy models (see Mendoza (1991), Aguiar and Gopinath (2007)), and female share in total employment of 0.33 (NSSO, 2004-05), we can write:

$$
0.33 \frac{3}{v_{l e}^{f}}+0.67 \frac{1}{v_{l e}^{m}}=2
$$

This obtains $1 / v_{l e}^{m}=1.20$ and $1 / v_{l e}^{f}=3.61$.

We calibrate the ratio of skill level of males to female worker in each sector, $\frac{s k i l l_{F}^{m}}{\text { skill }_{F}^{f}}$ and $\frac{s k i l l_{I}^{m}}{s k i l l_{I}^{f}}$, based on the data on education gaps between males and females in India. According to the 2004-05 NSSO survey, the average years of education of females is 4.5, as opposed to 6.8 for

\footnotetext{
${ }^{45}$ The official unemployment rate published by the Planning Commission in India is around 8 percent for 200910. However, empirical estimates in the literature suggest a much higher unemployment, close to 20 percent, with even higher estimates for youth employment (Sinha (2013), Mitra and Verick (2013))

${ }^{46}$ Calibration of substitution elasticity between males and females in home production is the same as the informal sector, i.e. $\rho_{H}=\rho_{I}$.
} 
Table 2: Calibration of Gender-related Parameters, Baseline model for India

\begin{tabular}{ccl}
\hline Parameter & Value & Description \\
\hline \hline $1 / v_{l e}^{m}$ & 1.2 & male's Frisch elasticity of labor supply \\
$1 / v_{l e}^{f}$ & 3.61 & female's Frisch elasticity of labor supply \\
$\frac{1}{\left(1-\rho_{F}\right)}$ & 2.5 & substitutability btw male \& female formal workers \\
$\frac{1}{\left(1-\rho_{I}\right)}, \frac{1}{\left(1-\rho_{H}\right)}$ & 5 & substitutability btw male \& female informal workers \\
$\frac{s k i l l_{F}^{m}}{s k i l l_{F}^{f}} ; \frac{\text { skill }}{\text { skill }}{ }_{I}^{f}$ & 1.7 & male-to-female skill ratio in employment \\
$\lambda_{F}^{m}$ & 0.67 & bargaining power of male formal worker \\
$\lambda_{I}^{m}$ & 0.27 & bargaining power of male informal worker \\
$\lambda_{F}^{f}$ & 0.46 & bargaining power of female formal worker \\
$\lambda_{I}^{f}$ & 0.02 & bargaining power of female informal worker \\
$\omega_{F}$ & 0.62 & male gender bias in formal employment \\
$\omega_{I}$ & 0.5 & male gender bias in informal employment \\
$\varphi_{l e}^{m}$ & 0.7 & male utility weight on leisure \\
$\varphi_{l e}^{f}$ & 0.5 & female utility weight on leisure \\
$\phi^{m}$ & 0.7 & male utility weight on staying at home \\
$\phi^{f}$ & 1 & female utility weight on staying at home \\
\hline \hline
\end{tabular}

males, which implies a male-to-female ratio of 1.5. Matching this, we calibrate these ratios at 1.7 .

According to the World Economic Forum (2010), females earn 62 percent of the male's salary for equal work, which implies a value of 1.62 for $\frac{W^{m}}{W^{f}}$. Setting bargaining values for male workers at $\lambda_{F}^{m}=0.67$ and $\lambda_{I}^{m}=0.27$, and for female workers at $\lambda_{F}^{f}=0.46$ and $\lambda_{I}^{f}=0.02$, pins down $\frac{W^{m}}{W^{f}}$ at 1.7. Lower bargaining power of female workers reflects the male domination of labor unions in India (see union membership data published by the ILO in 2011).

According to the Global Gender Gap Report published by the World Economic Forum (2010), 86 percent of female workers were employed in the informal sector, $\frac{L_{I}^{f}}{L_{F}^{f}+L_{I}^{f}}$, as opposed to 74 percent males, $\frac{L_{I}^{m}}{L_{F}^{m}+L_{I}^{m}}$. Gender discrimination at the firm level in formal employment is a key factor contributing to this disparity (Javeed and Manuhaar (2013)). This is captured in our model via firms' preference for male relative to female workers, $\omega_{F}$ and $\omega_{I}$. We assume no gender discrimination in informal employment, i.e. $\omega_{I}=0.5$. By setting $\omega_{F}$ at 0.62 , we obtain a value of 32 percent for male formality in employment, $\frac{L_{F}^{m}}{L_{F}^{m}+L_{I}^{m}}$, as opposed to 26 percent for female formality, $\frac{L_{F}^{f}}{L_{F}^{f}+L_{I}^{f}}$.

Household care work, $H P_{t}^{m}$ and $H P_{t}^{f}$, in particular, is widely regarded as especially feminine, and with the relative utility weight on leisure relative to home-work for males and females at, 
$\varphi_{l e}^{m}=0.7$ and $\varphi_{l e}^{f}=0.5$, the female to male ratio of home-work, $\frac{H P_{t}^{f}}{H P_{t}^{m}}$, is obtained at $1.65^{47}$.

According to the NSSO report in 2009-10, female labor force participation rate, $\frac{P^{f}}{p^{f}}$, is 39.9 percent which is less than half of that of the male labor force participation rate, $\frac{p^{m}}{p^{m}}$, at 84.8 percent. Combined with the above calibration, we obtain values of $\frac{P^{f}}{p^{f}}$ at 39.6 , and $\frac{p^{m}}{p^{m}}$ at 81.3 , by setting the male and female relative weight on utility from staying at home versus market-good consumption, $\phi^{m}$ and $\phi^{f}$, at 0.7 and 1 , respectively.

\subsection{Bayesian Estimation}

We estimate the model using Bayesian approach in Dynare. This choice is driven by the widely recognized advantages of the Bayesian-Maximum Likelihood methodology, which are as follows ${ }^{48}$. First, prior information about parameters available from empirical studies or previous macroeconomic studies, can be incorporated with the data in the estimation process. Second, it facilitates representing and taking fuller account of the uncertainties related to models and parameter values. Third, it allows for a formal comparison between different mis-specified models that are not necessarily encapsulated in the marginal likelihood of the model. In addition, there has been a growing trend among central banks to employ Bayesian methods for conducting policy analysis.

Table 3 summarizes the choice of prior distributions for the estimated parameters. The prior densities for the estimated parameters are chosen by considering the theoretical restrictions for the parameters, and empirical evidence. Due to scarce empirical evidence on India, we choose relatively diffuse priors that cover a wide range of parameter values. The use of a diffuse prior reduces the importance of the mean of the prior distribution on the outcome of the estimation.

\section{Empirical Results}

Bayesian estimates for the parameters are summarized in Table 3, along with the 95 percent posterior confidence band. Looking at price adjustment costs, consistent with the estimates in Gabriel et al. (2010), the estimation indicates that price re-setting is highest in the informal sector $\left(\phi_{I}^{a d j}=24.15\right)$, and lowest for the formal sector $\left(\phi_{F}^{a d j}=64.54\right)$. This means that the fluctuations in the formal sector are more persistent in response to shocks compared with the informal sector. Import price rigidity, $\phi_{f *}^{a d j}$, has a posterior mean of 42.44 , indicating that import prices change more frequently in comparison to formal prices, but less frequently relative to informal prices. Most emerging economies policy-related studies in the literature

\footnotetext{
${ }^{47}$ According to the Times User Survey conducted in 2010, female contribution towards unpaid domestic work in India is 10 times more than males. This unpaid work includes the inter-personal work for caring for other household members, and in countries like India with lack of sufficient infrastructure, the work of collecting water and fuel for household needs.

${ }^{48}$ See, for instance, An and Schorfheide (2007).
} 
do not allow the pricing parameters to differ across the tradable and non-tradable sectors. This puts a warning sign in interpreting the estimates of price stickiness in the literature.

Estimation results suggest a strong response of the Reserve Bank of India (RBI) to inflation deviations in the economy ( $\left.\alpha_{\pi}=3.2\right)$ and significantly lesser to output deviations $\left(\alpha_{Y}=0.32\right)$, along with considerable policy inertia $\left(\alpha_{i}=0.86\right)$. The estimates for $\alpha_{Y}$ and $\alpha_{i}$ are in the range of previous studies ${ }^{49}$, whereas $\alpha_{\pi}$ is estimated to be slightly higher than the previous values in the literature, that range from 1.5 to 2.9 across different studies ${ }^{50}$. This may be the result of the combined shock-absorbing role of the informal sector and of low skilled female workers, because of which the RBI needs to be more aggressive in order to stabilize prices.

The persistence of most of the shocks in the economy are estimated to be high ranging from 0.58 to 0.97 , with the exception of a few ${ }^{51}$. Posterior estimated means for the standard deviation of shocks are significantly higher than the corresponding prior means, which is consistent with higher business cycle volatility associated with emerging economies.

Overall, we obtain reasonable estimates for the common parameters used in other studies, in the sense that all of them are statistically significant and most of them are in the range of estimates in the existing studies on emerging economies relying on Bayesian DSGE models. Some of our estimates turn out to be away from the prior means, such as for $\kappa, \phi_{F}^{a d j}, \phi_{I}^{a d j}, \phi_{f^{*}}^{a d j}$, and for $\rho_{\pi}, \rho_{\theta_{F}}, \rho_{\theta_{I}}$, which suggests that the data is quite informative about these parameters. In addition, robustness checks described in Appendix A indicate that our estimation analysis is robust to the prior specification, which confirms that our arguments are strongly supported by the data. However, for some parameters, the data does not provide additional information ${ }^{52}$. We believe that our estimation results should be considered as preliminary estimates, and further work is necessary to ensure a robust identification of the key gender-related parameters.

\section{Policy Results}

\subsection{Gender-Specific Policies}

In this section, we study the dynamic impact of the following gender-specific policies: (i) increase in public provisions (including childcare support); (ii) improvements in female safety and mobility; (iii) increase in female education; and (iv) stronger enforcement of laws against employment based gender discrimination. The former two policies lower constraints on female labor supply, whereas the latter two are targeted towards lowering female labor demand constraints.

\footnotetext{
${ }^{49}$ Gabriel et al. (2010) and Anand et al. (2010) estimate similar numbers for India.

${ }^{50}$ The estimates for India range from 0.89 in Anand et al. (2010) to 2.5 in Gabriel et al. (2010). For other developing countries, it ranges from 1.27 in Castillo et al. (2006) for Peru to 2.6 in Tovar (2006a) for Korea.

${ }^{51}$ These include shocks to female worker skill in formal employment, $\rho_{\text {skill }}$, male gender-bias in formal employment, $\rho_{\omega_{F}^{m}}$, and the informal technology shock, $\rho_{\theta_{I}}$, that have posterior means of $0.37,0.10$, and 0.33 , respectively.

${ }^{52}$ This does not impact the results of our policy analysis.
} 
To see how the economy transitions from the initial to the new steady state post-reform, we consider a permanent shock to the relevant variables. Table 5 summarizes the short run and long run impact of reforms on aggregate economic activity (i.e. GDP, formality in the labor market, and unemployment), and on labor market indicators of gender inequality (female labor force participation, female formality, and gender wage gaps).

\section{Female Labor Supply Reforms}

The impact of policies that lower constraints on female labor supply is a combination of its direct impact on female labor force participation, combined with its indirect impact on the same through changes in wages and employment in each sector.

\section{(i) Increase in Public Provisions (including childcare)}

Home production consists of both childcare and other household activities, where an increase in public provisions ${ }^{53}$ lowers the burden of home-work for all individuals in the household, which is captured by an increase in the home-production technology, $\theta_{H}$. Childcare provisions, on the other hand, are assumed to be targeted towards females, which is captured by a simultaneous fall in $\frac{1}{\varphi_{l e}^{f}}$.

Figure 3 shows the combined effect of an increase in $\theta_{H}$ and a fall in $\frac{1}{\varphi_{l e}^{f}}$. An improvement in public provisions which increases female labor participation by 1.5 percent would lead to a 1.4 percent gain in GDP. However, it would also increase aggregate unemployment and informality by 1 and 0.1 percent, respectively, along with widening gender gaps in the same ${ }^{54}$. Below we provide a detailed analysis of the main channels at play.

Higher productivity of home production implies that males and females can consume the same amount of home goods with lower amount of home-work. Substitution effect leads to an increase in male and female labor force participation in the long run. Childcare support targeted towards females ( $\frac{1}{\varphi_{l e}^{f}}$ falls) leads to a larger increase in $P^{f}$, thus lowering gender gap in participation rates, $\frac{P^{f}}{P^{m}}$. Increase in overall labor supply and employment raises GDP. However, owing to the presence of labor market rigidities, increase in labor supply is not met with an equal increase in firm hiring, leading to an increase in unemployment, $U$. In addition, informal wholesalers hire more workers relative to ones in the relatively rigid formal sector, thus also reducing overall formality in the labor market, $\frac{L_{F}}{L_{F}+L_{I}}$.

More males relative to females get employed and are able to find formal employment, leading to a larger fall in female formality in comparison to that for males, which further widens wage gaps; $\frac{W^{m}}{W^{f}}$ increases. This is due to the higher constraints females face in their access to decent formal employment, including lower skills and gender-based discrimination against

\footnotetext{
${ }^{53}$ This refers to better water facilities, sanitation development, access to electricity etc.

${ }^{54}$ This is induced by a 1 percent increase in $\theta_{H}$ and a 5 percent fall in $\frac{1}{\varphi_{l e}^{f}}$.
} 
women. At home, relative burden of females' home-work, $\frac{H P^{f}}{H P^{m}}$, is now lower, improving gender equality at home ${ }^{55}$.

Qualitatively, the short run impacts of policy are similar to the ones in the long run. However, due to relatively higher rigidities, formal wholesalers increase hiring only gradually over time which increases unemployment and lowers aggregate, female and male formality by more in the short run.

Figure 3: Increase in Public Provisions (including childcare)
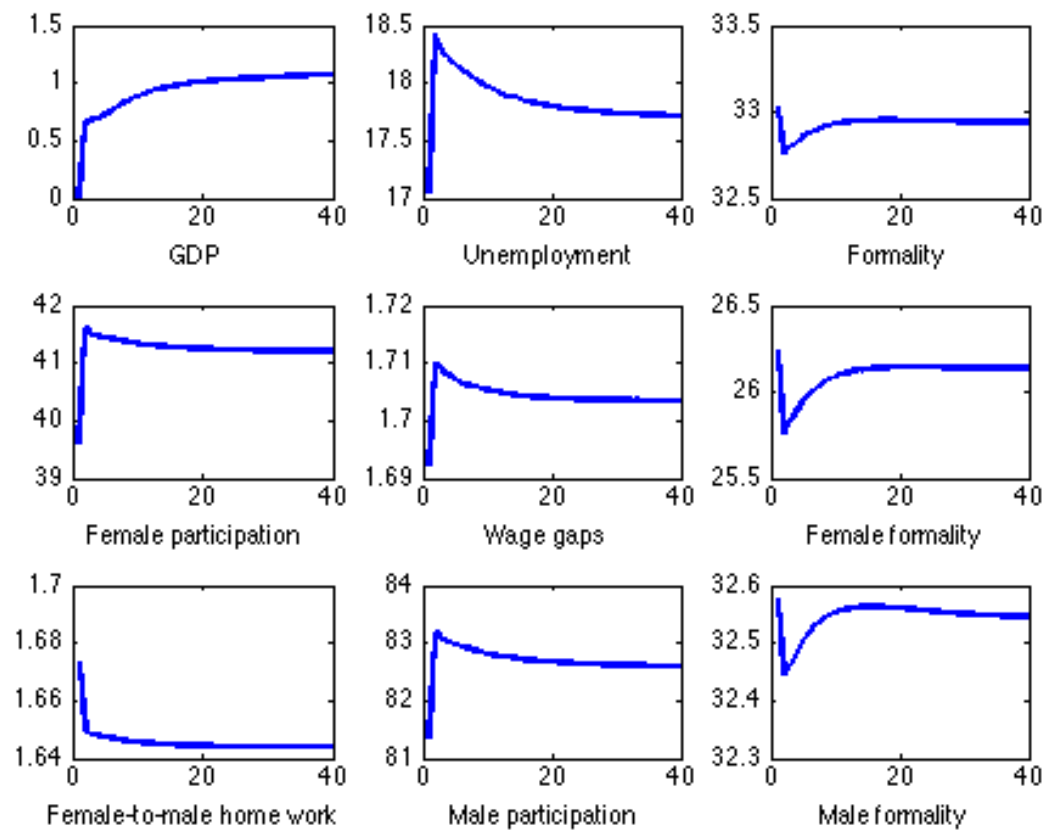

Note: The figure shows a percentage deviation from the initial steady state for GDP, while for the rest of the variables the levels $(\%)$ are shown.

\section{(ii) Increase in Female Safety and Mobility}

Improvements in safety and mobility of females directly lowers females' relative disutility from working outside home, which is captured by a fall in $\phi^{f}$ in Figure $4^{56}$.

Qualitatively, the impacts on GDP and labor market indicators of gender inequality are similar to the ones with the policy of increased public provisions. However, there is an increase in gender inequality in relative burden of female-to-male home-work, as opposed to a decrease

\footnotetext{
${ }^{55}$ Increase in the relative proportion of female wage income in total household income increases their intrahousehold bargaining power, $\left(1-B P_{t}\right)$, leading to females opting out of home-work into market-work and leisure. Instead, males now substitute out of leisure into market-work and home-work.

${ }^{56}$ This is induced by a 10 percent fall in $\phi^{f}$.
} 
with the public provisions reform. Quantitatively, the impacts are now smaller - an improvement in female safety and mobility which increases female labor participation by 1.5 percent would lead to a 1.15 percent gain in GDP, however, it would also increase unemployment and informality by 0.5 and 0.2 percent, respectively. Below we provide a detailed analysis of the exact transmission channels involved.

Figure 4: Increase in Female Safety and Mobility
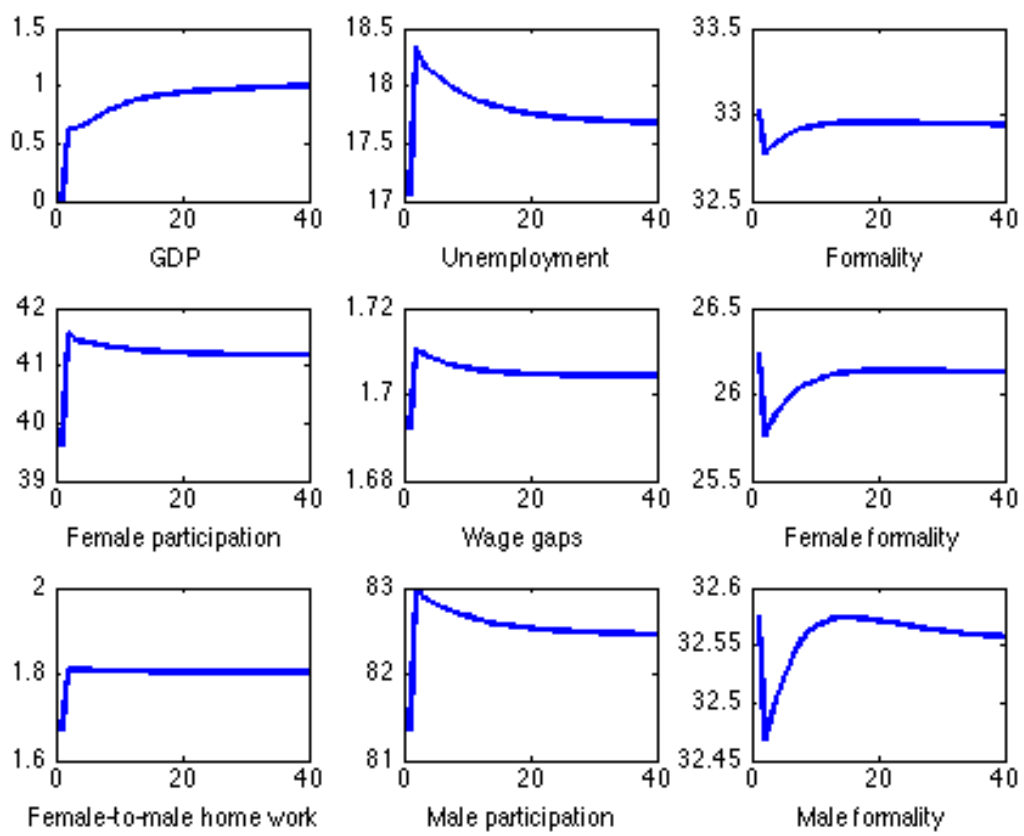

Note: The figure shows a percentage deviation from the initial steady state for GDP, while for the rest of the variables the levels $(\%)$ are shown.

Higher female safety and mobility lowers their disutility from working outside home, leading to a rise in their labor supply, $P^{f}$. Female labor supply curve shifts out, leading to a fall in female wages, $W_{F}^{f}$ and $W_{I}^{f}$, in both sectors. Higher likelihood of finding a job (lower labor costs increase wholesalers' labor demand) increases male labor participation, $P^{m}$. Male wages also fall, but by a smaller amount relative to females' which widens gender wage gaps; $\frac{W^{m}}{W^{f}}$ increases. Increase in overall labor supply and employment increases GDP. However, insufficient job creation due to rigidities in the labor market lead to an increase in unemployment and aggregate informality, and given higher constraints on female labor demand, female formality falls by more.

Home-work burden of females relative to males $\frac{H P^{f}}{H P^{m}}$, increases as females substitute out of leisure into market-work and home-work. This is in contrast to what we find with the policy of increased public provisions, where there is instead a fall in $\frac{H P^{f}}{H P^{m}}$, as the latter policy directly targets females' home-work burden via gender-targeted childcare policy (i.e. a fall in $\frac{1}{\varphi_{l e}^{f}}$ ). 


\section{Female Labor Demand Reforms}

The impact of policies that lower constraints on female labor demand is a combination of its direct impact on female employment, and its indirect impact on labor market participation rates, through changes in wages and employment creation in each sector.

\section{(iii) Increase in Female Education}

Figure 5 shows the effect of an increase in the skill level of female workers in both sectors, $\operatorname{skill}_{F}^{f}$ and $\operatorname{skill}_{I}^{f}$. In the long run, an increase in female education which raises female labor participation by 1.5 percent would raise GDP by 1.25 percent, lower unemployment by 1.75 percent and increase labor formality by 0.9 percent ${ }^{57}$. In addition, it lowers gender gaps in participation rate, formal employment, and wages. In the short run, however, there are adjustment costs in terms of a fall in female formality and wider gender wage gaps, which lasts up to 4 quarters.

Figure 5: Increase in Female Worker Skill
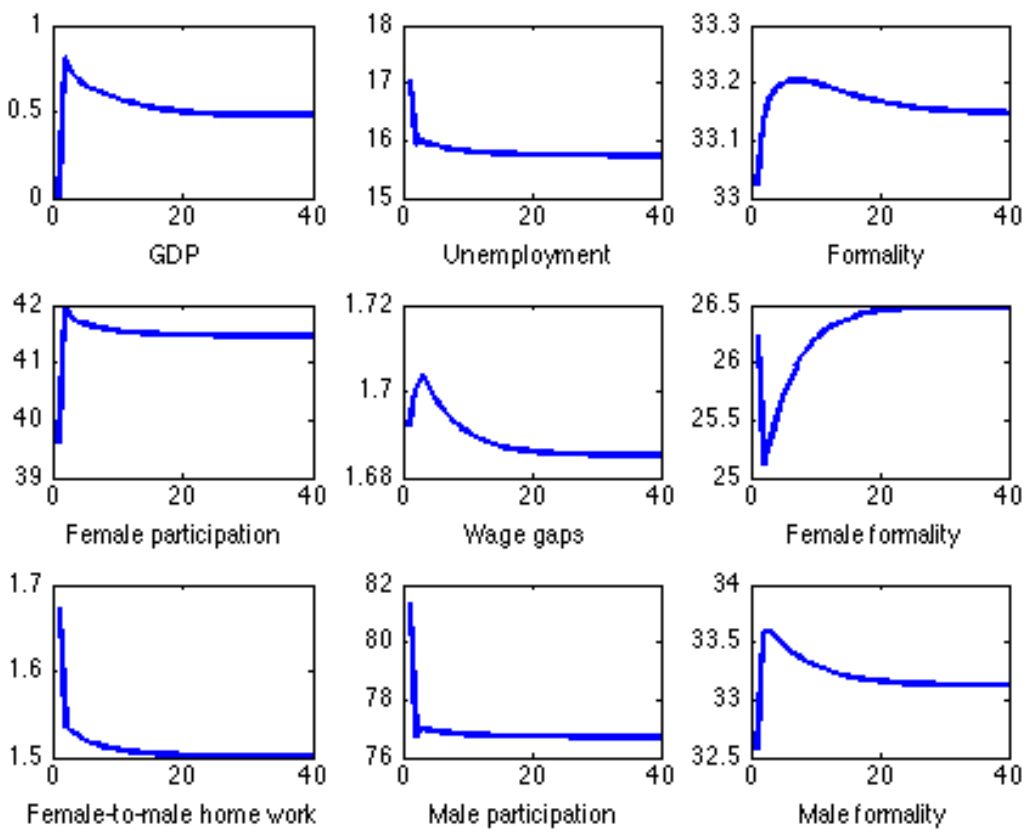

Note: The figure shows a percentage deviation from the initial steady state for GDP, while for the rest of the variables the levels $(\%)$ are shown.

Increase in females' skill level improves their productivity in the labor market, leading to wholesalers substituting out male workers for more productive female workers in both sectors.

${ }^{57}$ This is induced by a 5 percent increase in both $\operatorname{skill} l_{F}^{f}$ and $\operatorname{skill} l_{I}^{f}$. 
More females are hired in the formal relative to the informal sector, thus increasing female formality in labor employment, $\frac{L_{F}^{f}}{L_{F}^{f}+L_{I}^{f}}$, in the long run. Instead, we see a fall in the short run (up to 4 quarters), as higher flexibility of the informal labor market leads to an immediate increase in female informal employment, as opposed to a gradual increase in female formal employment over time. Higher job-finding rate increases females' return from job search, which increases female labor supply, $P^{f}$. The positive impact of higher productivity of female workers on wages outweighs the negative impact of higher female labor supply in the long run, leading to an increase in female wages, $W_{F}^{f}$ and $W_{I}^{f}$, in both sectors. However, female wages are lower in the short run as the latter effect dominates given slow job creation . Male participation rate declines due to two reinforcing effects - (i) household income effect: higher female wage incomes increase total household income, and (ii) substitution effect: fall in male job-finding rate reduces their return from job search ${ }^{58}$. Male labor supply curve shifts inwards, leading to an increase in their wages in both sectors. Higher aggregate formality and lower unemployment boosts GDP in the long run. At home, $\frac{H P^{f}}{H P^{m}}$ falls as females substitute out of home-work into market-work and leisure, and males on the other hand, substitute out of market-work and leisure into home-work.

\section{(iv) Lower Gender Discrimination in Formal Employment}

Figure 6 shows the effect of a decrease in formal wholesalers' relative preference for male relative to female workers in formal employment, $\omega_{F}{ }^{59}$. This corresponds to stronger enforcement of laws against gender-based discrimination in employment. Results indicate that gender equality in the labor market and at home improve, i.e. gender gaps in labor participation rates, wages, formal employment, and relative home-work burden are reduced. However, unless accompanied by higher female education, we see a fall in aggregate economic activity, i.e. GDP and formality are lower in the long run.

With this policy, formal wholesalers are forced to substitute out higher skilled male workers for relatively lower skilled female workers, increasing female formality. This reduces overall productivity and profits in the formal sector, which shrinks aggregate formality and worsens $\mathrm{GDP}^{60}$.

Higher probability of getting formal employment increases females' returns to job search, which raises female labor supply, $P^{f}{ }^{61}$ In contrast to the female education reform which leads to an increase in wages of both males and females in the new steady state, we find that female wages are higher, but male wage rates in both sectors are now lower. This is because demand for female relative to male workers is higher in the formal sector, increasing $W_{F}^{f}$ while

\footnotetext{
${ }^{58}$ Fall in male informal employment is higher relative to their fall in formal employment, thus increasing overall male formality, $\frac{L_{F}^{m}}{L_{F}^{m}+L_{I}^{m}}$.

${ }^{59}$ Since informal firms are not regulated, $\omega_{I}$ remains unchanged.

${ }^{60}$ This effect is a result of our assumption regarding homogenous male and female workers. Instead, allowing for heterogeinity in skill level might lead to a different outcome.

${ }^{61}$ Gonzalez et al. (2015) find that the presence of gender-based legal restrictions are strongly associated with larger gender gaps in labor force participation.
} 
lowering $W_{F}^{m}$. Female workers move from informal to formal jobs, reducing their supply to informal wholesalers, which increases $W_{I}^{f}$, and vice-versa for males. Male participation, $P^{m}$, falls due to two reinforcing income and substitution effects discussed above. Impact at home follows analogously from the policy of increase in female skill discussed above.

Figure 6: Lower Gender Discrimination in Formal Employment
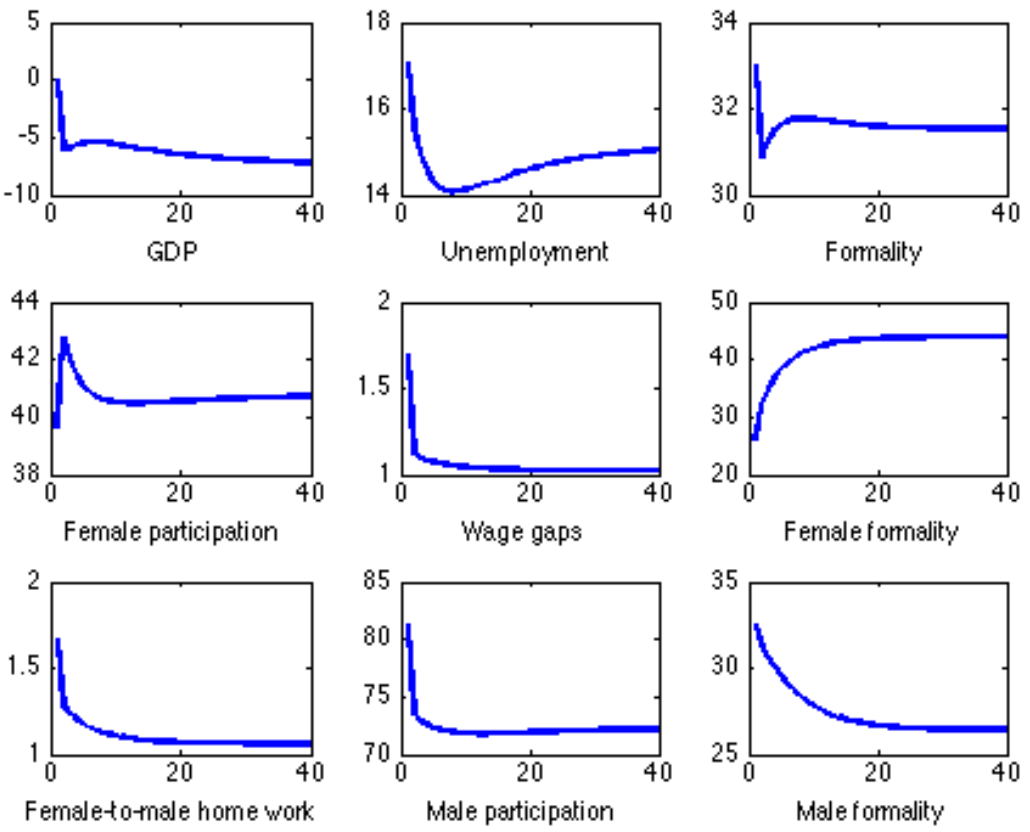

Note: The figure shows a percentage deviation from the initial steady state for GDP, while for the rest of the variables the levels (\%) are shown.

To summarize, the above results indicate the following. First, policies targeted towards reducing constraints on female labor supply, directly increase female labor force participation, reducing gender gaps in participation rates. However, due to labor market rigidities, these policies are unable to simultaneously generate enough employment creation in the formal sector, leading to an increase in aggregate informality and unemployment. In addition, given gender-specific constraints on females' access to decent formal jobs, it also worsens gender gaps in wages and informal employment. Regarding gender dynamics at home, increase in public provisions by directly reducing females' childcare burden improves gender division in home-work and leisure, whereas it worsens with higher female safety and mobility. Second, effects of the two policies targeted towards reducing female labor demand constraints vary. Increase in the skill level of females along with reducing gender gaps in participation rates, also simultaneously leads to adequate formal job creation due to increase in overall formal sector productivity. Aggregate formality and employment increase, resulting in higher formality in male and female employment, while also lowering gender gaps in wages and informal employment. However, female formality in employment falls in the short run. On the other hand, 
unless accompanied by an increase in female education, strengthening firm-based discrimination laws forces firms to hire lower skilled female workers, thus lowering formal sector productivity, which shrinks formality and GDP in the economy.

Comparing our results to the ones in the gender-based policy literature, the impact on female labor force participation and GDP is consistent with these studies, both qualitatively and quantitatively. However, our framework is additionally able to capture the impact on the female quality of employment, female unemployment rate, and gender wage gaps, which even though shown to be empirically relevant, is largely ignored in this theoretical literature.

\subsection{Labor Market Deregulation}

Figure 7: Labor Market Deregulation in the Formal Sector
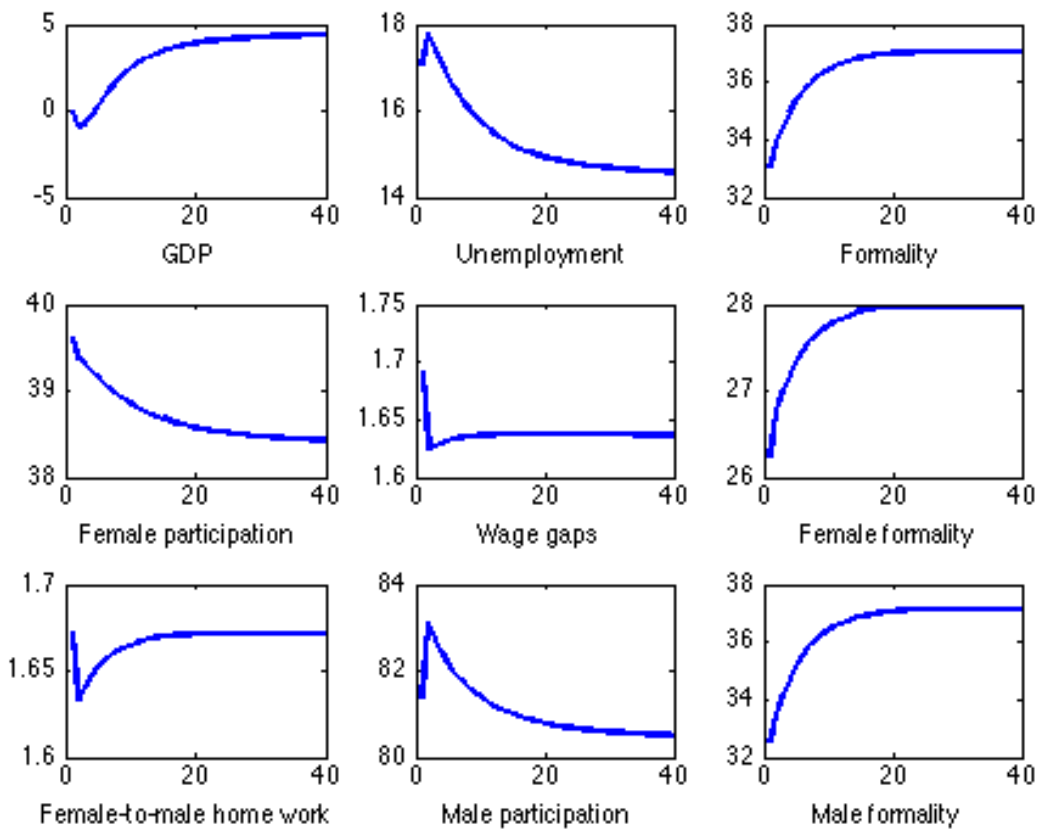

Note: The figure shows a percentage deviation from the initial steady state for GDP, while for the rest of the variables the levels (\%) are shown.

Figure 7 shows the combined effect of a decrease in formal wholesalers' labor hiring cost, $\beta_{H C_{F}}$, and a fall in the bargaining power of male workers in the formal sector, $\beta_{F}^{m 62}$. In the long run, lower labor regulations that decrease informality by 1.5 percent would increase GDP by 2 percent and lower unemployment by 1.5 percent, but due to gender related constraints

\footnotetext{
${ }^{62}$ We do not shock the bargaining power of female workers, $\beta_{F}^{f}$, as we already assume a considerably small value for this due to male domination in labor unions. Thus, even after a 10 percent fall in $\beta_{F}^{m}$, the gender gap in bargaining power is substantially large.
} 
females face in their access to decent formal employment, male workers gain more, leading to wider gender gaps in formal employment. This combined with the household income effect lowers female labor participation, which falls by 0.5 percent $^{63}$. In addition, in the short run, during the transition to the new steady state, unemployment increases and GDP falls, that lasts up to 4 quarters post-reform ${ }^{64}$.

There are two opposing effects on male and female participation rates, $P^{m}$ and $P^{f}$ : (i) substitution effect: increase in job-finding rate in the formal sector produces higher returns to job search, increasing $P^{f}$ and $P^{m}$, and (ii) household income effect: as more household members are employed in higher paying formal jobs, this increases total household income, which decreases $P^{f}$ and $P^{m}$. For males, substitution effect outweighs the income effect in the short run, increasing $P^{m}$, whereas it decreases in the long run due to stronger income effects. In contrast, due to a smaller increase in female's job-finding rate in the formal sector relative to males (due to gender-related constraints, including education gaps and discrimination by firms), the household income effect outweighs the substitution effect for females in both the short run and long run, decreasing $P^{f}$. Therefore, gender gaps in participation rates widen; $\frac{P^{f}}{P^{m}}$ falls.

Increase in male labor supply, $P^{m}$, has a negative impact on their wages, whereas decrease in female labor supply, $P^{f}$, has a positive impact on female wages, thus lowering gender wage gaps. At home, a larger increase in aggregate wage income of males relative to females, leads to a fall in the intra-household female bargaining power, worsening gender division in homework; $\frac{H P^{f}}{H P^{m}}$ increases.

\subsection{Reform Interactions}

Given the above policy outcomes, in this section, we ask the following question: what is the optimal strategy for implementing gender-specific reforms, one that will lead to gains in aggregate economic outcomes, and simultaneously improve gender equality in labor force participation, wages, and formal employment? We study the impact of implementing a combined package of reforms. Specifically, we look at three cases: (i) combining a female labor supply reform with a female labor demand side reform, (ii) combining a female labor supply reform with a labor market deregulation reform, and (iii) combining two female labor supply side reforms.

Figure 8 shows the effects of a simultaneous reform package (black solid line) combining improvements in female safety and mobility (blue dashed line) with increase in female education (red dashed line). In contrast to when only the former reform is implemented, which leads to a fall in female and aggregate formality, higher unemployment, and wider gender wage gaps in the economy, combining it with the latter reform instead overturns these adverse outcomes. It helps mitigate the short run fall in female formality associated with the education reform,

\footnotetext{
${ }^{63}$ This is induced by a 5 percent fall in $\beta_{H C_{F}}$ and $\beta_{F}^{m}$.

${ }^{64}$ This is consistent with the findings in the literature on market regulations. See, for instance, Blanchard and Giavazzi (2003), Cacciatore et al. (2012), and Cacciatore et al. (2013), for details regarding the transmission channels involved.
} 
Figure 8: Improvements in Female Safety and Skill
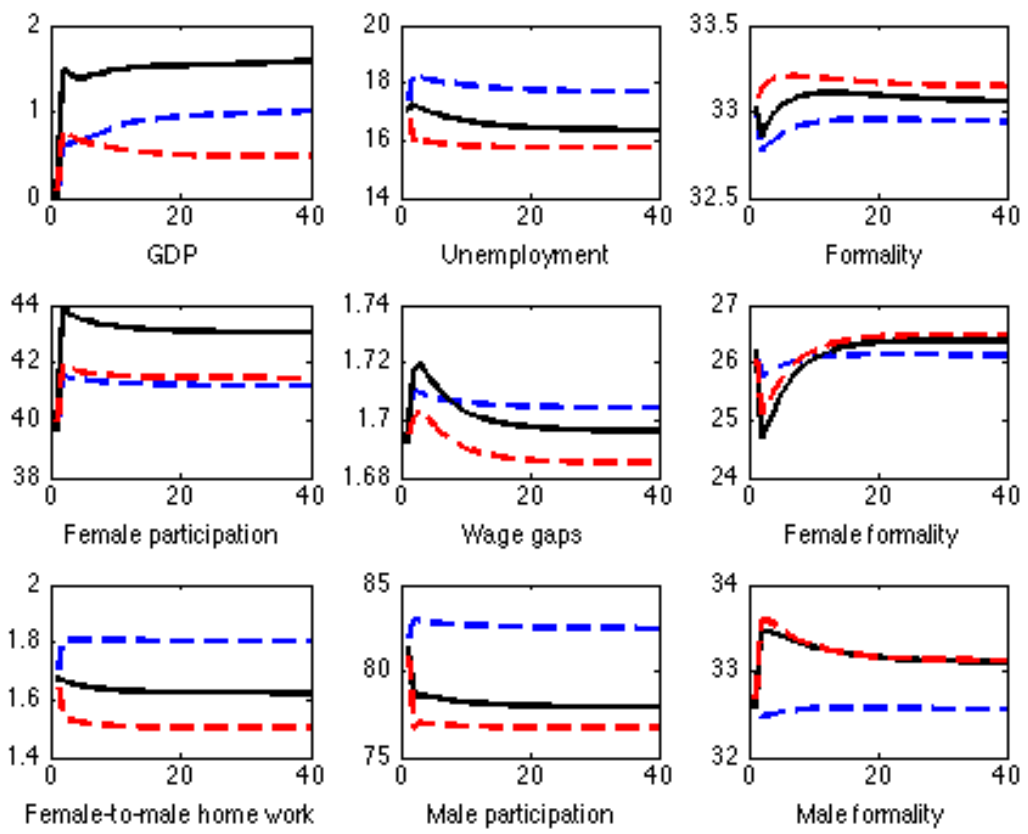

Note: The blue dashed line corresponds to increase in female safety and mobility, the red dashed line corresponds to the policy of increase in female skill, and the black solid line is the policy impact with a combination of both policies. The figure shows a percentage deviation from the initial steady state for GDP, while for the rest of the variables the levels (\%) are shown.

while also leading to significantly higher gains in GDP. Better safety and mobility outside home increases female labor supply, $P^{f}$, and due to a simultaneous increase in their skills, which increases female labor productivity, a larger proportion of these females get hired by formal relative to informal wholesalers, who also pay higher wages. Higher probability of getting employed and higher wages reinforces the positive impact on female participation, increasing it by more than when either policy is implemented on its own. Both substitution and income effect lower male participation, $P^{m}$. At home, increase in female wage income improves their intra-household bargaining power, thus reducing their home-work burden; $\frac{H P^{f}}{H P^{m}}$ falls.

Figure 9 shows the effect of a simultaneous reform package (black solid line) combining the policy of increase in female safety and mobility (blue dashed line) with a labor market deregulation reform (red dashed line). We find that in contrast to when the former policy is implemented on its own, unemployment is lower, both female and male formality increases, and gender wage gaps are lower. Moreover, female labor force participation increases, as opposed to a decrease when labor market deregulation policy is implemented on its own. Better safety and mobility of females outside home, directly increases their labor participation rate, where these females are now able to find high paying formal jobs, as the formal sector expands due to lower formal labor market rigidities. This expansion of the formal sector also increases 
Figure 9: Increase in Female Safety and Labor Market Deregulation
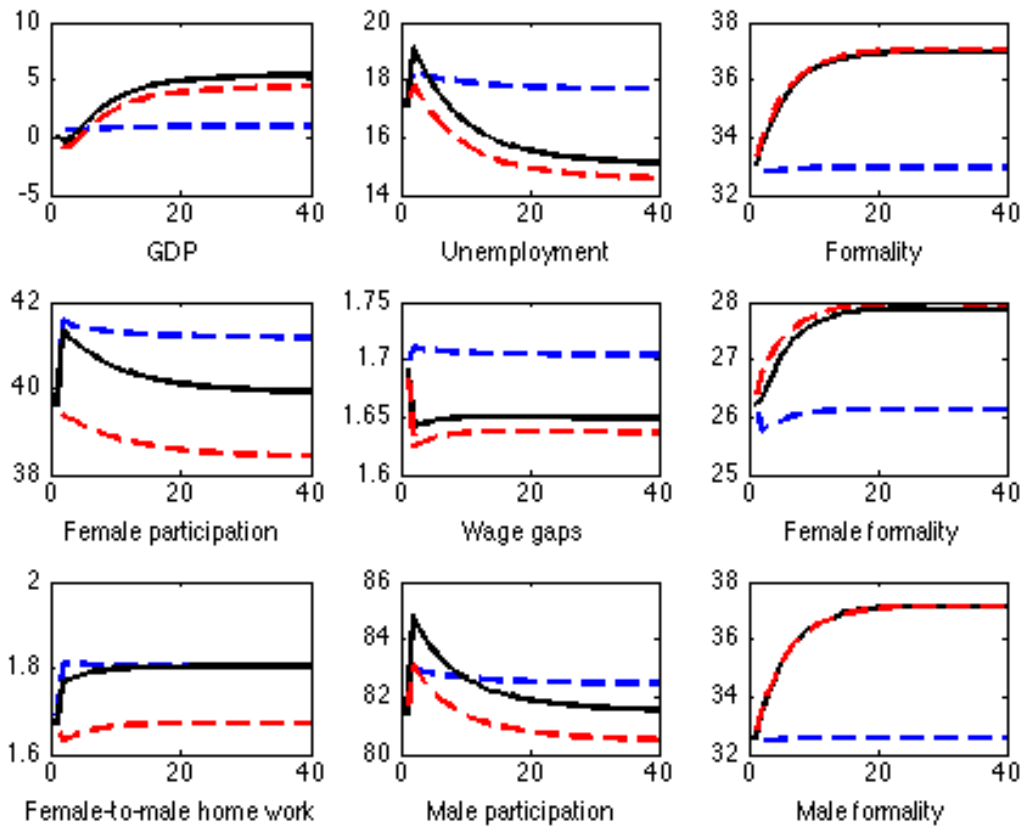

Note: The blue dashed line corresponds to increase in female safety and mobility, the red dashed line corresponds to the formal labor market deregulation, and the black solid line is the policy impact with a combination of both policies. The figure shows a percentage deviation from the initial steady state for GDP, while for the rest of the variables the levels (\%) are shown.

male formality in employment, which leads to higher male participation, as their return from job search is now higher. Thus, GDP increases by more now. Moreover, it also increases in the short run as opposed to when only the deregulation reform is implemented, however, there is a larger short run increase in unemployment ${ }^{65}$. The larger increase in unemployment is caused by two factors: increase in both male and female participation, and slower creation of jobs in the formal relative to the informal sector.

Figure 10 shows the effect of a simultaneous reform package combining the policy of increase in female safety and mobility with increase in public provisions. Since both reforms lower female labor supply constraints, there is a larger increase in female labor force participation rate, in contrast to when either policy is implemented on its own. Both policies are associated with inadequate formal job creation, which reinforces their individual impact resulting in an even larger increase in informality and unemployment.

Therefore, we find that not all combined policy packages lead to higher gains. In particular, we find that there is a complementarity in the impacts of policies that lower constraints on female labor participation and policies that boost formal job creation, leading to gains in both

${ }^{65}$ We find that a combined package of labor market deregulation and female education reform helps overturn this short run increase in unemployment. 
Figure 10: Increase in Female Safety and Public Provisions
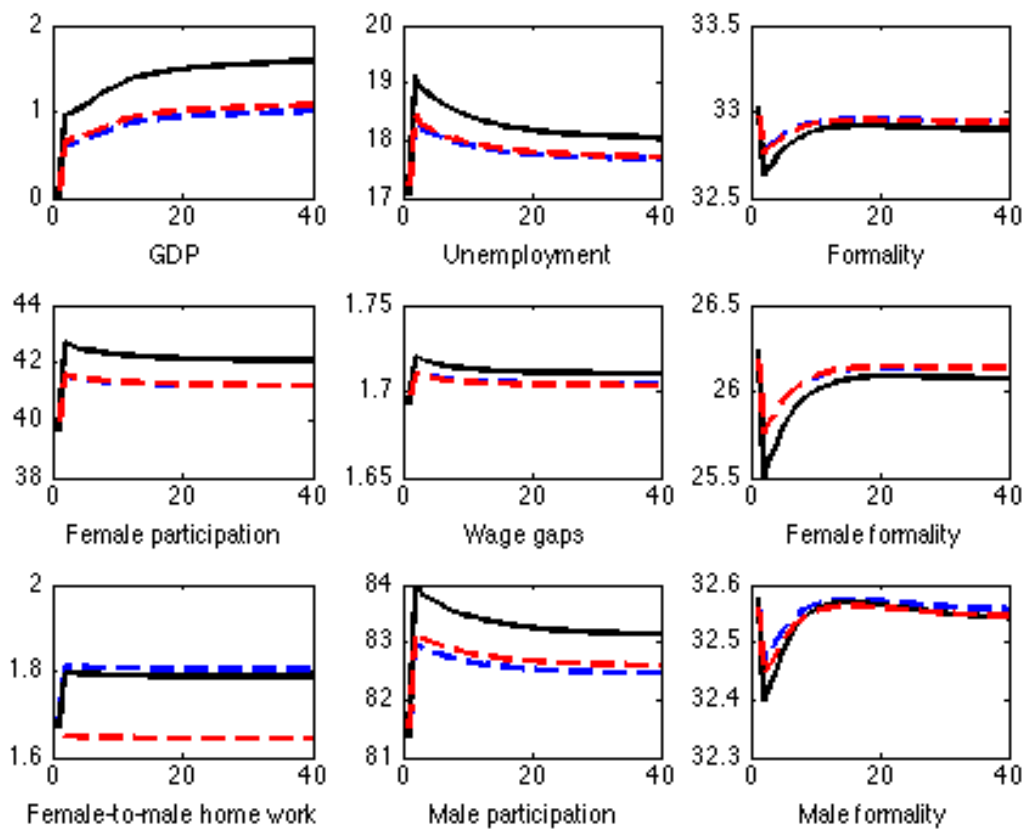

Note: The blue dashed line corresponds to increase in female safety and mobility, the red dashed line corresponds to increase in public provisions (including childcare), and the black solid line is the policy impact with a combination of both policies. The figure shows a percentage deviation from the initial steady state for

GDP, while for the rest of the variables the levels (\%) are shown.

gender equality and overall economic activity. Based on the above findings, we suggest that policies should be designed to prioritize getting females into paid work outside home (i.e. lower constraints on female labor supply), while at the same time making sure that there are enough formal job opportunities (i.e. lower labor market rigidities in the formal sector), and that females have access to these formal jobs (i.e. lower constraints on female labor demand).

\section{Conclusion}

In this paper, we investigate the interaction between informality and gender inequality in the labor market. Specifically, we study the impact of a number of gender-specific policies on female labor force participation, their access to formal employment, gender wage gaps, as well as on aggregate economic outcomes. To achieve this goal, we build a small open economy DSGE model by incorporating both gender inequality and informality within our framework. The model is estimated using Bayesian techniques and applied to Indian data. Our framework integrates the literature on gender with the literature on labor market rigidities, and is detailed enough to provide a starting point for studying the impact of various public policies. 
In our model, we have two sectors, formal and informal sector, where informality results from significantly higher rigidities in the formal sector. Households consist of males and females, where gender inequality is modeled as various frictions on their labor supply and demand, which are higher for females relative to males. Using this framework, we investigate the impact of the following gender-specific policies: (i) increase in female education; (ii) increase in public provisions (including childcare); (iii) increase in female safety and mobility to work; and (iv) fall in gender-based discrimination by firms in formal employment. In addition, the impact of lowering labor market rigidities (i.e. labor market deregulation) in the formal sector, is also considered.

Our findings carry both good and bad news. First, on the one hand, gender-targeted policies increase female labor force participation and GDP in both the short run and long run. On the other hand, however, due to labor market rigidities, gender-specific policies do not generate sufficient formal job creation. This results in a larger share of these increased female participants either being employed informally at low wages, or staying unemployed, which increases aggregate unemployment and informality and further widens gender gaps in wages and informal employment. The only exception to this is with the policy that increases female education, which by increasing female workers' efficiency at work, leads to higher formal employment of females. In addition, this increase in female efficiency leads to an expansion of the formal sector engendering an increase in both female and male formal employment. However, slow reallocation of workers due to labor market rigidities leads to a fall in female formality and widens gender wage gaps in the short run.

Second, there is an increase in the formal employment of both males and females with a labor market deregulation reform. However, male workers gain more, as constraints on female labor supply and demand combined with the household income effect lowers female participation and lead to a smaller increase in female formality in comparison to males. Finally, we show that simultaneously implementing gender-based policies that lower constraints on female participation combined with policies that boost formal job creation, as opposed to a piecemeal approach, generates substantial gains in gender equality in participation, formal employment, and wages along with larger gains in GDP and formality. 


\section{References}

[1] Acemoglu, D., Autor, D. H. and Lyle, D.S. (2004). Women, War, and Wages: The Effect of Female Labor Supply on the Wage Structure at Mid-Century. Journal of Political Economy, 112 (3), 497-551, June 2004.

[2] Agenor, P.R. (2012). A Computable OLG model for Gender and Growth Policy Analysis. Mimeo, University of Manchester and World Bank.

[3] Agenor P.R. and Canuto, O. (2013). Gender Equality and Economic Growth in Brazil: a Long-Run Analysis. Policy Research Working Paper, No. 6348, World Bank, January.

[4] Agenor, P.R. (2015). Gender Equality and Economic Growth: An Overlapping Generations Model for India. OECD Working Paper. Forthcoming.

[5] Aguiar, M. and Gopinath, G. (2007). Emerging Market Business Cycles: The cycle is the trend. Journal of Political Economy, 115, 69-112.

[6] Albanesi, S. and Patterson, C. (2014). Explaining the Behaviour of Aggregate Hours in the US: The Role of Gender. Mimoe, Federal Reserve Bank of New York.

[7] Anand, R., S. Peiris, and M. Saxegaard (2010). An Estimated Model with Macrofinancial Linkages for India. IMF Working Paper, WP/10/21, International Monetary Fund.

[8] An, S. and Schorfheide, F. (2007). Bayesian Analysis of DSGE Models. Econometrics Reviews, Volume 26 (2-4), 113-172.

[9] Barro, R.J. and Lee, J.W. (2013). A New Data Set of Educational Attainment in the World, 1950-2010. Journal of Development Economics, 104, 184-198.

[10] Becker, G.S. (1965). A Theory of the Allocation of Time. The Economic Journal, Vol. 75 (299), pp. 493-517.

[11] Besley, T. and Burgess, R. (2004). Can Labor Regulation Hinder Economic Performance? Evidence from India. The Quarterly Journal of Economics, 119: 91-134.

[12] Blanchard, O. and Gali, J. (2006). A New Keynesian Model with Unemployment. National Bank of Belgium Working Paper, No. 92, October 2006.

[13] Blundell, R. and MaCurdy, T. (1999). Labour Supply: A Review of Alternative Approaches. Handbook of Labor Economics Vol. 3A, 1999, 1560-1695.

[14] Campbell, D. and Ahmed, I. (2012). The Labour Market in Developing Countries," IZA, September 19.

[15] Campolmi, A. and Gnochhi, S. (2014). Labor Market Participation, Unemployment, and Monetary Policy. Bank of Canada Working Paper, European Central Bank.

[16] Castillo, P., Montoro, C. and Teusta, V. (2006). An Estimated Stochastic General Equilibrium Model with Partial Dollarization: A Bayesian Approach. Central Bank of Chile Working Papers, 381.

[17] Castillo, P. and Montoro, C. (2008). Monetary Policy in the Presence of Informal Labour Markets. Mimeo, Banco Central de Reseva del Peru. 
[18] Cavalcanti, T.V.D.V. and Tavares, J. (2008). The Output Cost of Gender Discrimination: A Model-Based Macroeconomic Estimate. Proceedings of the German Development Economics Conference, Zürich 2008 (No. 43).

[19] Chandrasekhar, C.P. and Ghosh, J. (2015). Growth, employment patterns and inequality in Asia: A case study of India. ILO Asia-Pacific Working Paper Series, International Labour Organization (ILO), January 2015.

[20] Christiano, L.J, Eichenbaum, M.S. and Trabandt, M. (2014). Understanding the Great Recession. NBER Working Paper, 20040.

[21] Conesa, J.C., Diaz-Moreno, C. and Galdon-Sanchez, J.E. (2002). Explaining CrossCountry Differences in Participation Rates and Aggregate Fluctuations. Journal of Economic Dynamics and Control, 26, 333-345.

[22] Cuberes, D. and Teigner, M. (2014). Gender inequality and Economic Growth: A Critical Review. Journal of International Development, Vol. 26, Issue 2, pp. 260-276, March 2014.

[23] Das, S., Jain-Chandra, S., Kochhar, K. and Kumar, N. (2015). Women Workers in India: Why So Few Among So Many? IMF Working Paper, 15/55, Washington, International Monetary Fund.

[24] Dixit, A.K. and Stiglitz, J. (1977). Monopolistic Competition and Optimum Product Diversity. The American Economic Review, 67, 297-308.

[25] Dollar, D. and Gatti, R. (1999). Gender Inequality, Income, and Growth: Are Good Times Good for Women? Policy Research Report on Gender and Development Working Paper Series, No. 1, May 1999.

[26] Duflo, E. (2012). Women Empowerment and Economic Development. Journal of Economic Literature, Vol. 50, No. 4: pp. 1051-079.

[27] Elborgh-Woytek, K., Newiak, M., Kochhar K., Fabrizio, S., Kpodar, K., Wigender P., Clements B., and Schwartz, G. (2013). Women, Work, and the Economy: Macroeconomic Gains from Gender Equity. IMF Staff Discussion Note 13/10, Washington, International Monetary Fund.

[28] Esteve-Volart, B. (2009). Gender discrimination and growth: Theory and evidence from India. Mimeo.

[29] Mendoza, E.G. (1991). Real Business Cycles in a Small Open Economy. The American Economic Review, Vol. 81, No. 4 (Sep., 1991), 797-818.

[30] Fontana, M. and Wood, A. (2000). Modeling the Effects of Trade on Women, at Work and at Home. World Development, Vol 28 No 7.

[31] Fontana, M. (2004). Modelling the effects of trade on women, at work and at home: Comparative Perspectives. Economic Internationale, 99, 49-80.

[32] Gabriel, V.J., Levine, P., Pearlman, J. and Yang, B. (2010). An Estimated DSGE Model of the Indian Economy. Discussion Paper in Economics, DP 12/10, University of Surrey. 
[33] Galor, O. and Weil, D. N. (1996). The gender gap, fertility, and growth. American Economic Review, 85(3), 374-387.

[34] Gonzalez, C., Jain-Chandra, S., Kochhar K. and Newiak M. (2015). Fair Play: More Equal Laws Boost Female Labor Force Participation. IMF Staff Discussion Note 15/02, Washington, International Monetary Fund.

[35] Hendy, R. and Zaki, C. (2010). Assessing the Effects of Trade Liberalization on Wage Inequalities in Egypt: A Microsimulation Analysis, ERF Working Paper, 555.

[36] Hsieh C.T., Hurst, E., Jones, C.I. and Klenow, P.J. (2013). The allocation of talent and U.S. economic growth. NBER Working Paper, No. 18693, January 2013.

[37] ILO (2011). Trade Union Membership Statistics. ILO Department of Statistics.

[38] ILO (2012). Statistical Update on Employment in the Informal Economy. International Labour Organization, Department of Statistics. June 2012.

[39] Javeed, S. and Manuhaar, A. (2013). Women and Wage Discrimination in India: A Critical Analysis. International Journal of Humanities and Social Science Invention, Vol. 2, Issue 4, April 2013, pp. 06-12.

[40] Klasen, S. (1999). Does Gender Inequality Reduce Growth and Development? Evidence from Cross-Country Regressions. Policy Research Report on Gender and Development Working Paper Series, No. 7, November 1999.

[41] Klasen, S. and Lamanna, F. (2009). The Impact of Gender Inequality in Education and Employment on Economic Growth: New evidence for a panel of countries. Feminist Economics, 15(3), 91-132.

[42] Klasen, S. and Pieters, J. (2015). What Explains the Stagnation of Female Labor Force Participation in Urban India. World Bank Economic Review, Vol. 29, pp. 1-30.

[43] Medina, J.P. and Soto, C. (2005). Oil Shocks and Monetary Policy in an Estimated DSGE Model for a Small Open Economy. Mimeo, Central Bank of Chile.

[44] Mitra, A. and Verick, S. (2013). Youth Employment and Unemployment: An Indian Perspective. ILO Asia Working Paper Series, ISSN 2227-4491, International Labour Organization (ILO).

[45] NCEUS (2009). Report on Definitional and Statistical Issues Related to the Informal Economy. National Commission for Enterprises in the Unorganized Sector (NCEUS), New Delhi.

[46] OECD (2008). The Price of Prejudice: Labour Market Discrimination on the Grounds of Gender and Ethnicity. Organization for Economic Cooperation and Development (OECD).

[47] Pal, R. and Rathore, U. (2013). Estimating Workers' Bargaining Power and Firms' Markup in India: Implications of Reforms and Labour Regulation, Indira Gandhi Institute of Development Research, IGIDR Working Paper, WP-2014-037.

[48] Rotemberg, J. (1982). Sticky prices in the Unites States. Journal of Political Economy, Vol. 90, No. 6, Dec. 1982, pp. 1187-1211. 
[49] Sahoo, A. and Raa, T.T. (2009). The Relative Performance of Formal and Informal Sectors in India. Economic Systems Research, 21:2, 151-162.

[50] Satchi, M. and Temple, J. (2009). Labor Markets and Productivity in Developing Countries. Review of Economic Dynamics, 26, 333-345.

[51] Sharma, S. (2009). Entry Regulation, Labor Laws, and Informality. Working Paper, Enterprises Analysis Unit, The World Bank.

[52] Sinha, P. (2013). Combating Youth Unemployment in India. Mimeo, Berlin, FriedrichEbert-Stiftung.

[53] Tobin, J. (1969). A General Equilibrium Approach to Monetary Theory. Journal of Money, Credit and Banking, 1(1): 15-29.

[54] Tovar, C. (2006a). Devaluations, Output, and the Balance Sheet Effect: A Structural Econometric Analysis. BIS Working Papers, No 215, September 2006.

[55] Ulyssea, G. (2009). Regulation of entry, labor market institutions and the informal sector. Journal of Development Economics, 91 (2010) 87-99.

[56] World Bank (2011). World Development Report 2012. Gender Equality and Development, The World Bank Group, Washington.

[57] World Bank (2013a). World Development Indicators, 2013. http://data.worldbank.org/data-catalog/worlddevelopment-indicators. The World Bank Group, Washington.

[58] World Economic Forum (2010). The Global Gender Gap Report 2010. Basel, World Economic Forum (WEF).

[59] World Economic Forum (2014). The Global Competitiveness Report 2014-15, Full Data Edition. Basel, World Economic Forum (WEF).

[60] World Economic Forum (2014a). The Global Gender Gap Report 2014. Basel, World Economic Forum (WEF).

[61] Zenou, Y. (2008). Job Search and Mobility in Developing Countries: Theory and Policy Implications. Journal of Development Economics, 86, 336-355. 


\section{A. Appendix: Estimation Results}

Table 3: Prior and Posterior Distributions, Baseline Model (India)

\begin{tabular}{|c|c|c|c|c|c|c|}
\hline \multirow[t]{2}{*}{ Parameter } & \multirow[t]{2}{*}{ Description } & \multirow[t]{2}{*}{ Dist. } & \multicolumn{2}{|c|}{ Prior } & \multicolumn{2}{|r|}{ Posterior } \\
\hline & & & Mean & Std. Dev. & Mean & $95 \% \mathrm{CB}$ \\
\hline$h_{C}$ & Habit & B & 0.6 & 0.25 & 0.3993 & {$[0.3406,0.4523]$} \\
\hline$\phi_{F}^{a d j}$ & Price A.C. in F & G & 50 & 20 & 64.546 & {$[60.710,68.270]$} \\
\hline$\phi_{I}^{a d j}$ & Price A.C. in I & G & 50 & 20 & 24.1511 & {$[20.240,27.860]$} \\
\hline$\phi_{f^{*}}^{a d j}$ & Price A.C. in $\mathrm{f}^{*}$ & G & 20 & 20 & 42.4417 & {$[38.750,45.610]$} \\
\hline$\kappa$ & Cap. A.C. & IG & 20 & 20 & 6.3579 & {$[5.0900,7.3700]$} \\
\hline$\chi$ & Country premium & IG & 0.002 & 0.002 & 0.0009 & {$[0.0007,0.0010]$} \\
\hline$\alpha_{i}$ & Coef. of $i_{t-1}$ & B & 0.75 & 0.20 & 0.862 & {$[0.8249,0.9000]$} \\
\hline$\alpha_{\pi}$ & Coef. of $\pi$ & G & 3 & 3 & 3.2349 & {$[2.8987,3.5581]$} \\
\hline$\alpha_{Y}$ & Coef. of $G D P$ & G & 0.4 & 0.2 & 0.3246 & {$[0.2821,0.3675]$} \\
\hline$\rho_{\theta F}$ & Pers. of $\theta_{F}$ & B & 0.75 & 0.20 & 0.9718 & {$[0.9579,0.9883]$} \\
\hline$\rho_{\theta I}$ & Pers. of $\theta_{I}$ & B & 0.65 & 0.20 & 0.3301 & {$[0.2731,0.4147]$} \\
\hline$\rho_{G}$ & Pers.of $G$ & B & 0.75 & 0.20 & 0.7886 & {$[0.7050,0.8782]$} \\
\hline$\rho_{\theta H}$ & Pers. of $\theta_{H}$ & B & 0.65 & 0.20 & 0.6989 & {$[0.6493,0.7559]$} \\
\hline$\rho_{\beta_{H C F}}$ & Pers. of $\beta_{H C F}$ & B & 0.75 & 0.20 & 0.778 & {$\left[\begin{array}{lll}0.6911 & 0.8604\end{array}\right]$} \\
\hline$\rho_{\lambda^{m}}$ & Pers. of $\lambda_{F}^{m}$ & B & 0.75 & 0.20 & 0.5823 & {$[0.5387,0.6232]$} \\
\hline$\rho_{\text {skillF }}$ & Pers. of $s k i l l_{F}^{f}$ & B & 0.75 & 0.20 & 0.3745 & {$[0.2661,0.4862]$} \\
\hline$\rho_{\text {skillI }}$ & Pers. of skill $I_{I}^{f}$ & B & 0.75 & 0.20 & 0.772 & {$[0.7191,0.8310]$} \\
\hline$\rho_{\phi^{f}}$ & Pers. of $\phi^{f}$ & B & 0.75 & 0.20 & 0.7348 & {$[0.6879,0.7835]$} \\
\hline$\rho_{\varphi l e}$ & Pers. of $\varphi_{l e}^{f}$ & B & 0.75 & 0.20 & 0.7782 & {$[0.6618,0.8775]$} \\
\hline$\rho_{\omega_{F}^{m}}$ & Pers. of $w_{F}^{m}$ & B & 0.75 & 0.20 & 0.1056 & {$[0.0671,0.1544]$} \\
\hline$\rho_{\pi^{*}}$ & Pers. of $\pi^{*}$ & B & 0.75 & 0.20 & 0.6385 & {$[0.5942,0.6725]$} \\
\hline$\rho_{i^{*}}$ & Pers. of $i^{*}$ & $\mathrm{~B}$ & 0.75 & 0.20 & 0.9492 & {$[0.9232,0.9751]$} \\
\hline$s d\left(\varepsilon_{\theta F}\right)$ & Std. Dev. of $\theta_{D}$ & IG & 0.01 & Inf & 0.1271 & {$[0.1061,0.1495]$} \\
\hline$s d\left(\varepsilon_{\theta I}\right)$ & Std. Dev. of $\theta_{I}$ & IG & 0.01 & Inf & 0.0307 & {$[0.0253,0.0356]$} \\
\hline$s d\left(\varepsilon_{G}\right)$ & Std. Dev. of $G$ & IG & 0.01 & Inf & 0.1265 & {$[0.1016,0.1517]$} \\
\hline$s d\left(\varepsilon_{\theta H}\right)$ & Std. Dev. of $\theta_{H}$ & IG & 0.01 & Inf & 0.0085 & {$[0.0022,0.0158]$} \\
\hline$s d\left(\varepsilon_{H C F}\right)$ & Std. Dev. of $\beta_{H C F}$ & IG & 0.01 & Inf & 0.0103 & {$[0.0023,0.0208]$} \\
\hline$s d\left(\varepsilon_{\lambda^{m}}\right)$ & Std. Dev. of $\lambda_{F}^{m}$ & IG & 0.01 & Inf & 0.1121 & {$[0.0933,0.1316]$} \\
\hline$s d\left(\varepsilon_{\text {skillF }}\right)$ & Std. Dev. of skill $f_{F}^{f}$ & IG & 0.01 & $\operatorname{Inf}$ & 0.0072 & {$[0.0024,0.0126]$} \\
\hline$s d\left(\varepsilon_{\text {skillI }}\right)$ & Std. Dev. of skill $I_{I}^{f}$ & IG & 0.01 & Inf & 1.1785 & {$[0.9458,1.4203]$} \\
\hline$s d\left(\varepsilon_{\phi^{f}}\right)$ & Std. Dev. of $\phi^{f}$ & IG & 0.01 & Inf & 0.0093 & {$[0.0023,0.0169]$} \\
\hline$s d\left(\varepsilon_{\varphi l e}\right)$ & Std. Dev. of $\varphi_{l e}^{f}$ & IG & 0.01 & Inf & 0.009 & {$[0.0022,0.0166]$} \\
\hline$s d\left(\varepsilon_{\omega F}\right)$ & Std. Dev. of $w_{F}^{m}$ & IG & 0.01 & Inf & 0.211 & {$[0.1622,0.2645]$} \\
\hline$s d\left(\varepsilon_{\pi^{*}}\right)$ & Std. Dev. of $\pi^{*}$ & IG & 0.01 & Inf & 0.02 & {$[0.0024,0.0208]$} \\
\hline$s d\left(\varepsilon_{i^{*}}\right)$ & Std. Dev. of $i^{*}$ & IG & 0.01 & Inf & 0.015 & {$[0.0023,0.0209]$} \\
\hline$s d\left(\varepsilon_{i}\right)$ & Std. Dev. of $i$ & IG & 0.01 & Inf & 0.0084 & {$[0.0074,0.0096]$} \\
\hline
\end{tabular}




\section{Robustness of the Result}

\section{Alternative model}

We evaluate the robustness of our estimation result by re-estimating the Baseline model with alternative and less informative priors. In the alternative model, the uniform distribution is assigned to the parameters bounded between 0 and 1 , such as $h_{C}, \alpha_{i}, \rho_{\theta H}, \rho_{\text {skillI }}, \rho_{\varphi_{l e}^{f}}, \rho_{\omega_{F}^{m}}, \rho_{\phi^{f}}$, $\rho_{\beta_{H C F}}, \rho_{\lambda^{m}}, \rho_{\theta_{F}}, \rho_{\theta_{I}}, \rho_{G}, \rho_{i^{*}}$, and $\rho_{\pi^{*}}$, instead of beta distributions in the Baseline model ${ }^{66}$. In addition, uniform distributions are also assigned to the monetary policy coefficient on inflation, $\alpha_{\pi}$, which is bounded between 0 and 3. Table 4 compares the priors and the posterior estimates in the alternative model with the Baseline scenario.

First of all, even though the posterior means of the Taylor rule coefficients $\alpha_{i}, \alpha_{\pi}$, and $\alpha_{Y}$ are smaller in the alternative model, our argument that there is considerable policy inertia, and that the RBI responds aggressively to inflation deviations and not much to output deviations, is robust to the change in priors. Second, and our argument that formal price rigidity is higher than informal price rigidity, and that import price rigidity falls within the range of formal and informal price rigidity, still holds. Third, the persistence and volatility of shock processes is estimated to take high values, and thus our third argument that shocks are more persistent and volatile in emerging economies could be maintained even under the looser prior.

Overall, even though there are some quantitative differences for estimates of some parameters in the two model specifications, Bayesian estimates are similar across the models. Thus, our estimation analysis is robust to the prior specification and our arguments are strongly supported by the data.

${ }^{66}$ Note that the mean value of these parameters is constrained to 0.5 . 
Table 4: Robustness of Result, Alternative and Baseline Model (India)

\begin{tabular}{|c|c|c|c|c|c|c|c|}
\hline \multirow[t]{3}{*}{ Param. } & \multicolumn{4}{|c|}{ Alternative Model } & \multicolumn{3}{|c|}{ Baseline Model } \\
\hline & \multicolumn{2}{|c|}{ Prior } & \multicolumn{2}{|c|}{ Posterior } & \multicolumn{2}{|c|}{ Prior } & \multirow{2}{*}{$\begin{array}{c}\text { Posterior } \\
\text { Mean } \\
\end{array}$} \\
\hline & Dist. & Mean & Mean & $95 \%$ C.I. & Dist. & Mean & \\
\hline$h_{C}$ & $\mathrm{U}$ & 0.5 & 0.04 & {$[0.02,0.07]$} & B & 0.6 & 0.3993 \\
\hline$\phi_{F}^{a d j}$ & G & 50 & 64.6 & {$[61.52,67.43]$} & G & 50 & 64.546 \\
\hline$\phi_{I}^{a d j}$ & G & 50 & 12.95 & {$[7.08,19.62]$} & $\mathrm{G}$ & 50 & 24.1511 \\
\hline$\phi_{f^{*} j}^{a d j}$ & G & 20 & 40.49 & {$[35.33,43.32]$} & G & 20 & 42.4417 \\
\hline$\kappa$ & IG & 20 & 3.86 & {$[3.40,4.32]$} & IG & 20 & 6.3579 \\
\hline$\chi$ & IG & 0.002 & 0.001 & {$[0.0008,0.0012]$} & IG & 0.002 & 0.0009 \\
\hline$\alpha_{i}$ & $\mathrm{U}$ & 0.5 & 0.79 & {$[0.74,0.84]$} & $\mathrm{B}$ & 0.75 & 0.862 \\
\hline$\alpha_{\pi}$ & $\mathrm{U}$ & 1.5 & 2.84 & {$[2.62,3.00]$} & G & 3 & 3.2349 \\
\hline$\alpha_{Y}$ & G & 0.4 & 0.05 & {$[0.02,0.09]$} & G & 0.4 & 0.3246 \\
\hline$\rho_{\theta F}$ & $\mathrm{U}$ & 0.5 & 0.97 & {$[0.95,0.99]$} & B & 0.75 & 0.9718 \\
\hline$\rho_{\theta I}$ & $\mathrm{U}$ & 0.5 & 0.14 & {$[0.09,0.18]$} & B & 0.65 & 0.3301 \\
\hline$\rho_{G}$ & $\mathrm{U}$ & 0.5 & 0.55 & {$[0.48,0.60]$} & B & 0.75 & 0.7886 \\
\hline$\rho_{\theta H}$ & $\mathrm{U}$ & 0.5 & 0.76 & {$[0.73,0.79]$} & B & 0.65 & 0.6989 \\
\hline$\rho_{\beta_{H C F}}$ & $\mathrm{U}$ & 0.5 & 0.8 & [0.62:0.69] & B & 0.75 & 0.778 \\
\hline$\rho_{\lambda^{m}}$ & $\mathrm{U}$ & 0.5 & 0.79 & {$[0.32,0.49]$} & B & 0.75 & 0.5823 \\
\hline$\rho_{\text {skillF }}$ & $\mathrm{U}$ & 0.5 & 0.41 & {$[0.74,0.85]$} & B & 0.75 & 0.3745 \\
\hline$\rho_{\text {skillI }}$ & $\mathrm{U}$ & 0.5 & 0.80 & {$[0.43,0.59]$} & B & 0.75 & 0.772 \\
\hline$\rho_{\phi^{f}}$ & $\mathrm{U}$ & 0.5 & 0.85 & {$[0.81,0.90]$} & B & 0.75 & 0.7348 \\
\hline$\rho_{\varphi l e}$ & $\mathrm{U}$ & 0.5 & 0.46 & {$[0.40,0.55]$} & B & 0.75 & 0.7782 \\
\hline$\rho_{\omega_{F}^{m}}$ & $\mathrm{U}$ & 0.5 & 0.02 & {$[0.01,0.04]$} & B & 0.75 & 0.1056 \\
\hline$\rho_{\pi^{*}}$ & $\mathrm{U}$ & 0.5 & 0.61 & {$[0.56,0.72]$} & B & 0.75 & 0.6385 \\
\hline$\rho_{i^{*}}$ & $\mathrm{U}$ & 0.5 & 0.92 & {$[0.90,0.94]$} & B & 0.75 & 0.9492 \\
\hline$s d\left(\varepsilon_{\theta F}\right)$ & IG & 0.01 & 0.30 & {$[0.25,0.35]$} & IG & 0.01 & 0.1271 \\
\hline$s d\left(\varepsilon_{\theta I}\right)$ & IG & 0.01 & 0.13 & {$[0.11,0.16]$} & IG & 0.01 & 0.0307 \\
\hline$s d\left(\varepsilon_{G}\right)$ & IG & 0.01 & 0.77 & {$[0.63,0.94]$} & IG & 0.01 & 0.1265 \\
\hline$s d\left(\varepsilon_{\theta H}\right)$ & IG & 0.01 & 0.017 & {$[0.002,0.022]$} & IG & 0.01 & 0.0085 \\
\hline$s d\left(\varepsilon_{H C F}\right)$ & IG & 0.01 & 3.64 & {$[3.23,4.23]$} & IG & 0.01 & 0.0103 \\
\hline$s d\left(\varepsilon_{\lambda^{m}}\right)$ & IG & 0.01 & 0.07 & {$[0.05,0.09]$} & IG & 0.01 & 0.1121 \\
\hline$s d\left(\varepsilon_{\text {skillF }}\right)$ & IG & 0.01 & 0.62 & {$[0.50,0.75]$} & IG & 0.01 & 0.0072 \\
\hline$s d\left(\varepsilon_{s k i l l I}\right)$ & IG & 0.01 & 1.02 & {$[0.83,1.20]$} & IG & 0.01 & 1.1785 \\
\hline$s d\left(\varepsilon_{\phi^{f}}\right)$ & IG & 0.01 & 0.012 & {$[0.002,0.038]$} & IG & 0.01 & 0.0093 \\
\hline$s d\left(\varepsilon_{\varphi l e}\right)$ & IG & 0.01 & 0.015 & {$[0.002,0.024]$} & IG & 0.01 & 0.009 \\
\hline$s d\left(\varepsilon_{\omega F}\right)$ & IG & 0.01 & 0.23 & {$[0.18,0.27]$} & IG & 0.01 & 0.211 \\
\hline$s d\left(\varepsilon_{\pi^{*}}\right)$ & IG & 0.01 & 0.02 & {$[0.015,0.023]$} & IG & 0.01 & 0.02 \\
\hline$s d\left(\varepsilon_{i^{*}}\right)$ & IG & 0.01 & 5.85 & {$[5.26,6.33]$} & IG & 0.01 & 0.015 \\
\hline$s d\left(\varepsilon_{i}\right)$ & IG & 0.01 & 0.018 & {$[0.014,0.021]$} & IG & 0.01 & 0.0084 \\
\hline
\end{tabular}




\section{B. Technical Appendix}

This Appendix discusses the derivation of the model's optimality conditions.

\section{Households}

\section{Partial Derivatives of Home Production}

Here we derive the partial derivatives of home-good production with respect to male and female home-workers, $H P_{t}^{m}$ and $H P_{t}^{f}$, and with respect to male and female leisure, $l e_{t}^{m}$ and $l e_{t}^{f}$. We assume the following functional form of the home production function (Eq. 3.45):

$$
H_{t}^{0}=\theta_{H, t}\left\{\left[\left(1-B P_{t}\right)\left(H P_{t}^{m}+\tau_{U} U_{t}^{m}\right)^{p_{H}}+\left(B P_{t}\right)\left(H P_{t}^{f}+\tau_{U} U_{t}^{f}\right)^{p_{H}}\right]^{1 / p_{H}}\right\}^{1-\alpha_{H}}
$$

In the equation above, the total number of females unemployed can be written as: $U_{t}^{f}=$ $p^{f}-H P_{t}^{f}-l e_{t}^{f}-L_{F, t}^{f}-L_{I, t}^{f}$. Similary, for males we get $U_{t}^{m}=p^{m}-H P_{t}^{m}-l e_{t}^{m}-L_{F, t}^{m}-L_{I, t}^{m}$. Then, differencing the above with respect to $H P_{t}^{f}$ :

$$
\frac{\partial H_{t}^{0}}{\partial H P_{t}^{f}}=\frac{\left(1-\alpha_{H}\right) \theta_{H, t}\left(B P_{t}\right)\left[1+\tau_{U}\right] H_{t}^{0}\left[H P_{t}^{f}+\tau_{U} U_{t}^{f}\right] p_{H}^{-1}}{\left(1-B P_{t}\right)\left(H P_{t}^{m}+\tau_{U} U_{t}^{m}\right)^{p_{H}}+\left(B P_{t}\right)\left(H P_{t}^{f}+\tau_{U} U_{t}^{f}\right)^{p_{H}}}
$$

and differencing the above with respect to $H P_{t}^{m}$ :

$$
\frac{\partial H_{t}^{0}}{\partial H P_{t}^{m}}=\frac{\left(1-\alpha_{H}\right) \theta_{H, t}\left(1-B P_{t}\right)\left[1+\tau_{U}\right] H_{t}^{0}\left[H P_{t}^{m}+\tau_{U} U_{t}^{m}\right]^{p_{H}-1}}{\left(1-B P_{t}\right)\left(H P_{t}^{m}+\tau_{U} U_{t}^{m}\right)^{p_{H}}+\left(B P_{t}\right)\left(H P_{t}^{f}+\tau_{U} U_{t}^{f}\right)^{p_{H}}}
$$

Partial derivatives with respect to female leisure consumption, $l e_{t}^{f}$ is obtained as follows:

$$
\frac{\partial H_{t}^{0}}{\partial l e_{t}^{f}}=-\left[\frac{\left(1-\alpha_{H}\right) \theta_{H, t}\left(B P_{t}\right)\left[\tau_{U}\right] H_{t}^{0}\left[H P_{t}^{f}+\tau_{U} U_{t}^{f}\right] p_{H}^{-1}}{\left(1-B P_{t}\right)\left(H P_{t}^{m}+\tau_{U} U_{t}^{m}\right)^{p_{H}}+\left(B P_{t}\right)\left(H P_{t}^{f}+\tau_{U} U_{t}^{f}\right)^{p_{H}}}\right]
$$

and similarly for males:

$$
\frac{\partial H_{t}^{0}}{\partial l e_{t}^{m}}=-\left[\frac{\left(1-\alpha_{H}\right) \theta_{H, t}\left(1-B P_{t}\right)\left[\tau_{U}\right] H_{t}^{0}\left[H P_{t}^{m}+\tau_{U} U_{t}^{m}\right]^{p_{H}-1}}{\left(1-B P_{t}\right)\left(H P_{t}^{m}+\tau_{U} U_{t}^{m}\right)^{p_{H}}+\left(B P_{t}\right)\left(H P_{t}^{f}+\tau_{U} U_{t}^{f}\right)^{p_{H}}}\right]
$$


Table 5: Impact of Gender-Specific and Labor Market Reforms

\begin{tabular}{lccccccc}
\hline Shock & & Output & Formality & Unemp. & Female LFP & Female Formal & Wage gap \\
\hline \hline & & $Y$ & $L_{F} /\left(L_{F}+L_{I}\right)$ & $U / P$ & $P^{f} / p^{f}$ & $L_{F}^{f} /\left(L_{F}^{f}+L_{I}^{f}\right)$ & $W^{m} / W^{f}$ \\
\hline \hline Increase in public & $\mathrm{SR}$ & 1 & -0.3 & 1 & 2 & -0.5 & 1.04 \\
provisions & $\mathrm{LR}$ & 1.45 & -0.1 & 1 & 1.5 & -0.1 & 0.7 \\
\hline Increase in female safety \& & $\mathrm{SR}$ & 0.62 & -0.25 & 1.28 & 1.96 & -0.48 & 1.07 \\
mobility & $\mathrm{LR}$ & 1.35 & -0.18 & 0.51 & 1.5 & -0.1 & 0.70 \\
\hline Increase in female & $\mathrm{SR}$ & 0.8 & 0.1 & -1.3 & 2.4 & -1.1 & 0.5 \\
education & $\mathrm{LR}$ & 0.7 & 0.15 & -1.4 & 1.5 & 0.25 & -0.4 \\
\hline Lower firm-based gender & $\mathrm{SR}$ & -5.7 & -2 & -1.5 & 3.1 & 6 & -34 \\
discrimination & $\mathrm{LR}$ & -8.3 & -1.5 & -1.3 & 1.5 & 17.5 & -39.5 \\
\hline \multirow{2}{*}{ Labor market deregulation } & $\mathrm{SR}$ & -0.45 & 0.4 & 0.3 & 0.2 & 0.5 & -3 \\
& $\mathrm{LR}$ & 2 & 1.5 & -1.4 & -0.5 & 2.2 & -3.5 \\
\hline \hline
\end{tabular}

Note: SR denotes short run impact (within first 20 quarters) and LR denotes long run (100 quarters) impact of policy. All values are percentage deviations from steady state. 
Table 6: Impact of Combined Package of Reforms

\begin{tabular}{lccccccc}
\hline Shock & & Output & Formality & Unemp. & Female LFP & Female Formal & Wage gap \\
\hline \hline & & $Y$ & $L_{F} /\left(L_{F}+L_{I}\right)$ & $U / P$ & $P^{f} / p^{f}$ & $L_{F}^{f} /\left(L_{F}^{f}+L_{I}^{f}\right)$ & $W^{m} / W^{f}$ \\
\hline \hline Increase in female safety \& & $\mathrm{SR}$ & 1.5 & -0.2 & 0.2 & 4.5 & -1.5 & 1.5 \\
education & $\mathrm{LR}$ & 2 & -0.1 & -1 & 3.5 & 0.2 & 0.2 \\
\hline Increase in female safety \& & $\mathrm{SR}$ & 1 & -0.4 & 2 & 3 & -0.7 & 1.6 \\
public provisions & $\mathrm{LR}$ & 2.1 & -0.1 & 0.8 & 2.5 & -0.15 & 1.07 \\
\hline Increase in female safety \& labor & $\mathrm{SR}$ & 2.2 & 0.2 & 1.5 & 2.2 & 0.1 & -2 \\
deregulation & $\mathrm{LR}$ & 3.5 & 1.7 & -0.1 & 1 & 2.2 & -3 \\
\hline \hline
\end{tabular}

Note: SR denotes short run impact (first 20 quarters), and LR denotes long run (100 quarters) impact of policy.

All values are percentage deviations from steady state. 


\section{Partial Derivatives and Marginal Rate of Substitution (MRS)}

Here we obtain expressions for the partial derivatives of the household utility with respect to $C_{t}, H P_{t}^{m}, H P_{t}^{f}, l e_{t}^{m}$, and $l e_{t}^{f}$ which are then used to obtain the MRS of consumption with respect to home production, $M R S_{H P_{t}, C_{t}}^{h}$, and with respect to leisure, $M R S_{l e_{t}, C_{t}}^{h}$.

Aggregate household utility is given by Eq. 3.42 in the text as:

$$
\Lambda_{t}=E_{t} \sum_{t=0}^{\infty} \beta^{t}\left[\left(B P_{t}\right)\left(p^{m}\right) \Lambda_{t}^{m}+\left(1-B P_{t}\right)\left(p^{f}\right) \Lambda_{t}^{f}\right]
$$

Inserting for utility of males and females, $\Lambda_{t}^{m}$ and $\Lambda_{t}^{f}$, given by Eq. 3.43 and Eq. 3.44:

$$
\Lambda_{t}=E_{0} \sum_{t=0}^{\infty} \beta^{t}\left\{\begin{array}{c}
{\left[\left(B P_{t}\right)\left(p^{m}\right)+\left(1-B P_{t}\right)\left(p^{f}\right)\right]\left[\left(1-h_{c}\right) \ln \left(C_{t}-h_{c} C_{t-1}\right)\right]} \\
+\left(B P_{t}\right)\left(p^{m}\right)\left[\phi_{t}^{m}\left(\frac{\left(H_{t}^{0}\right)^{1+v_{H, t}^{m}}}{1+v_{H, t}^{m}}+\varphi_{l e, t}^{m} \frac{\left(l e_{t}^{m}\right)^{1+v_{l e, t}^{m}}}{1+v_{l e, t}^{m}}\right)\right] \\
+\left(1-B P_{t}\right)\left(p^{f}\right)\left[\phi_{t}^{f}\left(\frac{\left(H_{t}^{0}\right)^{1+v_{H, t}^{f}}}{1+v_{H, t}^{f}}+\varphi_{l e, t}^{f} \frac{\left(l e_{t}^{f}\right)^{1+v_{l e, t}^{f}}}{1+v_{l e, t}^{f}}\right)\right]
\end{array}\right\}
$$

Partial derivative of aggregate utility with respect to $C_{t}$ is the marginal utility of household market-good consumption ${ }^{67}$ :

$$
\frac{\partial \Lambda_{t}}{\partial C_{t}}=\frac{\left[\left(B P_{t}\right)\left(p^{m}\right)+\left(1-B P_{t}\right)\left(p^{f}\right)\right]\left(1-h_{c}\right)}{C_{t}-h_{c} C_{t-1}}=\frac{1}{2} \frac{\left(1-h_{c}\right)}{C_{t}-h_{c} C_{t-1}}
$$

Partial derivative with respect to female home production participation, $H P_{t}^{f}$ yields Eq. 3.46 in the main text with $h=f$ as:

$$
\frac{\partial \Lambda_{t}}{\partial H P_{t}^{f}}=\left(B P_{t}\right)\left(p^{m}\right) \frac{\partial \Lambda_{t}^{m}}{\partial H_{t}^{0}} \frac{\partial H_{t}^{0}}{\partial H P_{t}^{f}}+\left(1-B P_{t}\right)\left(p^{f}\right) \frac{\partial \Lambda_{t}^{f}}{\partial H_{t}^{0}} \frac{\partial H_{t}^{0}}{\partial H P_{t}^{f}}
$$

We have derived $\frac{\partial H_{t}^{0}}{\partial H P_{t}^{f}}$ above in Eq. B.1, and the partial derivative of female utility with respect to home production is given by: $\frac{\partial \Lambda_{t}^{f}}{\partial H_{t}^{0}}=\phi_{t}^{f}\left(\left(H_{t}^{0}\right)^{v_{H, t}^{f}}\right)$. Similarly, for males it is: $\frac{\partial \Lambda_{t}^{m}}{\partial H_{t}^{0}}=\phi_{t}^{m}\left(\left(H_{t}^{0}\right)^{v_{H, t}^{m}}\right)$. By inserting these in the above expression, we obtain the following:

$$
\frac{\partial \Lambda_{t}}{\partial H P_{t}^{f}}=\left\{\begin{array}{c}
{\left[\left(B P_{t}\right)\left(p^{m}\right) \phi_{t}^{m}\left(\left(H_{t}^{0}\right)^{v_{H, t}^{m}}\right)+\left(1-B P_{t}\right)\left(p^{f}\right) \phi_{t}^{f}\left(\left(H_{t}^{0}\right)^{v_{H, t}^{f}}\right)\right]} \\
{\left[\frac{\left(1-\alpha_{H}\right) \theta_{H, t}\left(B P_{t}\right)\left[1+\tau_{U}\right] H_{t}^{0}\left[H P_{t}^{f}+\tau_{U} U_{t}^{f}\right] p_{H}}{\left(1-B P_{t}\right)\left(H P_{t}^{m}+\tau_{U} U_{t}^{m}\right)^{p_{H}}+\left(B P_{t}\right)\left(H P_{t}^{f}+\tau_{U} U_{t}^{f}\right)^{p_{H}}}\right]}
\end{array}\right\}
$$

$\overline{{ }^{67} \mathrm{We} \text { assume } p^{m}=p^{m}=\frac{1}{2} \text { and from } B P_{t} \varepsilon(0,1)}$, we get $\left[\left(B P_{t}\right)\left(p^{m}\right)+\left(1-B P_{t}\right)\left(p^{f}\right)\right]=0.5$. 
Analogously, we obtain the partial derivative with respect to male home production labor:

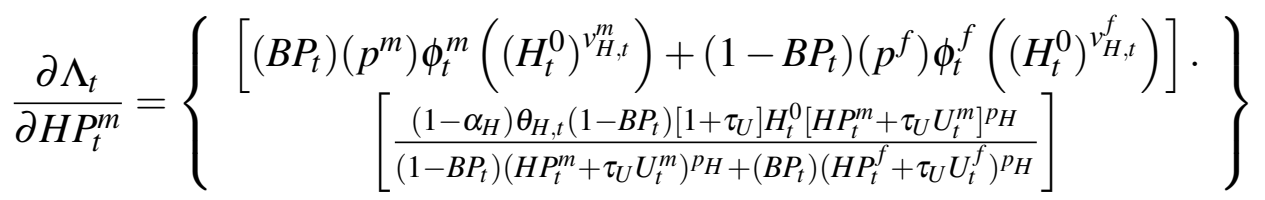

Partial derivatives with respect to female home production participation, $l e_{t}^{f}$, yields Eq. 3.47 in the main text with $h=f$ as:

$$
\frac{\partial \Lambda_{t}}{\partial l e_{t}^{f}}=\left(B P_{t}\right)\left(p^{m}\right) \frac{\partial \Lambda_{t}^{m}}{\partial H_{t}^{0}} \frac{\partial H_{t}^{0}}{\partial l e_{t}^{f}}+\left(1-B P_{t}\right)\left(p^{f}\right)\left(\frac{\partial \Lambda_{t}^{f}}{\partial l e_{t}^{f}}+\frac{\partial \Lambda_{t}^{f}}{\partial H_{t}^{0}} \frac{\partial H_{t}^{0}}{\partial l e_{t}^{f}}\right)
$$

By inserting the expressions for $\frac{\partial H_{t}^{0}}{\partial e_{t}^{f}}$ derived above in Eq. B.3, the partial derivative of female utility with respect to home production as $\frac{\partial \Lambda_{t}^{f}}{\partial l e_{t}^{f}}=\phi_{t}^{f}\left(\varphi_{l e, t}^{f}\left(l e_{t}^{f}\right)^{v_{l e, t}^{f}}\right)$, and for males as $\frac{\partial \Lambda_{t}^{m}}{\partial l e_{t}^{m}}=$ $\phi_{t}^{m}\left(\varphi_{l e, t}^{m}\left(l e_{t}^{m}\right)^{v_{l e, t}^{m}}\right)$, we obtain the following:

$$
\frac{\partial \Lambda_{t}}{\partial l e_{t}^{f}}=\left\{\begin{array}{c}
{\left[\left(B P_{t}\right)\left(p^{m}\right) \phi_{t}^{m}\left(\varphi_{l e, t}^{m}\left(l e_{t}^{m}\right)^{v_{l e, t}^{m}}\right)+\left(1-B P_{t}\right)\left(p^{f}\right) \phi_{t}^{f}\left(\varphi_{l e, t}^{f}\left(l e_{t}^{f}\right)^{v_{l e, t}^{f}}\right)\right]} \\
{\left[\frac{\left(1-\alpha_{H}\right) \theta_{H, t}\left(B P_{t}\right)\left[-\tau_{U}\right] H_{t}^{0}\left[H P_{t}^{f}+\tau_{U} U_{t}^{f}\right] p_{H}^{-1}}{\left(1-B P_{t}\right)\left(H P_{t}^{m}+\tau_{U} U_{t}^{m}\right)^{p_{H}}+\left(B P_{t}\right)\left(H P_{t}^{f}+\tau_{U} U_{t}^{f}\right)^{p_{H}}}\right]}
\end{array}\right\}
$$

Similarly, we obtain the partial derivative with respect to male leisure consumption:

$$
\frac{\partial \Lambda_{t}}{\partial l e_{t}^{m}}=\left\{\begin{array}{c}
{\left[\left(B P_{t}\right)\left(p^{m}\right) \phi_{t}^{m}\left(\varphi_{l e, t}^{m}\left(l e_{t}^{m}\right)^{v_{l e, t}^{m}}\right)+\left(1-B P_{t}\right)\left(p^{f}\right) \phi_{t}^{f}\left(\varphi_{l e, t}^{f}\left(l e_{t}^{f}\right)^{v_{l e, t}^{f}}\right)\right]} \\
{\left[\frac{\left(1-\alpha_{H}\right) \theta_{H, t}\left(1-B P_{t}\right)\left[-\tau_{U}\right] H_{t}^{0}\left[H P_{t}^{m}+\tau_{U} U_{t}^{m}\right]^{p_{H}-1}}{\left(1-B P_{t}\right)\left(H P_{t}^{m}+\tau_{U} U_{t}^{m}\right)^{p_{H}}+\left(B P_{t}\right)\left(H P_{t}^{f}+\tau_{U} U_{t}^{f}\right)^{p_{H}}}\right]}
\end{array}\right\}
$$

The MRS between market-good and home-good consumption for females is given as:

$$
M R S_{H P_{t}, C_{t}}^{f}=\left(\frac{\partial \Lambda_{t}}{\partial H P_{t}^{f}}\right) /\left(\frac{\partial \Lambda_{t}}{\partial C_{t}}\right)
$$

where $\frac{\partial \Lambda_{t}}{\partial H P_{t}^{f}}$ is derived in Eq. B.6 and $\frac{\partial \Lambda_{t}}{\partial C_{t}}$ is derived in Eq. B.5. Similarly for males we get:

$$
M R S_{H P_{t}, C_{t}}^{m}=\left(\frac{\partial \Lambda_{t}}{\partial H P_{t}^{m}}\right) /\left(\frac{\partial \Lambda_{t}}{\partial C_{t}}\right)
$$

where $\frac{\partial \Lambda_{t}}{\partial H P_{t}^{m}}$ is given by Eq. B.7. 
MRS between market-good consumption and leisure for females is:

$$
M R S_{l e_{t}, C_{t}}^{f}=\left(\frac{\partial \Lambda_{t}}{\partial l e_{t}^{f}}\right) /\left(\frac{\partial \Lambda_{t}}{\partial C_{t}}\right)
$$

where $\frac{\partial \Lambda_{t}}{\partial l_{t}^{f}}$ is determined as Eq. B.8 above. Similarly for males we get:

$$
M R S_{l e_{t}, C_{t}}^{m}=\left(\frac{\partial \Lambda_{t}}{\partial l e_{t}^{m}}\right) /\left(\frac{\partial \Lambda_{t}}{\partial C_{t}}\right)
$$

where $\frac{\partial \Lambda_{t}}{\partial l e_{t}^{m}}$ is derived in Eq. B.9.

\section{Solution to Households' Utility Maximization}

To solve for the households' utility maximization problem, we first begin by inserting the following equations in the household budget constraint (Eq. 3.54) described in the text: (i) market clearing condition for unemployment of males and females, $U_{t}^{m}$ and $U_{t}^{f}$; (ii) market clearing conditions for male and female participation, $P_{t}^{m}$ and $P_{t}^{f}$; (iii) law of motion of male and female workers in the formal sector (Eq. 3.9 and Eq. 3.10); and (iv) law of motion of male and female workers in the informal sector, (Eq. 3.11 and Eq. 3.12).

In the household budget constraint the total wage income and unemployment benefits of females in period $t$ is included as:

$$
\left(1-\tau_{F}\right) W_{F, t}^{f} L_{F, t}^{f}+W_{I, t}^{f} L_{I, t}^{f}+W_{U, t}\left(U_{t}^{f}\right)
$$

The total number of females unemployed can be written as: $U_{t}^{f}=p^{f}-H P_{t}^{f}-l e_{t}^{f}-L_{F, t}^{f}-L_{I, t}^{f}$. Inserting this above:

$$
\begin{aligned}
& \left(1-\tau_{F}\right) W_{F, t}^{f} L_{F, t}^{f}+W_{I, t}^{f} L_{I, t}^{f}+W_{U, t}\left(U_{t}^{f}\right) \\
& =\left(1-\tau_{F}\right)\left(W_{F, t}^{f}-W_{U, t}\right) L_{F, t}^{f}+\left(W_{I, t}^{f}-W_{U, t}\right) L_{I, t}^{f}+W_{U, t}\left(p^{f}-H P_{t}^{f}-l e_{t}^{f}\right)
\end{aligned}
$$

Substituting for $L_{F, t}^{f}$ and $L_{I, t}^{f}$ with Eq. 3.10 and Eq. 3.12 in the text, we get: 


$$
\begin{aligned}
& \left(1-\tau_{F}\right) W_{F, t}^{f} L_{F, t}^{f}+W_{I, t}^{f} L_{I, t}^{f}+W_{U, t}\left(U_{t}^{f}\right) \\
& =\left(1-\tau_{F}\right)\left(W_{F, t}^{f}-W_{U, t}\right)\left[\left(1-\sigma_{F}\right)\left(1-p\left(H_{F, t}^{f}\right)\right) L_{F, t-1}^{f}\right] \\
& +\left(1-\tau_{F}\right)\left(W_{F, t}^{f}-W_{U, t}\right)\left[p\left(H_{F, t}^{f}\right) P_{t}^{f}-p\left(H_{F, t}^{f}\right)\left(1-\sigma_{I}\right) L_{I, t-1}^{f}\right] \\
& +\left(W_{I, t}^{f}-W_{U, t}\right)\left[\left(1-\sigma_{I}\right)\left(1-p\left(H_{I, t}^{f}\right)\right) L_{I, t-1}^{f}\right] \\
& +\left(W_{I, t}^{f}-W_{U, t}\right)\left[p\left(H_{I, t}^{f}\right) P_{t}^{f}-p\left(H_{I, t}^{f}\right)\left(1-\sigma_{F}\right) L_{F, t-1}^{f}\right] \\
& +W_{U, t}\left(p^{f}-H P_{t}^{f}-l e_{t}^{f}\right)
\end{aligned}
$$

Female labor force participation, $P_{t}^{f}$, is given by $P_{t}^{f}=p^{f}-H P_{t}^{f}-l e_{t}^{f}$, which when substituted above yields the following:

$$
\begin{aligned}
& \left(1-\tau_{F}\right) W_{F, t}^{f} L_{F, t}^{f}+W_{I, t}^{f} L_{I, t}^{f}+W_{U, t}\left(U_{t}^{f}\right) \\
& =\left(1-\tau_{F}\right)\left(W_{F, t}^{f}-W_{U, t}\right)\left[\left(1-\sigma_{F}\right)\left(1-p\left(H_{F, t}^{f}\right)\right) L_{F, t-1}^{f}\right] \\
& +\left(1-\tau_{F}\right)\left(W_{F, t}^{f}-W_{U, t}\right) p\left(H_{F, t}^{f}\right)\left[p^{f}-H P_{t}^{f}-l e_{t}^{f}-\left(1-\sigma_{I}\right) L_{I, t-1}^{f}\right] \\
& +\left(W_{I, t}^{f}-W_{U, t}\right)\left[\left(1-\sigma_{I}\right)\left(1-p\left(H_{I, t}^{f}\right)\right) L_{I, t-1}^{f}\right] \\
& +\left(W_{I, t}^{f}-W_{U, t}\right)\left[p\left(H_{I, t}^{f}\right)\left(p^{f}-H P_{t}^{f}-l e_{t}^{f}-\left(1-\sigma_{F}\right) L_{F, t-1}^{f}\right)\right] \\
& +W_{U, t}\left(p^{f}-H P_{t}^{f}-l e_{t}^{f}\right)
\end{aligned}
$$

Analogously, total wage income plus the unemployment benefits of males in the budget constraint is included as:

$$
\left(1-\tau_{F}\right) W_{F, t}^{m} L_{F, t}^{m}+W_{I, t}^{m} L_{I, t}^{m}+W_{U, t}\left(U_{t}^{m}\right)
$$

which can then be written as:

$$
\begin{aligned}
& \left(1-\tau_{F}\right) W_{F, t}^{m} L_{F, t}^{m}+W_{I, t}^{m} L_{I, t}^{m}+W_{U, t}\left(U_{t}^{m}\right) \\
& =\left(1-\tau_{F}\right)\left(W_{F, t}^{m}-W_{U, t}\right)\left[\left(1-\sigma_{F}\right)\left(1-p\left(H_{F, t}^{m}\right)\right) L_{F, t-1}^{m}\right] \\
& +\left(1-\tau_{F}\right)\left(W_{F, t}^{m}-W_{U, t}\right)\left[\left(p\left(H_{F, t}^{m}\right)\left(p^{m}-H P_{t}^{m}-l e_{t}^{m}-\left(1-\sigma_{I}\right) L_{I, t-1}^{m}\right)\right]\right. \\
& +\left(W_{I, t}^{m}-W_{U, t}\right)\left[\left(1-\sigma_{I}\right)\left(1-p\left(H_{I, t}^{m}\right)\right) L_{I, t-1}^{m}\right] \\
& +\left(W_{I, t}^{m}-W_{U, t}\right)\left[p\left(H_{I, t}^{m}\right)\left(p^{m}-H P_{t}^{m}-l e_{t}^{m}-\left(1-\sigma_{F}\right) L_{F, t-1}^{m}\right)\right] \\
& +W_{U, t}\left[p^{m}-H P_{t}^{m}-l e_{t}^{m}\right]
\end{aligned}
$$


To solve the households' utility maximization problem described in the text, we insert Eq. B.10 and Eq. B.11 derived above in the household budget constraint, and establish the associated Lagrangian $(\mathscr{L})$ as follows:

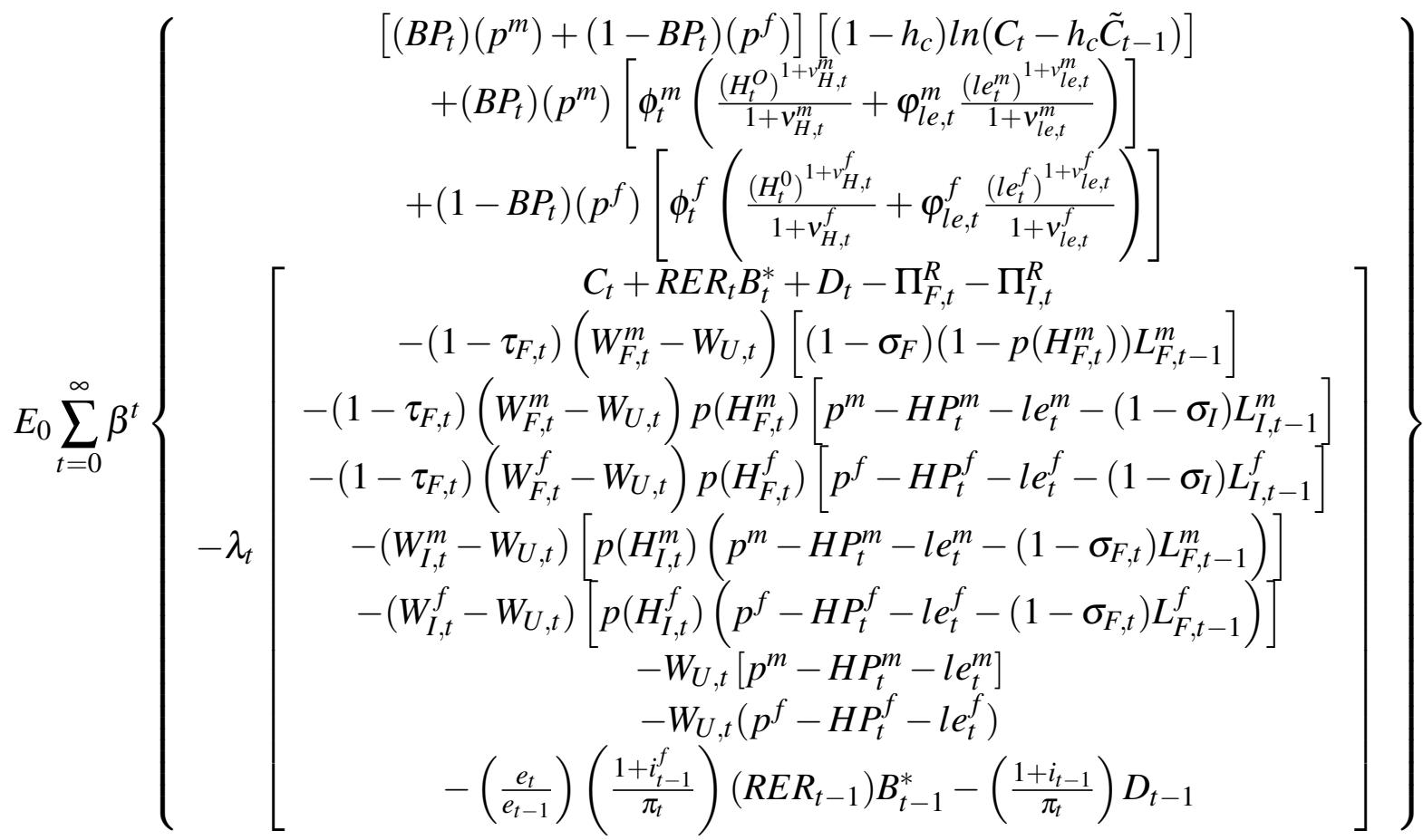

where $\lambda_{t}$ is the shadow price for the budget constraint in period $t$, i.e. the value in terms of utility of relaxing the budget constraint at the margin. Differencing the above Lagrangian with respect to $C_{t}, B_{t}$, and $D_{t}$, yields the following first order conditions:

$$
\begin{gathered}
{\left[C_{t}\right]: \quad \frac{1}{2} \frac{\zeta_{C, t}\left(1-h_{C}\right)}{C_{t}-h_{C} C_{t-1}}-\lambda_{t}=0} \\
{\left[D_{t}\right]: \quad-\lambda_{t}+\beta E_{t}\left[\lambda_{t+1}\left(\frac{1+i_{t}}{\pi_{t+1}}\right)\right]=0} \\
{\left[B_{t}\right]: \quad-\lambda_{t}+\beta E_{t}\left[\lambda_{t+1}\left(\frac{1+i_{t}^{f}}{\pi_{t+1}}\right)\left(\frac{e_{t+1}}{e_{t}}\right)\right]=0}
\end{gathered}
$$

Eq. B.13 and Eq. B.14 imply the evolution of shadow price evaluated in domestic and foreign interest rate. Combining Eq. B.12 and Eq. B.13 is the Euler equation for domestic bonds given as Eq. 3.55 in the text, and combining Eq. B.12 and Eq. B.14 derives the Euler equation for foreign bond holdings given as Eq. 3.56 in the text.

Differencing the above Lagrangian with respect to $H P_{t}^{f}$ and $H P_{t}^{m}$ : 


$$
\begin{aligned}
& {\left[H P_{t}^{f}\right]: \quad\left(\frac{\partial \Lambda_{t}}{\partial H P_{t}^{f}}\right)-\lambda_{t}\left\{\begin{array}{c}
\left(1-\tau_{F}\right)\left(W_{F, t}^{f}-W_{U, t}\right) p\left(H_{F, t}^{f}\right) \\
+\left(W_{I, t}^{f}-W_{U, t}\right) p\left(H_{F, t}^{f}\right)+W_{U, t}
\end{array}\right\}=0} \\
& {\left[H P_{t}^{m}\right]: \quad\left(\frac{\partial \Lambda_{t}}{\partial H P_{t}^{m}}\right)-\lambda_{t}\left\{\begin{array}{c}
\left(1-\tau_{F}\right)\left(W_{F, t}^{m}-W_{U, t}\right) p\left(H_{F, t}^{m}\right) \\
+\left(W_{I, t}^{m}-W_{U, t}\right) p\left(H_{F, t}^{m}\right)+W_{U, t}
\end{array}\right\}=0}
\end{aligned}
$$

Combining these equations with Eq. B.12 yields the following first order conditions:

$$
\begin{aligned}
& M R S_{H P_{t}, C_{t}}^{f}=\left(1-\tau_{F}\right)\left(W_{F, t}^{f}-W_{U, t}\right) p\left(H_{F, t}^{f}\right)+\left(W_{I, t}^{f}-W_{U, t}\right) p\left(H_{F, t}^{f}\right)+W_{U, t} \\
& M R S_{H P_{t}, C_{t}}^{m}=\left(1-\tau_{F}\right)\left(W_{F, t}^{m}-W_{U, t}\right) p\left(H_{F, t}^{m}\right)+\left(W_{I, t}^{m}-W_{U, t}\right) p\left(H_{F, t}^{m}\right)+W_{U, t}
\end{aligned}
$$

which corresponds to Eq. 3.57 for worker $h$ described in the text.

Differencing the above Lagrangian with respect to $l e_{t}^{f}$ and $l e_{t}^{m}$ :

$$
\begin{aligned}
& {\left[l e_{t}^{f}\right]: \quad\left(\frac{\partial \Lambda_{t}}{\partial H P_{t}^{f}}\right)-\lambda_{t}\left\{\begin{array}{c}
\left(1-\tau_{F, t}\right)\left(W_{F, t}^{f}-W_{U, t}\right) p\left(H_{F, t}^{f}\right) \\
+\left(W_{I, t}^{f}-W_{U, t}\right) p\left(H_{F, t}^{f}\right)+W_{U, t}
\end{array}\right\}=0} \\
& {\left[l e_{t}^{m}\right]: \quad\left(\frac{\partial \Lambda_{t}}{\partial H P_{t}^{m}}\right)-\lambda_{t}\left\{\begin{array}{c}
\left(1-\tau_{F, t}\right)\left(W_{F, t}^{m}-W_{U, t}\right) p\left(H_{F, t}^{m}\right) \\
+\left(W_{I, t}^{m}-W_{U, t}\right) p\left(H_{F, t}^{m}\right)+W_{U, t}
\end{array}\right\}=0}
\end{aligned}
$$

Combining these equations with Eq. B.12 yields the following first order conditions:

$$
\begin{gathered}
M R S_{l e_{t}, C_{t}}^{f}=\left(1-\tau_{F, t}\right)\left(W_{F, t}^{f}-W_{U, t}\right) p\left(H_{F, t}^{f}\right)+\left(W_{I, t}^{f}-W_{U, t}\right) p\left(H_{F, t}^{f}\right)+W_{U, t} \\
M_{R S_{l e_{t}, C_{t}}^{m}}^{m}=\left(1-\tau_{F, t}\right)\left(W_{F, t}^{m}-W_{U, t}\right) p\left(H_{F, t}^{m}\right)+\left(W_{I, t}^{m}-W_{U, t}\right) p\left(H_{F, t}^{m}\right)+W_{U, t}
\end{gathered}
$$

which corresponds to Eq. 3.58 for worker $h$ described in the text.

\section{Wholesale Producers}

\section{Solution to the Wholesaler Profit Maximization Problem}

To solve the wholesalers' profit maximization problem described in the text, we establish the associated Lagrangian for the wholesalers in each sector $s$ as follows where $l=t+k$ : 


$$
\mathscr{L}_{s}^{E}=E_{t} \sum_{k=0}^{\infty} \rho_{t, t+k}\left\{\begin{array}{c}
\frac{P_{s, l}^{W}}{P_{l}} \theta_{s, l}\left(K_{s, l-1}\right)^{\psi_{s}}\left(\left[\omega_{s, l}\left(s k i l l_{s}^{m} L_{s, l}^{m}\right)^{p_{s}}+\left(1-\omega_{s, l}\right)\left(s k i l l_{s}^{f} L_{s, l}^{f}\right)^{p_{s}}\right]^{1 / p_{s}}\right)^{1-\psi_{s}} \\
-W_{s, l}^{m} L_{s, l}^{m}-W_{s, l}^{f} L_{s, l}^{f}-R_{t}^{K} K_{s, l}-H C_{s, l}^{m} H_{s, l}^{m}-H C_{s, l}^{f} H_{s, l}^{f} \\
-\lambda_{s, l}^{m}\left(L_{s, l}^{m}-\left(1-\sigma_{s}\right) L_{s, l-1}^{m}-p\left(H_{s, l}^{m}\right) S_{l}^{m}\right) \\
-\lambda_{s, l}^{f}\left(L_{F, l}^{f}-\left(1-\sigma_{s}\right) L_{s, l-1}^{f}-p\left(H_{s, l}^{f}\right) S_{l}^{f}\right)
\end{array}\right\}
$$

where $\lambda_{s, t}^{m}$ and $\lambda_{s, t}^{f}$ are the Lagrangian multipliers for the law of motion of male and female labor in period $t$. Differencing the above Lagrangian with respect to $K_{s, t-1}, L_{s, t}^{m}, L_{s, t}^{f}, H_{s, t}^{m}$, and $H_{s, t}^{f}$ yields the following first order conditions:

$$
\begin{gathered}
{\left[K_{s, t}\right]: \quad R_{t}^{K}-\frac{P_{s, t}^{W}}{P_{t}} \psi_{s} \frac{Y_{s, t}^{W}}{K_{s, t-1}}=0} \\
{\left[L_{s, t}^{m}\right]: \quad\left(1-\psi_{s}\right) \omega_{s} \frac{P_{s, t}^{W}}{P_{t}} \frac{Y_{s, t}^{W}}{L_{s, t}^{m}}\left(s k i l l_{s}^{m} \frac{L_{s, t}^{m}}{L_{s, t}}\right)^{\rho_{s}}-W_{s, t}^{m}-\lambda_{s, t}^{m}+E_{t}\left(\rho_{t, t+1} \lambda_{s, t+1}^{m}\left(1-\sigma_{s}\right)\right)=0} \\
{\left[L_{s, t}^{f}\right]: \quad\left(1-\psi_{s}\right)\left(1-\omega_{s}\right) \frac{P_{s, t}^{W} \frac{Y_{s, t}^{W}}{P_{t}}\left(s k i l l_{s, t}^{f} \frac{L_{s, t}^{f}}{L_{s, t}^{f}}\right)^{\rho_{s}}-W_{s, t}^{f}-\lambda_{s, t}^{f}-E_{t}\left(\rho_{t, t+1} \lambda_{s, t+1}^{f}\left(1-\sigma_{s}\right)\right)=0}{\left[H_{s, t}^{m}\right]: \quad-H C_{s, t}^{m}+\lambda_{s, t}^{m}=0}} \\
{\left[H_{s, t}^{f}\right]: \quad-H C_{s, t}^{f}+\lambda_{s, t}^{f}=0}
\end{gathered}
$$

The first condition is the wholesaler demand for capital Eq. 3.25, whereas the second and fourth conditions combined determine the demand for male labor Eq. 3.26 in the text. Similarly, the third and fifth conditions combined determine the demand for female labor Eq. 3.27 in the text.

\section{Wage Bargaining}

We begin by deriving the wages of a female worker $(h=f)$ in the formal sector $(s=F)$, given as $W_{F, t}^{f}$. In period $t$, a worker's marginal value of being employed in the formal, $V_{F, t}^{f}$ and the informal sector, $V_{I, t}^{h}$ is given by Eq. 3.28 and Eq. 3.30 in the text. By substituting these in $\left(V_{F, t}^{h}-V_{U, t}^{h}\right)$, we obtain the utility gain of an unemployed worker $h$ of getting hired in the formal sector: 


$$
\begin{aligned}
\left(V_{F, t}^{h}-V_{U, t}^{h}\right)=\left(1-\tau_{F}\right) W_{F, t}^{h}-W_{U, t}-\tau_{U} M R S_{H P_{t}, C_{t}}^{h} \\
+E_{t} \rho_{t, t+1}\left\{\begin{array}{c}
\left(1-\sigma_{F}^{h}\right) V_{F, t+1}^{h} \\
-V_{F, t+1}^{h}\left[\left(1-\sigma_{F}^{h}\right) p\left(S_{t+1}^{h}\right) p\left(H_{F, t+1}^{h}\right)\right] \\
-V_{I, t+1}^{h}\left[\left(1-\sigma_{F}^{h}\right) p\left(S_{t+1}^{h}\right) p\left(H_{I, t+1}^{h}\right)\right] \\
-V_{U, t+1}^{h}\left[\left(1-\sigma_{F}^{h}\right) p\left(S_{t+1}^{h}\right)\left(1-p\left(H_{F, t+1}^{h}\right)-p\left(H_{I, t+1}^{h}\right)\right)\right] \\
-V_{N P, t+1}^{h}\left[\left(1-\sigma_{F}^{h}\right)\left(1-p\left(S_{t+1}^{h}\right)\right)\right]
\end{array}\right\}
\end{aligned}
$$

Inserting the worker's value of not participating in the labor market, $V_{N P, t+1}^{h}$ in period $t+1$ given by Eq. 3.31, we can rewrite the above equation as:

$$
\begin{aligned}
\left(V_{F, t}^{h}-V_{U, t}^{h}\right)=\left(1-\tau_{F}\right) W_{F, t}^{h}-W_{U, t}-\tau_{U} M R S_{H P_{t}, C_{t}}^{h} & \left(1-\sigma_{F}^{h}\right) V_{F, t+1}^{h} \\
+ & E_{t} \rho_{t, t+1}\left\{\begin{array}{c}
\left(1-\left(V_{F, t+1}^{h}-V_{U, t+1}^{h}\right)\left[\left(1-\sigma_{F}^{h}\right) p\left(S_{t+1}^{h}\right) p\left(H_{F, t+1}^{h}\right)\right]\right. \\
-\left(V_{I, t+1}^{h}-V_{U, t+1}^{h}\right)\left[\left(1-\sigma_{F}^{h}\right) p\left(S_{t+1}^{h}\right) p\left(H_{I, t+1}^{h}\right)\right] \\
-V_{U, t+1}^{h}\left[\left(1-\sigma_{F}^{h}\right)\right] \\
-V_{H, t+1}^{h}\left[\left(1-\sigma_{F}^{h}\right)\left(1-p\left(S_{t+1}^{h}\right)\right)\left(1-p\left(l e_{t+1}^{h}\right)\right]\right. \\
-V_{l e, t+1}^{h}\left[\left(1-\sigma_{F}^{h}\right)\left(1-p\left(S_{t+1}^{h}\right)\right) p\left(l e_{t+1}^{h}\right)\right]
\end{array}\right\}
\end{aligned}
$$

Add and subtract $\left(1-\sigma_{F}\right) V_{t+1}^{U}$ on the right hand side in the equation above:

$$
\begin{aligned}
\left(V_{F, t}^{h}-V_{U, t}^{h}\right)=\left(1-\tau_{F}\right) W_{F, t}^{h}-W_{U, t}-\tau_{U} M R S_{H P_{t}, C_{t}}^{h} & \left\{\begin{array}{c}
\left(1-\sigma_{F}^{h}\right)\left(V_{F, t+1}^{h}-V_{U, t+1}^{h}\right)\left[1-p\left(S_{t+1}^{h}\right) p\left(H_{F, t+1}^{h}\right)\right] \\
-\left(V_{I, t+1}^{h}-V_{U, t+1}^{h}\right)\left[\left(1-\sigma_{F}^{h}\right) p\left(S_{t+1}^{h}\right) p\left(H_{I, t+1}^{h}\right)\right] \\
+E_{t} \rho_{t, t+1}\left\{\begin{array}{c}
h \\
U, t+1
\end{array}\left[\left(1-\sigma_{F}^{h}\right)\right]\right. \\
+\left(\begin{array}{c}
\left.V_{U, t+1}^{h}-V_{H, t+1}^{h}\right)\left[\left(1-\sigma_{F}^{h}\right)\left(1-p\left(S_{t+1}^{h}\right)\right)\left(1-p\left(l e_{t+1}^{h}\right)\right]\right. \\
-\left(V_{l e, t+1}^{h}-V_{U, t+1}^{h}\right)\left[\left(1-\sigma_{F}^{h}\right)\left(1-p\left(S_{t+1}^{h}\right)\right) p\left(l e_{t+1}^{h}\right)\right]
\end{array}\right.
\end{array}\right\}
\end{aligned}
$$

Finally, expressions for wages of male and female workers in the formal sector are derived by plugging in Eq. B.15 and $J_{F, t}^{f}=H C_{F, t}^{f}$ in the Nash bargaining solution (Eq. 3.34) given in the 
text (for $s=F$ ) where $k=(t+1)$ :

$$
\begin{aligned}
& W_{F, t}^{m}\left(1-\tau_{F}\right)=\frac{\lambda_{F, t}^{m}}{1-\lambda_{F, t}^{m}}\left(1-\tau_{F}\right) H C_{F, t}^{m}+W_{U, t} \\
& -\left(1-\sigma_{F}\right) E_{t}\left\{\rho_{t, k}\left[\begin{array}{c}
\frac{\lambda_{F, k}^{m}}{1-\lambda_{F, k}^{m}}\left[1-p\left(S_{k}^{m}\right) p\left(H_{F, k}^{m}\right)\right]\left(1-\tau_{F}\right) H C_{F, k}^{m} \\
-\frac{\lambda_{I, k}^{m}}{1-\lambda_{I, k}^{m}}\left(p\left(H_{I, k}^{m}\right)\right) H C_{I, k}^{m} \\
+\left(1-p\left(S_{k}^{m}\right)\right) W_{U, k} \\
+\left(1-p\left(S_{k}^{m}\right)\right) p\left(l e_{k}^{m}\right) M R S_{l e, C_{k}}^{m} \\
+\left(1-p\left(S_{k}^{m}\right)\right)\left[1-p\left(l e_{k}^{m}\right)-\tau_{U}\right] M R S_{H P, C_{k}}^{m}
\end{array}\right]\right\} \\
& W_{F, t}^{f}\left(1-\tau_{F}\right)=\frac{\lambda_{F, t}^{f}}{1-\lambda_{F, t}^{f}}\left(1-\tau_{F}\right)\left(H C_{F, t}^{f}\right)+W_{U, t} \\
& -\left(1-\sigma_{F}\right) E_{t}\left\{\rho_{t, k}\left[\begin{array}{c}
\frac{\lambda_{F, k}^{f}}{1-\lambda_{F, k}^{f}}\left[1-p\left(S_{k}^{f}\right) p\left(H_{F, k}^{f}\right)\right]\left(1-\tau_{F,}\right) H C_{F, k}^{f} \\
-\frac{\lambda_{I, k}^{f}}{1-\lambda_{I, k}^{f}}\left(p\left(H_{I, k}^{f}\right)\right) H C_{I, k}^{f} \\
+\left(1-p\left(S_{k}^{f}\right)\right) W_{U, k} \\
+\left(1-p\left(S_{k}^{f}\right)\right) p\left(l e_{k}^{f}\right) M R S_{l e, C_{k}}^{f} \\
+\left(1-p\left(S_{k}^{m}\right)\right)\left[1-p\left(l e_{k}^{f}\right)-\tau_{U}\right] M R S_{H P, C_{k}}^{m}
\end{array}\right]\right\}
\end{aligned}
$$

Analogously, we derive expressions for informal wages, except that wage income taxes are nil in the informal sector $\left(\tau_{I}=0\right)$, as follows:

$$
\begin{aligned}
W_{I, t}^{m}=\frac{\lambda_{I, t}^{m}}{1-\lambda_{I, t}^{m}} H C_{I, t}^{m}+W_{U, t} \\
-\left(1-\sigma_{F}\right) E_{t}\left\{\rho_{t, k}\left[\begin{array}{c}
\frac{\lambda_{I, k}^{m}}{1-\lambda_{I, k}^{m}}\left[1-p\left(S_{k}^{m}\right) p\left(H_{I, k}^{m}\right)\right] H C_{I, k}^{m} \\
-\frac{\lambda_{F, k}^{m}}{1-\lambda_{F, k}^{m}}\left(1-\tau_{F}\right)\left(p\left(H_{F, k}^{m}\right)\right) H C_{F, k}^{m} \\
+\left(1-p\left(S_{k}^{m}\right)\right) W_{U, k} \\
+\left(1-p\left(S_{k}^{m}\right)\right) p\left(l e_{k}^{m}\right) M R S_{l e, C_{k}}^{m} \\
+\left(1-p\left(S_{k}^{m}\right)\right)\left[1-p\left(l e_{k}^{m}\right)-\tau_{U}\right] M R S_{H P, C_{k}}^{m}
\end{array}\right]\right\}
\end{aligned}
$$




$$
\begin{aligned}
W_{I, t}^{f}= & \frac{\lambda_{I, t}^{f}}{1-\lambda_{I, t}^{f}}\left(H C_{I, t}^{f}\right)+W_{U, t} \\
& -\left(1-\sigma_{F}\right) E_{t}\left\{\rho_{t, k}\left[\begin{array}{c}
\frac{\lambda_{I, k}^{f}}{1-\lambda_{I, k}^{f}}\left[1-p\left(S_{k}^{f}\right) p\left(H_{I, k}^{f}\right)\right] H C_{I, k}^{f} \\
-\frac{\lambda_{F, k}^{f}}{1-\lambda_{F, k}^{f}}\left(1-\tau_{F}\right)\left(p\left(H_{F, k}^{f}\right)\right) H C_{F, k}^{f} \\
+\left(1-p\left(S_{k}^{f}\right)\right) W_{U, k} \\
+\left(1-p\left(S_{k}^{f}\right)\right) p\left(l e_{k}^{f}\right) M R S_{l e, C_{k}}^{f} \\
+\left(1-p\left(S_{k}^{m}\right)\right)\left[1-p\left(l e_{k}^{f}\right)-\tau_{U}\right] M R S_{H P, C_{k}}^{m}
\end{array}\right]\right\}
\end{aligned}
$$

\section{Solution to Retailer Price Setting Problem}

To solve the retailer's profit maximization problem described in the text, we establish the associated Lagrangian for the retailer $j_{s}$ in each sector $s$ as follows where $l=t+k$ :

$$
\mathscr{L}_{s}^{R}=E_{t} \sum_{k=0}^{\infty} \rho_{t, t+k}\left(1-\delta_{s}\right)^{k}\left\{\begin{array}{c}
\left(\frac{P_{F, l}\left(j_{F}\right)}{P_{l}}-M C_{F, t}^{W}\right)\left(\frac{P_{F, l}\left(j_{F}\right)}{P_{F, l}}\right)^{-\varepsilon_{F}}\left(Q_{F, l}^{d}+Q_{l}^{x}\right) \\
-\frac{\phi_{F}^{a d j}}{2}\left(\frac{P_{F, l}\left(j_{F}\right)}{\pi\left(P_{F, l-1}\left(j_{F}\right)\right)}-1\right)^{2}\left(Q_{F, l}^{d}+Q_{l}^{x}\right)
\end{array}\right\}
$$

Above $M C_{F, t}^{W}=P_{F, t}^{W} / P_{t}$ is the real marginal cost in period $t$.

Differencing the above equation with respect to $P_{F, t}\left(j_{F}\right)$ yields the following first order condition:

$$
\left(1-\delta_{s}\right)\left\{\begin{array}{c}
\frac{1}{P_{t}}\left(\frac{P_{F, t}\left(j_{F}\right)}{P_{F, t}}\right)^{-\varepsilon_{F}} Q_{F, t}^{d}-\varepsilon_{F, t}\left(\frac{1}{P_{F, t}}\right)\left(\frac{P_{F, t}\left(j_{F}\right)}{P_{t}}-M C_{F, t}^{W}\right)\left(\frac{P_{F, t}\left(j_{F}\right)}{P_{F, t}}\right)^{-\varepsilon_{F}-1} Q_{F, t}^{d} \\
+\frac{1}{P_{t}}\left(\frac{P_{F, t}\left(j_{F}\right)}{P_{F, t}}\right)^{-\varepsilon_{F}} Q_{t}^{x}-\varepsilon_{F, t}\left(\frac{1}{P_{F, t}}\right)\left(\frac{P_{F, t}\left(j_{F}\right)}{P_{t}}-M C_{F, t}^{W}\right)\left(\frac{P_{F, t}\left(j_{F}\right)}{P_{F, t}}\right)^{-\varepsilon_{F}-1} Q_{t}^{x} \\
\quad-\phi_{F}^{a d j}\left(\frac{1}{\pi\left(P_{F, t-1}\left(j_{F}\right)\right)}\right)\left(\frac{P_{F, t}\left(j_{F}\right)}{\pi\left(P_{F, t-1}\left(j_{F}\right)\right)}-1\right)\left(Q_{F, t}^{d}+Q_{t}^{x}\right) \\
+\rho_{t, t+1} \phi_{F}^{a d j}\left(\frac{1}{P_{F, t}\left(j_{F}\right)}\right)^{2}\left(\frac{P_{F, t+1}\left(j_{F}\right)}{\pi}\right)\left(\frac{P_{F, t+1}\left(j_{F}\right)}{\pi\left(P_{F, t}\left(j_{F}\right)\right)}-1\right)\left(Q_{F, t+1}^{d}+Q_{t+1}^{x}\right)
\end{array}\right\}=0
$$

As all firms are identical, i.e. $P_{F, t}\left(j_{F}\right)=P_{F, t}$, we can write the above equation as:

$$
\left(1-\delta_{S}\right)\left\{\begin{array}{c}
\frac{1}{P_{t}} Q_{F, t}^{d}-\varepsilon_{F}\left(\frac{1}{P_{F, t}}\right)\left(\frac{P_{F, t}}{P_{t}}-M C_{F, t}^{W}\right) Q_{F, t}^{d} \\
+\frac{1}{P_{t}} Q_{t}^{x}-\varepsilon_{F}\left(\frac{1}{P_{F, t}}\right)\left(\frac{P_{F, t}}{P_{t}}-M C_{F, t}^{W}\right) Q_{t}^{x} \\
-\phi_{F}^{a d j}\left(\frac{1}{\pi\left(P_{F, t-1}\right)}\right)\left(\frac{P_{F, t}}{\pi\left(P_{F, t-1}\right)}-1\right)\left(Q_{F, t}^{d}+Q_{t}^{x}\right) \\
+\rho_{t, t+1} \phi_{F}^{a d j}\left(\frac{1}{P_{F, t}\left(j_{F}\right)}\right)^{2}\left(\frac{P_{F, t+1}}{\pi}\right)\left(\frac{P_{F, t+1}}{\pi\left(P_{F, t}\right)}-1\right)\left(Q_{F, t+1}^{d}+Q_{t+1}^{x}\right)
\end{array}\right\}=0
$$


Using $Y_{F, t}=\left(Q_{F, t}^{d}+Q_{t}^{x}\right)$

$$
\left(1-\delta_{s}\right)\left\{\begin{array}{c}
\frac{1}{P_{t}} Y_{F, t}-\varepsilon_{F}\left(\frac{1}{P_{F, t}}\right)\left(\frac{P_{F, t}}{P_{t}}-M C_{F, t}^{W}\right) Y_{F, t} \\
-\phi_{F}^{a d j}\left(\frac{1}{\pi\left(P_{F, t-1}\right)}\right)\left(\frac{P_{F, t}}{\pi\left(P_{F, t-1}\right)}-1\right)\left(Y_{F, t}\right) \\
+\rho_{t, t+1} \phi_{F}^{a d j}\left(\frac{1}{P_{F, t}}\right)^{2}\left(\frac{P_{F, t+1}}{\pi}\right)\left(\frac{P_{F, t+1}}{\pi\left(P_{F, t}\right)}-1\right)\left(Y_{F, t+1}\right)
\end{array}\right\}=0
$$

Rearranging terms:

$$
\left(1-\delta_{S}\right)\left\{\begin{array}{c}
\frac{1}{P_{t}}\left(1-\varepsilon_{F}\right) Y_{F, t}+\varepsilon_{F}\left(\frac{1}{P_{F, t}}\right) M C_{F, t}^{W} Y_{F, t} \\
-\phi_{F}^{a d j}\left(\frac{1}{\pi\left(P_{F, t-1}\right)}\right)\left(\frac{P_{F, t}}{\pi\left(P_{F, t-1}\right)}-1\right)\left(Y_{F, t}\right) \\
+\rho_{t, t+1} \phi_{F}^{a d j}\left(\frac{1}{P_{F, t}}\right)^{2}\left(\frac{P_{F, t+1}}{\pi}\right)\left(\frac{P_{F, t+1}}{\pi\left(P_{F, t}\right)}-1\right)\left(Y_{F, t+1}\right)
\end{array}\right\}=0
$$

Multiplying both sides by $P_{F, t}$ :

$$
\left(1-\delta_{s}\right)\left\{\begin{array}{c}
\frac{P_{F, t}}{P_{t}}\left(1-\varepsilon_{F}\right) Y_{F, t}+\varepsilon_{F} M C_{F, t}^{W} Y_{F, t} \\
-\phi_{F}^{a d j}\left(\frac{\pi_{F, t}}{\pi}\right)\left(\frac{\pi_{F, t}}{\pi}-1\right)\left(Y_{F, t}\right) \\
+\rho_{t, t+1} \phi_{F}^{a d j}\left(\frac{\pi_{F, t+1}}{\pi}\right)\left(\frac{\pi_{F, t+1}}{\pi}-1\right)\left(Y_{F, t+1}\right)
\end{array}\right\}=0
$$

Solving for $\frac{P_{F, t}}{P_{t}}$ yields:

$$
\begin{aligned}
\frac{P_{F, t}}{P_{t}}\left(\varepsilon_{F}-1\right)\left(Y_{F, t}\right) & =\varepsilon_{F} M C_{F, t}^{W}\left(Y_{F, t}\right)-\phi_{F}^{a d j}\left(\frac{\pi_{F, t}}{\pi}\right)\left(\frac{\pi_{F, t}}{\pi}-1\right)\left(Y_{F, t}\right) \\
& +\rho_{t, t+1} \phi_{F}^{a d j}\left(\frac{\pi_{F, t+1}}{\pi}\right)\left(\frac{\pi_{F, t+1}}{\pi}-1\right)\left(Y_{F, t+1}\right)
\end{aligned}
$$

Dividing both sides by $\left(\varepsilon_{F}-1\right)\left(Y_{F, t}\right)$ results in the price setting equation in the formal sector given as:

$$
\begin{aligned}
\frac{P_{F, t}}{P_{t}} & =\frac{\varepsilon_{F}}{\left(\varepsilon_{F}-1\right)} M C_{F, t}^{W}-\frac{\phi_{F}^{a d j}}{\left(\varepsilon_{F, t}-1\right)}\left(\frac{\pi_{F, t}}{\pi}\right)\left(\frac{\pi_{F, t}}{\pi}-1\right) \\
& +\rho_{t, t+1} \frac{\phi_{F}^{a d j}}{\left(\varepsilon_{F}-1\right)}\left(\frac{\pi_{F, t+1}}{\pi}\right)\left(\frac{\pi_{F, t+1}}{\pi}-1\right)\left(\frac{Y_{F, t+1}}{Y_{F, t}}\right)
\end{aligned}
$$

Similarly, the informal price equation is obtained as:

$$
\begin{aligned}
\frac{P_{I, t}}{P_{t}} & =\frac{\varepsilon_{I}}{\left(\varepsilon_{I}-1\right)} M C_{I, t}^{W}-\frac{\phi_{I}^{a d j}}{\left(\varepsilon_{I, t}-1\right)}\left(\frac{\pi_{I, t}}{\pi}\right)\left(\frac{\pi_{I, t}}{\pi}-1\right) \\
& +\rho_{t, t+1} \frac{\phi_{I}^{a d j}}{\left(\varepsilon_{I}-1\right)}\left(\frac{\pi_{I, t+1}}{\pi}\right)\left(\frac{\pi_{I, t+1}}{\pi}-1\right)\left(\frac{Y_{I, t+1}}{Y_{I, t}}\right)
\end{aligned}
$$

The above equations correspond to Eq. 3.41 for sector $s$ in the main text. 


\section{Solution to Capital Producer Profit Maximization}

The capital producer invests $I_{t}$ such that its profit is maximized, where $Q_{t}$ is the real price of capital, resulting in the following profit maximization problem described in the text:

$$
\max _{I_{t}} Q_{t}\left(\frac{P_{t}^{I n v}}{P_{t}} I_{t}-\frac{\kappa}{2}\left(\frac{P_{t}^{I n v}}{P_{t}} \frac{I_{t}}{K_{t-1}}-\delta_{K}\right)^{2} K_{t-1}\right)-\frac{P_{t}^{I n v}}{P_{t}} I_{t}
$$

Differencing the above equation with respect to $I_{t}$ results in the following first order condition:

$$
\left[I_{t}\right]: \quad Q_{t}\left[\frac{P_{t}^{I n v}}{P_{t}}-\kappa\left(\frac{P_{t}^{I n v}}{P_{t}} \frac{I_{t}}{K_{t-1}}-\delta_{K}\right) \frac{P_{t}^{I n v}}{P_{t}}\right]-\frac{P_{t}^{I n v}}{P_{t}}=0
$$

Rearranging terms gives us the supply of capital determined by:

$$
Q_{t}=\left[1-\kappa\left(\frac{P_{t}^{I n v}}{P_{t}} \frac{I_{t}}{K_{t-1}}-\delta_{K}\right)\right]^{-1}
$$

which corresponds to the Tobin's Q Eq. 3.62 given in the main text. 